\author{
UNIVERSIDADE DE SÃO PAULO \\ ESCOLA DE ENGENHARIA DE SÃO CARLOS
}

ALAOR JOSÉ VIEIRA NETO

Metodologia de aperfeiçoamento de suspensões veiculares através de modelo virtual em ambiente multicorpos 


\title{
Metodologia de aperfeiçoamento de suspensões veiculares através de modelo virtual em ambiente multicorpos
}

\author{
Dissertação apresentada à Escola de \\ Engenharia de São Carlos da Universidade de \\ São Paulo, como parte dos requisitos para \\ obtenção do título de mestre em Engenharia \\ Mecânica \\ Área de concentração: Dinâmica de máquinas \\ e sistemas \\ Orientador: Prof. Dr. Álvaro Costa Neto
}

\begin{abstract}
Versão corrigida
Versão original encontra-se disponível na Secretaria de Pós Graduação da Escola de Engenharia de São Carlos
\end{abstract}

São Carlos 
AUTORIZO A REPRODUÇÃO E DIVULGAÇÃO TOTAL OU PARCIAL DESTE TRABALHO, POR QUALQUER MEIO CONVENCIONAL OU ELETRÔNICO, PARA FINS DE ESTUDO E PESQUISA, DESDE QUE CITADA A FONTE.

Ficha catalográfica preparada pela Seção de Tratamento da Informação do Serviço de Biblioteca - EESC/USP

\footnotetext{
V658m Neira Neto, Alaor José
Metodologia de aperfeiçoamento de suspensões veiculares através de modelo virtual em ambiente multicorpos / Alaor José Vieira Neto ; orientador Álvaro Costa Neto. -- São Carlos, 2011.

Dissertação (Mestrado - Programa de Pós-Graduação em Engenharia Mecânica e Área de Concentração em Dinâmica das Máquinas e Sistemas) -- Escola de Engenharia de São Carlos da Universidade de São Paulo, 2011.

1. Conforto veicular. 2. Sistemas veiculares. 3. Dinâmica veicular - simulação. 4. Sistemas multicorpos. I. Título.
} 


\section{FOLHA DE JULGAMENTO}

Candidato(a): Engenheiro ALAÔR JOSÉ VIEIRA NETO.

Dissertação defendida e julgada em 19/04/2011 perante a Comissão Julgadora:

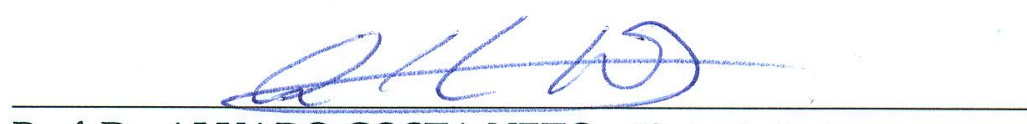

APROVADO

Prof. Dr. ALVARO COSTA NETO - (Orientador)

(Escola de Engenharia de São Carlos/USP)

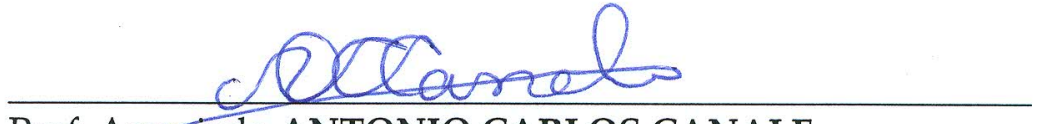

APROVADO

Prof. Associado ANTONIO CARLOS CANALE

(Escola de Engenharia de São Carlos/USP)

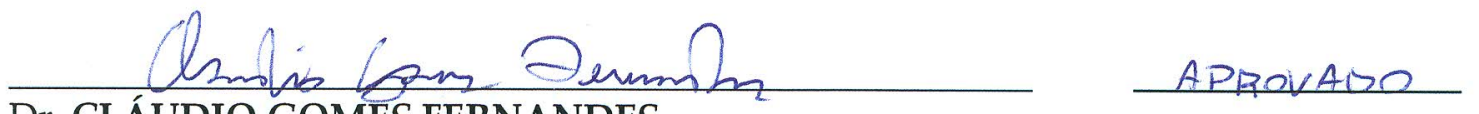

Dr. CLÁUDIO GOMES FERNANDES

(Ford Motor Company)

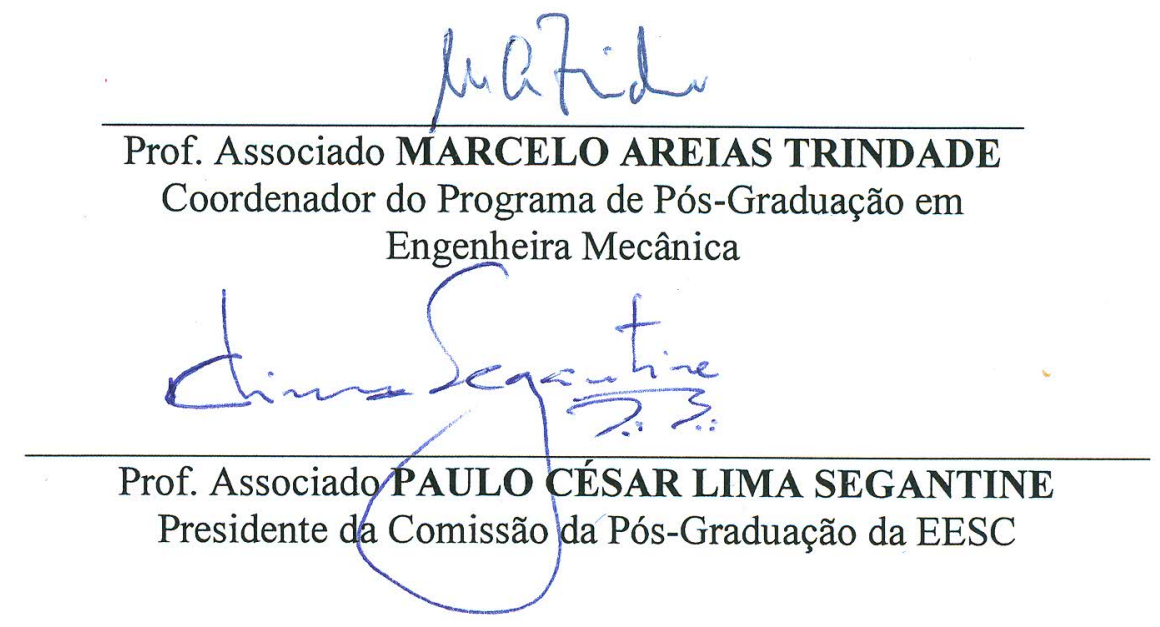




\section{Agradecimentos}

Aos meus pais, com amor e gratidão pelas oportunidades, presença e incansável apoio em todos os momentos.

Aos colegas da Ford Motor Company pelo suporte e apoio ao trabalho. 
“É melhor lançar-se à luta em busca do triunfo mesmo expondo-se ao insucesso, que formar fila com os pobres de espírito, que nem gozam muito nem sofrem muito; E vivem nessa penumbra cinzenta sem conhecer nem vitória nem derrota." 


\section{Resumo}

Entre as etapas do desenvolvimento de automóveis pode-se apontar a definição das características de suas suspensões. A fase de definição da suspensão pode ser dividida dentro do seguinte cenário: a escolha de um determinado tipo de suspensão, os pontos (geometria) e quais os valores de rigidez / amortecimento para todo o sistema irá resultar em um comportamento dinâmico desejado para o veículo, bem como a viabilidade de produção. Além disso, o entendimento da interação entre os parâmetros de suspensão, é crucial para a otimização do desempenho. Este trabalho pretende propor um método para aperfeiçoar a fase de "tuning" da suspensão, com foco principal no conforto. O veículo considerado é um caminhão comercial, e entre os seus parâmetros considerados estão rigidezes de molas da cabine e suspensão, amortecimento da suspensão de cabine e curvas do amortecedor da suspensão primária. O modelo virtual do veículo foi desenvolvido em ambiente ADAMS, o qual, previamente à otimização, foi validado contra dados experimentais. Métricas foram especialmente desenvolvidas levando em consideração aspectos subjetivos de conforto veicular, para dessa forma eliminar a variabilidade entre as avaliações subjetivas e análises das simulações. Os resultados mostraram expressivas melhorias no conforto e através de dados experimentais essas melhorias foram confirmadas.

Palavras chave: Conforto veicular. Sistemas veiculares. Dinâmica veicular - simulação. Sistemas multicorpos. 


\section{Abstract}

Among the development phases of an automotive vehicle one can point out the definition of the characteristics of its suspensions. Suspension definition phase can be understood as the following scenario: given a suspension type, which hard points (geometric) and what values of stiffness/damping for the whole system will result in a desired dynamic behavior for the vehicle as well as production feasibility. Moreover, understanding the iteration among the suspension parameters, even considering just the tuning ones, is crucial for performance optimization. This work intends to propose a method for vehicle tuning characteristics optimization, having as a target the ride comfort. The vehicle considered here is a commercial truck, and among its parameters one considers cabin and suspension springs, cabin dampers and suspension damper curves. A vehicle model was developed in ADAMS environment and prior to the optimization the vehicle was validated against experimental data. Metrics were specially developed to take into account subjective aspects of ride, and, in this way, eliminating the gap between subjective evaluations and simulations analysis. Results showed improvements in ride comfort. The resulting setup was measured and the improvements were confirmed with experimental data.

Key words: Vehicle confort. Vehicle systems. Vehicle dynamics - Simulation. Multibody Systems. 


\section{Lista de Figuras}

Figura 1 - Fluxograma de desenvolvimento da metodologia............................................... 14

Figura 2 - Sistema massa mola com vibração forçada....................................................... 22

Figura 3 - Transmissibilidade de um sistema com amortecimento.......................................23

Figura 4 - Diagrama simplificado de um sistema dinâmico (Costa,1991) .............................24

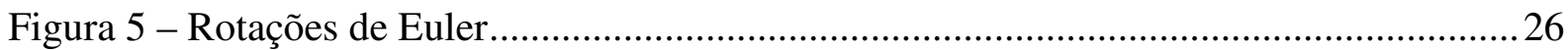

Figura 6 - O sistema dinâmico de Ride (Gillespie, 1992)....................................................... 37

Figura 7 - Perfil de lombada e deslocamento vertical de roda em lombada ............................39

Figura 8 - Elevação vertical e PSD de pista do tipo Belgian Pavê ........................................ 40

Figura 9 - Diferentes categorias dos fatores (Coleman and Montgomery,1993)....................47

Figura 10 - Gráfico de efeitos principais, planejamento fatorial $2^{k}$.....................................54

Figura 11 - Gráficos de efeitos de iteração .........................................................................55

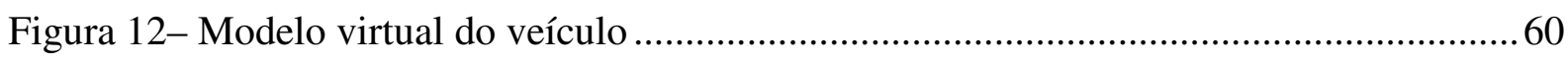

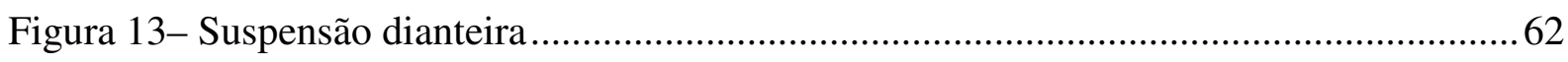

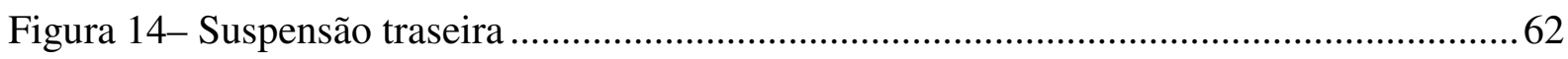

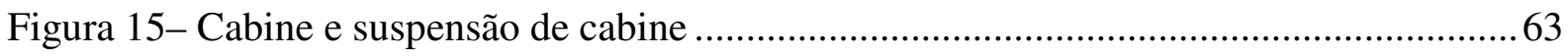

Figura 16- Chassi dividido com ligação por junta esférica....................................................63

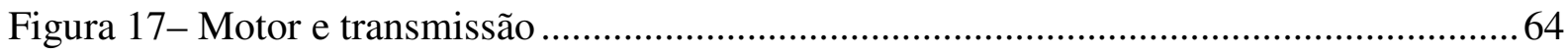

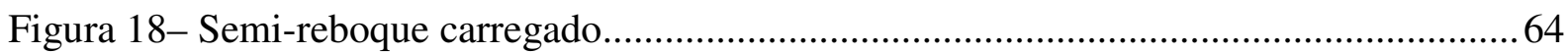

Figura 19 - Posição dos acelerômetros no modelo (Cabine) ................................................65

Figura 20 - Posição dos acelerômetros no modelo (Eixo dianteiro) .......................................65

Figura 21 - Posição dos acelerômetros no protótipo (teto do veículo) ....................................66

Figura 22 - Posição dos acelerômetros no protótipo (eixo dianteiro) .....................................67

Figura 23 - Posição dos acelerômetros no protótipo (assoalho) ...........................................67

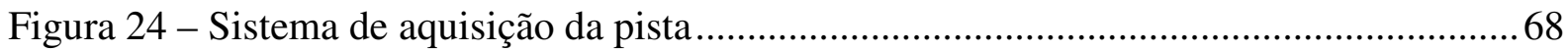

Figura 25 - Lombada medida $($ Linhas tracejadas = métodp proposto $/$ Linha sólida $=$ medida

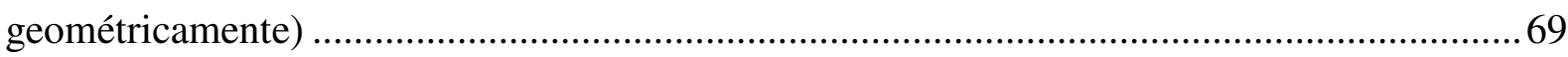

Figura 26 - Pista de paralelepípedos utilizada como excitação do modelo ............................. 70

Figura 27 - Aceleração longitudinal no teto do veículo (passando pela lombada) ...................71

Figura 28 - Aceleração longitudinal no assento do veículo (passando pela lombada) ...........71

Figura 29 - PSD Aceleração vertical no eixo do veículo (passando por paralelepípedos alinhados) 
Figura 30 - PSD Aceleração lateral no assento do veículo (passando por paralelepípedos alinhados)

Figura 31 - PSD Aceleração vertical no teto do veículo (passando por paralelepípedos alinhados) 73

Figura 32 - PSD Aceleração vertical no teto do veículo (passando por paralelepípedos alinhados) 74

Figura 33 - PSD Aceleração vertical no assento do veículo (passando por paralelepípedos alinhados) .74

Figura 34 - PSD Aceleração longitudinal no assento do veículo (passando por paralelepípedos alinhados) .75

Figura 35 - Resultados do Planejamento de experimentos .................................................. 77

Figura 36 -Resultados do Planejamento de experimentos (continuação) ..............................78

Figura 37 - Influência da combinação de entradas ............................................................... 80

Figura 38 - Curvas de tolerância do corpo humano a acelerações verticais ..............................82

Figura 39 - Resultados do veículo medido antes e depois do tuning ......................................83 


\section{Lista de Tabelas}

Tabela 1 - Experimento fatorial de dois fatores 49

Tabela 2 - Matriz de experimento do planejamento fatorial $2^{3}$ 52

Tabela 3 - Experimento fatorial $2^{3}$ (Devor et al. 1992) 57

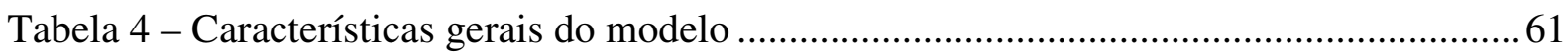

Tabela 5 - Ordem de influência das entradas no deslocamento vertical................................ 78

Tabela 6 - Ordem de influência das entradas na aceleração vertical ..................................... 79 


\section{Sumário}

LISTA DE FIGURAS

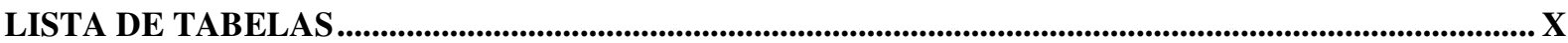

SUMÁRIO...............................................................................................................................................................................XI

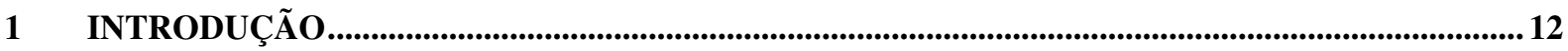

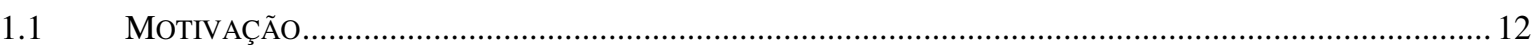

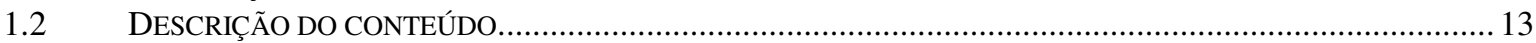

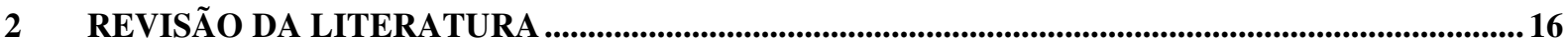

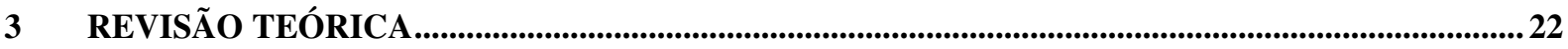

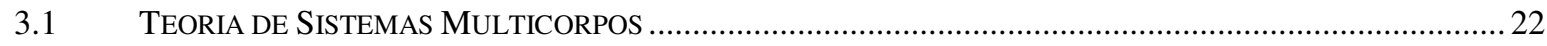

3.1.1 Coordenadas Generalizadas .................................................................................................. 24

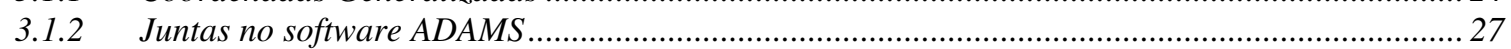

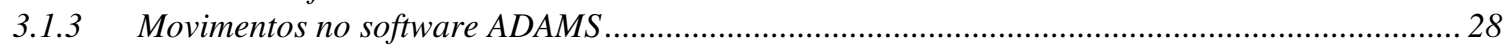

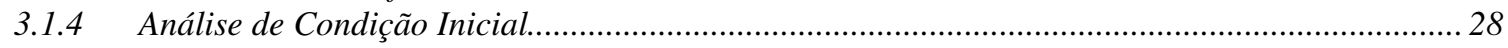

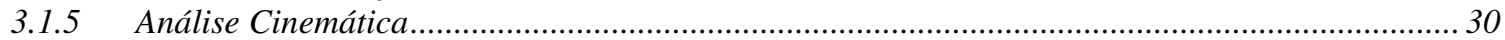

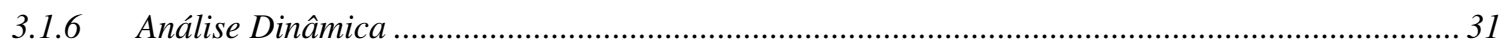

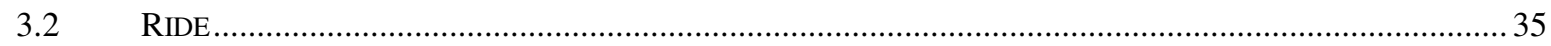

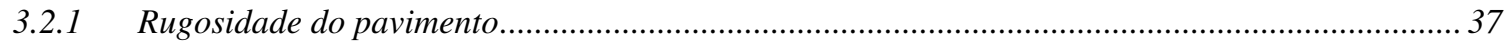

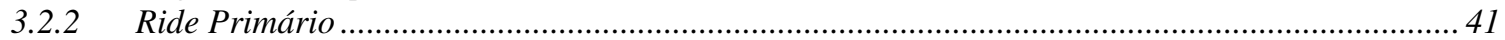

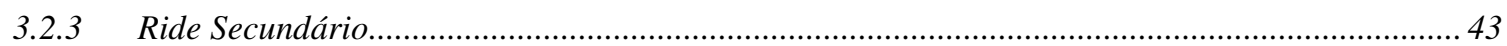

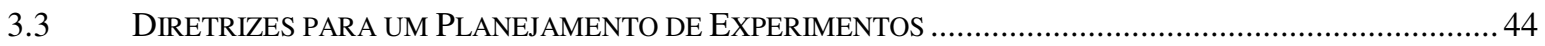

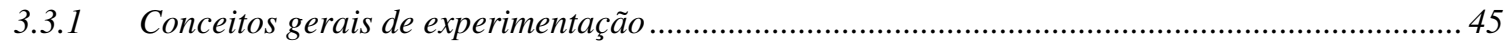

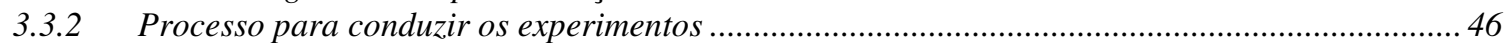

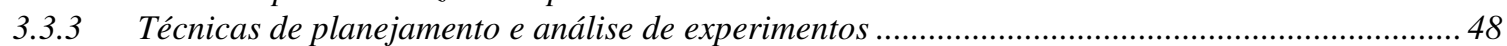

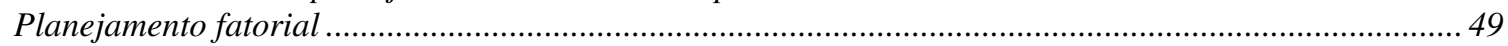

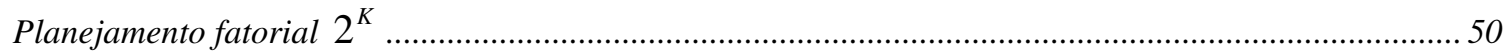

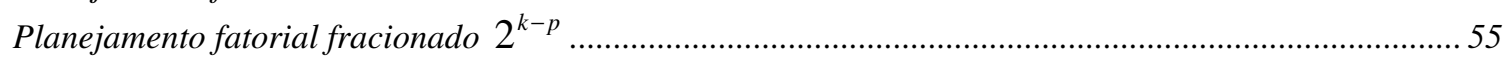

4 DESENVOLVIMENTO DO MODELO .....................................................................................................60

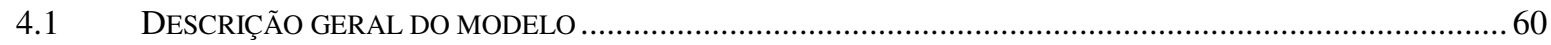

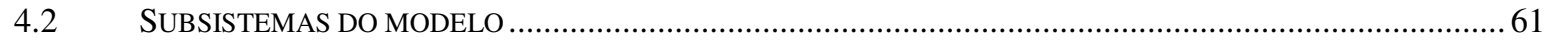

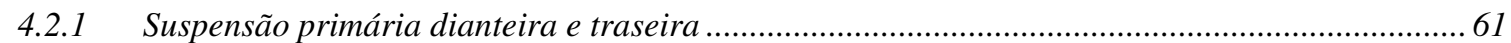

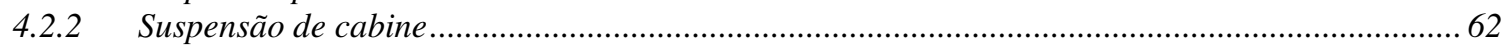

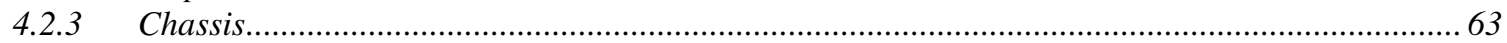

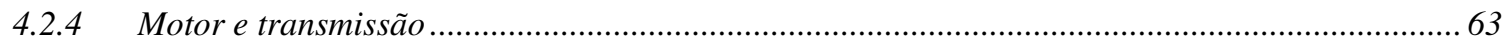

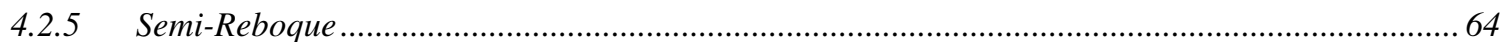

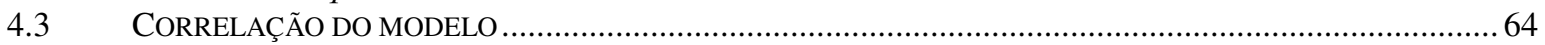

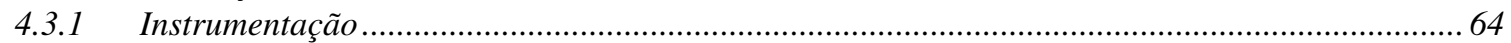

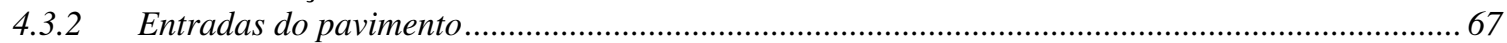

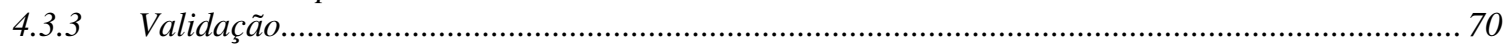

5 DESENVOLVIMENTO DO PLANEJAMENTO DE EXPERIMENTOS (DOE) ...........................76

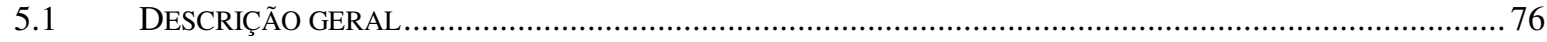

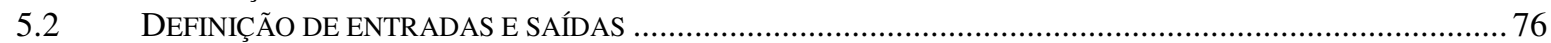

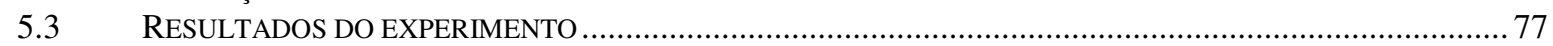

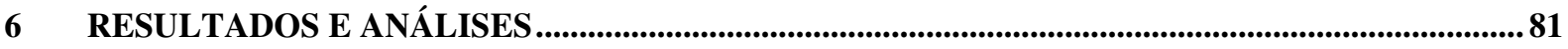

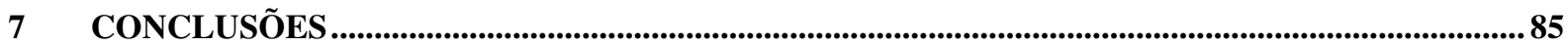

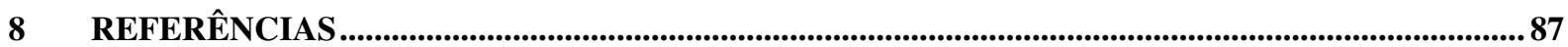




\section{Introdução}

Devido ao aumento na competitividade do mercado automotivo, as montadoras vêm sendo obrigadas a implementar um processo de desenvolvimento de veículo cada vez mais curto. Ao final da década de 1990 aceitava-se um padrão de 48 meses e hoje consideram padrões de 24, 20 e até 18 meses. Esta realidade direciona os esforços das montadoras na incorporação de novas ferramentas e implementação de novos processos de gestão.

A partir dessa realidade nota-se uma intensificação de análises virtuais visando à redução de protótipos físicos, tendo como consequência menor custo e tempo de desenvolvimento. O aprimoramento de sistemas CAE (Computer Aided Engineering) se tornou uma das principais iniciativas nesse campo, englobando desde análises estruturais, escoamentos e aerodinâmica envolvendo elementos finitos, até comportamentos dinâmicos complexos de suspensões.

Mais especificamente na área da dinâmica veicular as simulações são realizadas utilizando a ferramenta MBS (Multibody Systems), por meio do software MSC.ADAMS, em que se torna possível desenvolver análises dinâmicas e cinemáticas dos sistemas com levantamento de esforços (forças e torques), velocidades e acelerações.

\subsection{Motivação}

Levando-se em consideração o curto espaço de tempo, a grande quantidade de veículos a serem desenvolvidos e as ferramentas de simulação disponíveis, surgiu o desafio de desenvolver uma metodologia de análise de suspensões, utilizando um modelo computacional em ambiente multicorpos para auxiliar na fase de "tuning" dos inúmeros parâmetros da suspensão de um veículo comercial.

O objetivo seria diminuir o tempo proposto para a fase de afinação dos componentes da suspensão e consequentemente o custo de desenvolvimento do veículo. Para isso, seria necessário reduzir a quantidade de amostras avaliadas através da geração de um direcional ou até mesmo valores finais para parâmetros como rigidez de molas e curvas de amortecedores, chegando a uma configuração ótima no que diz respeito ao conforto, uma vez que esse se tornou um dos mais importantes pontos no design automotivo. 
A partir desse contexto, foi disponibilizado o protótipo de um veículo comercial atrelado a um semi-reboque carregado. Esse veículo foi a base da construção do modelo virtual, utilizado para medições de correlação e na sequência a confirmação de resultados propostos pela metodologia.

Para testar e avaliar a alteração de qualquer parâmetro em um sistema é necessário que métricas sejam pré-estabelecidas. Medir o conforto é uma tarefa complexa que vem sendo estudada há décadas. A definição das métricas propostas neste trabalho foi baseada na literatura que trata do assunto e na opinião de profissionais do time de avaliação de conforto da Ford Moto Company.

Visto que a matriz de avaliação entre os parâmetros da suspensão a serem estudados (entradas) e suas influências nas métricas definidas (saídas) seriam enormes, necessitando de um tempo de simulação considerável, uma ferramenta estatística chamada de planejamento de experimentos foi utilizada dentro do próprio software de simulação, permitindo que inúmeras amostras fossem testadas sem a necessidade de alteração manual pelo usuário.

Um ponto importante a ser destacado nesta ferramenta é capacidade de gerar uma análise de sensibilidade a qual exibe a influência dos parâmetros de entrada nas saídas, permitindo assim que a ação do engenheiro tenha um alvo certo.

A partir de prévias avaliações subjetivas, foi definido como objetivo principal do trabalho a redução de movimentações verticais e longitudinais na cabine, além da redução de acelerações em torno da freqüência de "shake", métrica essa explicada no decorrer da dissertação.

\subsection{Descrição do conteúdo}

Como será apresentado no decorrer do texto, o projeto trata-se de uma metodologia envolvendo assuntos relativos à dinâmica veicular, estatística, aquisição e tratamento de sinais, bem como a utilização dessas teorias na solução de um problema prático no desenvolvimento de um produto, nesse caso específico na indústria automobilística.

O trabalho foi divido em etapas que realizadas sequencialmente, como mostrado na Figura 1, permitem a obtenção de resultados rápidos e precisos. 


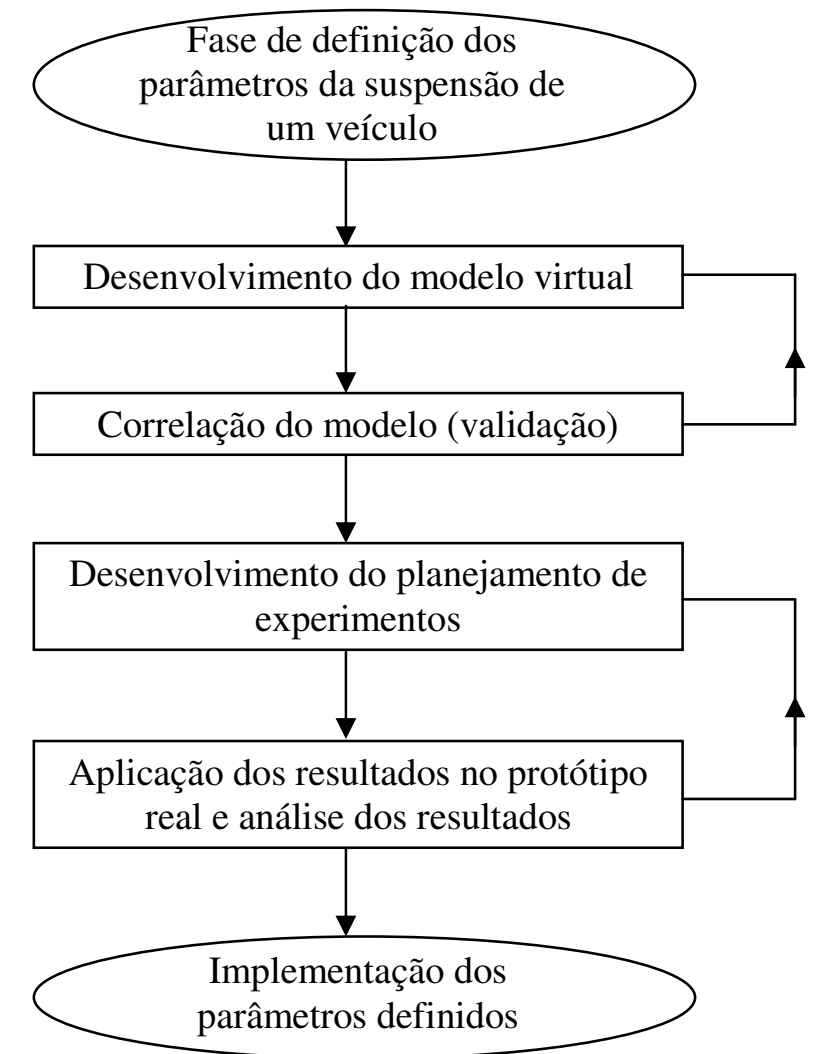

Figura 1 - Fluxograma de desenvolvimento da metodologia

Seguindo a ordem do fluxograma apresentado, o trabalho foi dividido em oito capítulos. O desenvolvimento da metodologia se iniciará a partir do capitulo 4, em que será apresentado o modelo simplificado em ambiente multicorpos de um veículo comercial atrelado a um semi-reboque, com todos os parâmetros os quais seriam relevantes e influenciariam no conforto do veículo. Foi modelado um chassi com os primeiros modos de vibrar de torção e flexão, todo o conjunto de suspensão de cabine, fixação do motor através de coxins, suspensão primária com amortecedores e modelo simplificado de feixes de mola, modelo simplificado de pneu utilizando elementos de mola, finalmente, quinta roda com semi-reboque carregado atrelado.

Ainda no capítulo 4 é apresenta a fase de correlação e validação do modelo desenvolvido. Com a contribuição do departamento de tecnologia de testes do Campo de Provas de Tatuí da Ford Motor Comapny, o protótipo real, o qual foi utilizado como base na construção do modelo, foi instrumentado com acelerômetros em pontos estratégicos. As pistas utilizadas para aquisição dos dados também foram escolhidas estrategicamente, primeiro pela extensa faixa de freqüência excitada e segundo por se tratar de pistas constantemente utilizadas em avaliações subjetivas de conforto. Um método descrito por 
Fernandes, C. G. (2005) foi utilizado para digitalizar as pistas, tornando possível empregálas no modelo, de tal forma que as excitações geradas nos pneus se aproximem da realidade. A partir dos dados extraídos dos acelerômetros no protótipo e modelo, foi realizado o processo de correlação. Gráficos dos resultados obtidos com as medições comprovam a funcionalidade do modelo.

A etapa seguinte à fase de validação é o desenvolvimento do planejamento de experimentos, o qual será descrito no capítulo 5. Para se realizar um processo minucioso de definição dos parâmetros da suspensão, foi utilizada a ferramenta estatística planejamento de experimentos (Design of experiments), com a qual se define variáveis em um processo e observa a influência de suas combinações em métricas pré-estabelecidas. Os parâmetros a serem avaliados na suspensão foram escolhidos como fatores e as respostas baseadas em métricas de conforto definidas na literatura da dinâmica veicular.

Como resultado da análise experimental, o capítulo 6 mostra os valores direcionais gerados para os parâmetros da suspensão. Resultados comparativos de medições no protótipo real mostram a eficácia da metodologia apresentada no trabalho. Melhorias confirmadas também por especialistas em avaliações subjetivas de conforto. Além da eficácia da ferramenta em definir a suspensão, ela mostrou-se bastante eficiente na redução de tempo de desenvolvimento e quantidade de protótipos construídos.

A conclusão adicionada à sugestão de trabalhos futuros foi descrita no capítulo 7, e seguindo as referências no capítulo 8. 


\section{Revisão da literatura}

Inúmeras técnicas e metodologias para o aperfeiçoamento de processos vêm sendo implementadas na indústria atualmente. Dentro do contexto da engenharia automotiva, vários trabalhos os quais combinam ferramentas de análises estatísticas com o processo de desenvolvimento da dinâmica veicular já foram publicados.

Nessa secção estão apresentados alguns dos trabalhos que geraram a inspiração para o desenvolvimento da metodologia proposta no decorrer da dissertação.

Dohi and Maruyama, (1990) propõe em seu trabalho a utilização do método de Teguthi na solução do problema denominado por eles de "FreeWay Hoop" que se trata de uma movimentação ou um desconforto gerado em um veículo comercial médio, pela forma com a qual são asfaltadas as rodovias na região da Califórnia nos Estados Unidos.

O método proposto é baseado em um planejamento de experimentos sobre o modelo numérico do veiculo. Utilizando uma entrada periódica de força nos pneus, o autor observou a influência na aceleração gerada no assoalho da cabine, de parâmetros como rigidez de pneus, feixe de molas, amortecedores.

Lamps and Ekert, (1993) integraram um planejamento de experimentos (DOE) à técnica de modelagem em sistemas multicorpos (MBS) utilizando o software ADAMS. Segundo Lamps, a união da técnica MBS com o DOE gerou uma potente ferramenta capaz de investigar uma especifica área de projeto, identificando a configuração ótima do sistema, além de ilustrar os efeitos de mudanças em parâmetros do sistema em uma saída.

Com os resultados obtidos utilizando um modelo simples de um quarto de veículo e entradas representando pistas severas, Lamps acreditava que quando utilizada em larga escala na dinâmica veicular, essa ferramenta iria gerar mudanças revolucionárias no projeto de sistemas.

Suh and Yoon, (2000) propuseram um método para aperfeiçoar o ângulo de convergência de uma suspensão dianteira do tipo double wishbone. O método foi baseado também em um planejamento de experimentos sobre um modelo desenvolvido utilizando a técnica de sistemas multicorpos. Para Suh, a integração dessas ferramentas possibilitou a definição dos pontos da suspensão de maneira fácil e eficiente. 
Avutapalli, B. et al. (2003) abordaram a influência da variação das buchas do veículo e suas respostas na vibração. Foram comparados dois veículos para estudo de confiabilidade e robustez. Foi abordada também a relação entre capacidade de aperfeiçoamento e robustez do projeto. O método primeira ordem segundo momento (FOSM), foi utilizado para gerar uma estimativa da robustez do projeto.

O método (FOSM) foi considerado por Avutapalli como um bom ponto de partida para realizar estudos detalhados de estocástica. Os resultados das análises os ajudaram a identificar as variáveis importantes, permitindo que estudos mais detalhados fossem focados nas mesmas. Outro importante ponto citado foi a capacidade do método de considerar um grande número de variáveis em uma tentativa, não exigindo portanto, grandes requisitos computacionais. Concluiu-se então que a estratégia de gestão robusta é essencial para se alcançar uma concepção de veículos mais ajustável.

Fernandes, C. (2003) apresenta uma abordagem estatística para simulação baseada no método de Monte Carlo. Como um exercício do método, um modelo CAE voltado para dinâmica veicular foi utilizado para avaliar a resistência à rolagem de veículos para dadas variações em entradas. No exercício, três diferentes parâmetros foram escolhidos como entradas estocásticas (também chamados de fatores de ruído) e todas as informações relevantes sobre suas estatísticas foram levantadas com base em informações dos veículos em produção. As entradas escolhidas foram: curvas de amortecedores dianteiros e traseiros, temperatura da superfície do pneu e as alturas do assoalho dianteira e traseira.

Uma breve descrição da técnica de Monte Carlo foi apresentada. Para Fernandes, C. (2003), a escolha deste método foi devido ao reduzido número de simulações necessárias para se ter uma alta precisão de dados, em comparação com outras abordagens, especialmente para o sistema multivariável.

Gobbi, M. et al (2006) apresentou e aplicou um método de otimização estocástica multi-objetivo. Um modelo linear com dois graus de liberdade foi utilizado para descrever de forma analítica o comportamento dinâmico de veículos durante a passagem por pistas de perfil aleatório. A irregularidade da estrada foi considerada como um processo aleatório Gaussiano e modelado por meio de uma PSD exponencial. As variáveis de projeto foram: rigidez e amortecimento da suspensão e os ganhos do controlador (suspensão ativa do veículo). As incertezas e as variações dos parâmetros foram tomadas em conta por meio de 
uma abordagem robusta que envolve a minimização da soma ponderada da média e desvio padrão de cada função objetivo.

Realizou-se uma comparação entre três diferentes abordagens de otimização: determinista, robusta e estocástica. Constatou-se a vantagem do design robusto, em termos de probabilidade de falha, levando-se em consideração que a perda de desempenho médio foi insignificante. A otimização da média e do desvio padrão levou a um bom compromisso entre robustez e desempenho, por isso concluiu-se que essa abordagem deve ser considerada como técnica de otimização padrão para o design de sistemas complexos.

Vilela and Gueler (2005) lembram que o meio tradicional para ajuste de suspensões requer a utilização de inúmeras avaliações em protótipos físicos por parte de engenheiros especializados, os quais analisam o desempenho do veículo em termos subjetivos.

Nesta abordagem, os componentes da suspensão (molas, amortecedores, amortecedores, etc) normalmente são avaliados um a cada vez, independentemente das conseqüências de suas interações, comprometendo assim o comportamento global da suspensão, geralmente levando à sub-otimização das configurações.

Outro problema é a dependência de protótipos de componentes físicos, cujos custos e prazos de construção tornam inviáveis no curto tempo de desenvolvimento disponível. Vilela apresentou uma abordagem objetiva, com base em ferramentas de simulação, com o objetivo de definir os componentes da suspensão sem a necessidade de protótipos físicos. Foi utilizado um modelo em ambiente multicorpos para analisar o comportamento do veículo em diferentes condições de estrada e uma ferramenta de otimização com base no método de engenharia robusta.

Cherian, T. et al. (2007) apresentou uma metodologia envolvendo Design for Six Sigma (DFSS) e simulação dinâmica em ambiente multicorpos, utilizada no ajuste da suspensão de um veículo de passeio, com o objetivo de melhorar o conforto. A rigidez e o amortecimento dos conjuntos de suspensão foram escolhidos como fatores de controle do experimento virtual.

A variação desses parâmetros a partir das definições nominais, assim como o tamanho do eixo, pneus e combinações de rodas, pressão dos pneus, amortecimentos e velocidade, constituíram-se como fatores de ruído. Essa metodologia se mostrou extremamente eficaz na 
análise comportamental do veículo, mostrando a influência de cada parâmetro específico no desempenho. Cherian concluiu que por meio do Design for Six Sigma (DFSS) e da simulação dinâmica multicorpos tornou-se possível obter informações valiosas da influência de certos parâmetros, que devido ao alto custo e tempo seria inviável de obtê-las em protótipo real. Em sequiência foram apresentadas sugestões para valores de entrada, que testadas em protótipo real confirmaram a eficácia da ferramenta, tanto em análise subjetiva quanto em medições objetivas.

Além dos trabalhos apresentados e citados, que utilizaram a união de ferramentas de simulação com análises estatísticas para aperfeiçoar o comportamento de veículos, outras publicações tiveram grande influência no desenvolvimento da dissertação. Esses trabalhos apresentados em seguida tratam de assuntos relativos a métricas de avaliação de conforto e técnicas para construção e correlação de modelos.

Wambold, C.J. (1986) descreve o uso e de técnicas de tratamento de dados para obter uma avaliação objetiva de conforto, técnica essa que pode ser aplicada a todos os tipos de veículos de transporte. Inclui-se outros dois métodos: um baseado na Norma IS0 2631 e outro baseado em uma equação de regressão desenvolvida na Universidade de Virginia.

Para isto foi desenvolvido um simulador de um corpo humano para diminuir a necessidade de avaliações subjetivas. O dispositivo foi criado para simular as respostas verticais em um homem de aproximadamente 70 quilogramas. Esse trabalho influenciou a escolha dos pontos mais importantes de análise das acelerações, posições que tivessem maior influência na sensibilidade do ser humano.

Perseguim, O. et al, (2000) descreve o uso de simulação computacional apoiada por dados experimentais na análise do conforto de um veículo comercial atrelado a um semi reboque. Este artigo discute a metodologia utilizada para desenvolver e validar um modelo de multicorpos ADAMS para simular conforto.

Após ser validado, o modelo foi utilizado para verificar a melhoria da qualidade do conforto, alterando alguns parâmetros do veículo. Algumas mudanças no primeiro protótipo real foram orientadas por resultados extraídos desse modelo.

Hassan and McManus, (2001) sugere que o conforto para o condutor de um veículo pesado é o produto da excitação aplicada e das propriedades de resposta do veículo. A 
rugosidade da superfície é considerada como uma importante fonte de excitação. No entanto, trechos de estradas com características semelhantes podem ter diferentes valores de rugosidades, e consequentemente gerarem diferentes respostas de conforto. Este estudo mostrou que a qualidade do conforto percebida pelo passageiro é influenciada pelo teor de rugosidade. Assim, uma nova faixa de rugosidade foi implementada, gerando valores preditos para o conforto percebido e boa correlação com os níveis de vibração transmitidos para o passageiro através do banco.

Strandemar and Thorvald, (2004) apresenta o diagrama de conforto, uma nova forma de avaliação e apresentação de conforto em veículos. Uma metodologia simplificada é sugerida para teste e correlação de medições objetivas com impressões subjetivas do condutor. O diagrama de conforto é calculado a partir de acelerações resultantes na cabine para vários níveis de excitação. A idéia básica é visualizar graficamente como o conforto varia com a excitação da pista.

A metodologia proposta é ilustrada em caminhões com diferentes configurações de suspensão de cabine. Para uma dada pista, são utilizados vários níveis de velocidade para aumentar o nível de excitação. Os caminhões são colocados em um simulador de estrada, permitindo fácil variação no tipo e nível de excitação. Medições mostrado o diagrama de conforto são comparadas com as análises das raízes médias quadradas e PSD.

Wang and Yang, (2004) apresentam um método de simulação visual para avaliação do conforto de veículos. Primeiro, modelo 3D de um veículo foi construído usando o software ADAMS. Com um total 596 graus de liberdade, este modelo incorpora todos os principais fatores que influenciam o conforto para o condutor do veículo. Com base no modelo virtual, simulações no domínio do tempo, utilizando entradas aleatórias de pavimentos, geraram parâmetros dinâmicos característicos.

Fernandes, G. et al, (2005) lembra que o conforto tem sido sempre um ponto crítico no desenvolvimento de veículos. Nos últimos anos, tornou-se um fator cada vez mais importante no design automotivo. Apenas a avaliação subjetiva já não é aceitável, existe a necessidade de avaliações objetivas para se tornar o veículo mais competitivo. Outro ponto é que geralmente as métricas objetivas muitas vezes não são correlacionadas com a avaliação subjetiva e com "feed-back" de clientes devido às dificuldades no processo de avaliação. 
As dificuldades apresentadas são, em grande parte, devido a variações nas pistas onde o veículo é avaliado, incluindo sua velocidade do veículo, intempéries, etc. Em outras palavras, é difícil ter um processo com uma boa repetibilidade. Este trabalho sugere um método para medição de pistas que melhora a repetibilidade e também cria a possibilidade de avaliação de problemas específicos no conforto.

O método consiste em um sistema de aquisição de dados em um veículo montado sobre sistema hidráulico de 4 postes, permitindo a passagem do veículo sobre a mesma linha de pista, com a mesma velocidade, eliminando, assim, ruídos que poderiam influenciar nas avaliações e medições.

Kudritzki, D. (2007) propõe uma ferramenta de medição do conforto, a qual fornece um valor predito à avaliação subjetiva com base em medições objetivas. Foi proposta uma ligação e correlação entre a experiência de avaliadores com dados objetivos tratados de maneira adequada. Segundo Kudritzki, o "confortômetro" é capaz de gerar avaliações para diferentes conceitos de veículos trafegando em diferentes tipos de pavimentos. Esse trabalho sugeriu alguns tipos de tratamentos de dados os quais foram considerados nas métricas escolhidas como resposta do planejamento de experimentos desenvolvido no capítulo 5.

Soliman, A. (2008) afirma que as novas gerações de caminhões estão vindo equipadas com conjuntos de suspensões de cabine. Esse sistema vem instalado entre a cabine e o chassi para reduzir as vibrações transmitidas aos passageiros melhorando o conforto do caminhão.

Soliman, no artigo ora apresentado, tratou do controle de suspensão da cabine utilizando um modelo de nove graus de liberdade, criado para avaliação do desempenho de um caminhão atrelado ao semi-reboque transitando sobre um piso irregular. A suspensão da cabine para o sistema passivo foi representada por um arranjo paralelo de molas e amortecedores. Utilizando algumas idéias propostas nesse trabalho, o desenvolvimento do modelo para a suspensão de cabine do protótipo utilizado nessa dissertação se tornou mais rápido e confiável.

Na construção do modelo estudado nesta dissertação, foi levado em consideração as conclusões feitas por Rill, (2003) em que o amortecedor, os passageiros, o sistema de coxinização do motor e as buchas do sistema têm influência especialmente nas acelerações e consequentemente no conforto dos passageiros. Portanto, para se ter uma metodologia de "tuning" eficiente, as influências desses parâmetros devem ser respeitadas. 


\section{Revisão teórica}

No decorrer da dissertação serão utilizados alguns conhecimentos específicos de engenharia, voltada à teoria de sistemas multicorpos na construção do modelo, dinâmica veicular na análise do modelo, e estatística no desenvolvimento do planejamento de experimentos. Dentro desse capítulo será apresentada uma revisão de tais conhecimentos, de modo a facilitar o entendimento de todo o processo de desenvolvimento da metodologia.

\subsection{Teoria de Sistemas Multicorpos}

Pode-se considerar que a base da teoria de sistemas multicorpos foi estabelecida por Newton em 1686 com os estudos de partículas, mas foi a partir de Euler em 1775 com a introdução de corpos rígidos no estudo da mecânica que os principais elementos da teoria foram estabelecidos. As equações de Newton-Euler foram então usadas para a modelagem de veículos, através do Princípio do Corpo Livre Schiehlen, (1997).

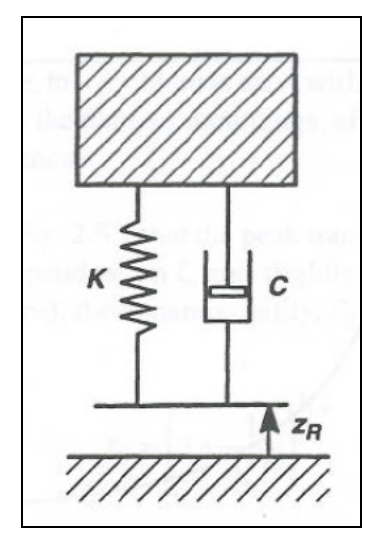

Figura 2 - Sistema massa mola com vibração forçada 


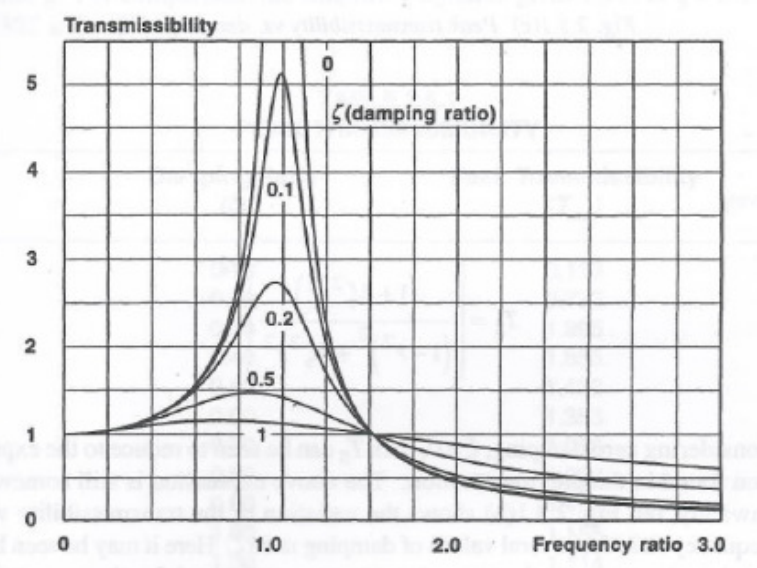

Figura 3 - Transmissibilidade de um sistema com amortecimento

Em 1743 um sistema de corpos rígidos vinculados distinguindo as forças aplicadas e as forças de reação foi proposto por d'Alembert (princípio de d'Alembert). Partindo desse princípio Lagrange apresentou uma formulação matemática combinando-o com o Princípio de Trabalho Virtual, resultando em um número mínimo de equações diferenciais ordinárias de segunda ordem.

Dando continuidade ao seu trabalho Lagrange aplicou em 1788 o Princípio Variacional da energia cinética e potencial total do sistema considerando vínculos cinemáticos. O resultado correspondente às coordenadas generalizadas é conhecido como as equações de Lagrange do primeiro e do segundo tipo. As equações do primeiro tipo representam o conjunto de equações diferenciais algébricas e as do segundo tipo, o conjunto mínimo de equações diferenciais ordinárias.

Jourdain apresentou em 1913 uma extensão do Princípio de d'Alembert válido para sistemas holonômicos. Para sistemas não holonômicos, as velocidades generalizadas, identificadas como velocidades parciais, foram introduzidas por Kane e Levinson, resultando em uma descrição compacta de sistemas multicorpos Da Silva, (2004).

O diagrama apresentado por Costa, (1991) ilustrado na Figura 4 mostra de maneira simplificada as relações entre as várias formas de descrever as equações que modelam o comportamento do sistema. 


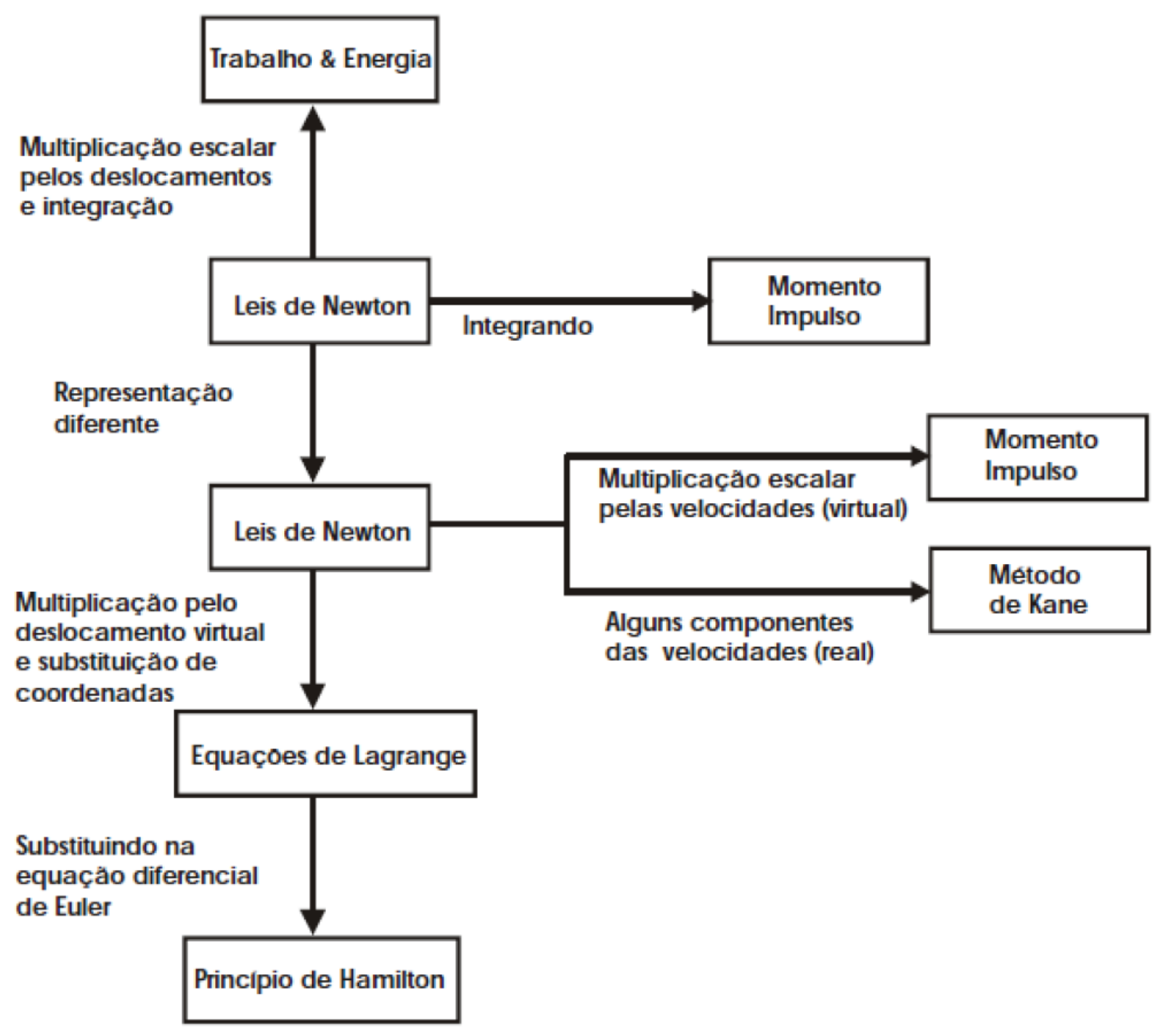

Figura 4 - Diagrama simplificado de um sistema dinâmico Costa,(1991)

O software usado neste trabalho (ADAMS) é baseado no formalismo numérico e utiliza o método de Newton-Euler Lagrange para a construção dos sistemas de equações.

Na seção a seguir, a teoria de multicorpos usada no software ADAMS é apresentada de acordo com o trabalho de Da Silva, (2004). Primeiramente são mostradas as definições de coordenadas generalizadas, vínculos de juntas e movimentos e então são apresentados os formalismos e as análises realizadas pelo software. As análises abordadas na seção são as de condições iniciais, cinemáticas e dinâmicas.

\subsubsection{Coordenadas Generalizadas}

Em um sistema multicorpos, a posição relativa de cada um dos corpos em relação ao referencial inercial do sistema é dada por um vetor posição. Esse vetor contém as três coordenadas cartesianas do centro de massa do corpo e pelo vetor definido pelos ângulos de 
Euler, correspondentes à sequência de rotações 3-1-3 (rotação em torno do eixo Z seguida por rotação em torno do eixo $\mathrm{X}$ e por nova rotação em torno do eixo Z) como segue:

$$
\begin{gathered}
p=[x y z]^{T} \\
\varepsilon=[\psi \phi \theta]^{T}
\end{gathered}
$$

Assim para um corpo rígido i qualquer em um sistema, o conjunto das coordenadas associadas a este corpo é dado pelo vetor:

$$
\text { (3.3) } \quad q_{i}=[p \varepsilon]^{T}
$$

No cálculo cinemático utilizado pelo software ADAMS quatro referenciais auxiliares são utilizados: o referencial inercial $N=\left\{\vec{n}_{1} \vec{n}_{2} \vec{n}_{3}\right\}$, o primeiro referencial auxiliar do corpo $B^{\prime}=\left\{\vec{b}_{1}^{\prime} \vec{b}_{2}^{\prime} \vec{b}_{3}^{\prime}\right\}$, o segundo referencial auxiliar do corpo $B^{\prime}=\left\{\vec{b}_{1}^{\prime \prime} \vec{b}_{2}^{\prime \prime} \vec{b}_{3}^{\prime \prime}\right\}$ e o referencial fixo no corpo $B=\left\{\vec{b}_{1} \vec{b}_{2} \vec{b}_{3}\right\}$. A seguir são descritas as transformações entre esses referenciais.

$$
\begin{aligned}
& \text { (3.4) }\left\{\vec{b}_{1}^{\prime} \vec{b}_{2}^{\prime} \vec{b}_{3}^{\prime}\right\}=\left\{\vec{n}_{1} \vec{n}_{2} \vec{n}_{3}\right\}\left[\begin{array}{ccc}
\cos \psi & -\sin \psi & 0 \\
\sin \psi & \cos \psi & 0 \\
0 & 0 & 1
\end{array}\right] \\
& \text { (3.5) }\left\{\vec{b}_{1}^{\prime \prime} \vec{b}_{2}^{\prime \prime} \vec{b}_{3}^{\prime \prime}\right\}=\left\{\vec{b}_{1}^{\prime} \vec{b}_{2}^{\prime} \vec{b}_{3}^{\prime}\right\}\left[\begin{array}{ccc}
1 & 0 & 0 \\
0 & \cos \theta & -\sin \theta \\
0 & \sin \theta & \cos \theta
\end{array}\right] \\
& \text { (3.6) }\left\{\vec{b}_{1} \vec{b}_{2} \vec{b}_{3}\right\}=\left\{\vec{b}_{1}^{\prime \prime} \vec{b}_{2}^{\prime \prime} \vec{b}_{3}^{\prime \prime}\right\}\left[\begin{array}{ccc}
\cos \phi & -\sin \phi & 0 \\
\sin \phi & \cos \phi & 0 \\
0 & 0 & 1
\end{array}\right]
\end{aligned}
$$

$\left\{\vec{b}_{1} \vec{b}_{2} \vec{b}_{3}\right\}=\left\{\vec{n}_{1} \vec{n}_{2} \vec{n}_{3}\right\} A$, onde A é a matriz:

$$
\left[\begin{array}{ccc}
\cos \psi \cos \phi-\sin \psi \cos \theta \sin \phi & -\sin \psi \cos \theta \cos \phi-\cos \psi \sin \phi & \sin \psi \sin \theta \\
\sin \psi \cos \phi+\cos \psi \cos \theta \sin \phi & \cos \psi \cos \theta \cos \phi-\sin \psi \sin \phi & -\cos \psi \sin \theta \\
\sin \theta \sin \phi & \sin \theta \cos \phi & \cos \theta
\end{array}\right]
$$

A Figura 5 ilustra as transformações acima. 
Baseado na escolha da coordenada generalizada as velocidades longitudinal e angular do corpo são obtidas como:

$$
\text { (3.8) } \quad u=\dot{p}
$$

(3.9) $\bar{\omega}=B . \dot{\varepsilon} \equiv B . \zeta$

Onde:

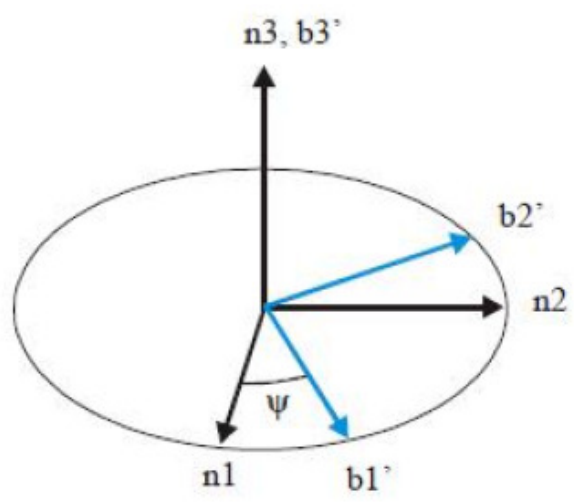

rotação em $\psi$

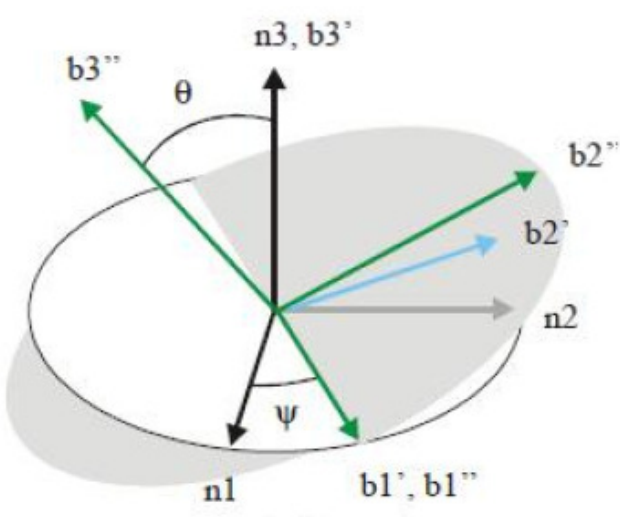

rotação em $\theta$

n3, b3'

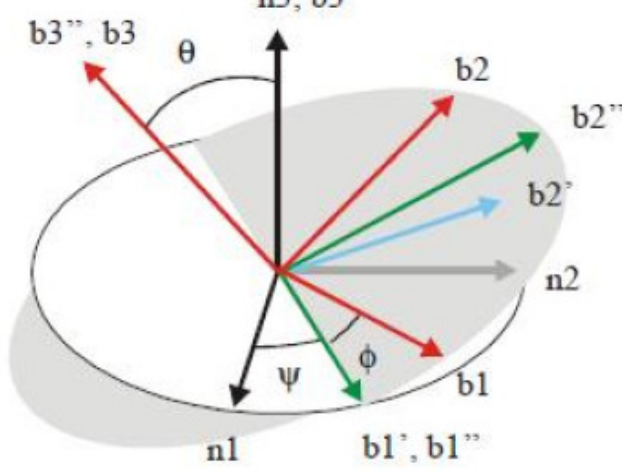

rotação em $\phi$

Figura 5 - Rotações de Euler

$$
\left[\begin{array}{ccc}
\sin \psi \sin \theta & 0 & \cos \phi \\
\cos \phi \sin \theta & 0 & -\sin \phi \\
\cos \theta & 1 & 0
\end{array}\right]
$$

Na equação (3.9) $\bar{\omega}$ é a velocidade angular do corpo no sistema de coordenadas local B. 
Por fim, a relação entre a derivada temporal da matriz de orientação do corpo rígido $\mathbf{A}$ e $\bar{\omega}$ é dada por:

$$
\text { (3.11) } \quad \tilde{\bar{\omega}}=A \cdot \dot{A}
$$

Onde $\tilde{\bar{\omega}}$ é a matriz determinada pelo operador anti-simétrico:

$$
\tilde{\bar{\omega}}=\left[\begin{array}{ccc}
0 & -\omega_{z} & \omega_{y} \\
\omega_{z} & 0 & -\omega_{x} \\
-\omega_{y} & \omega_{x} & 0
\end{array}\right]
$$

Para um sistema contendo nb corpos, o vetor das coordenadas generalizadas q pode ser definido como:

$$
\text { (3.13) } \quad q=\left[q_{1}^{T} q_{2}^{T} \ldots q_{n}^{T} b\right]^{T}=\left[q_{1} q_{2} \ldots q_{n}\right]^{T}
$$

Com $n=6 n b$.

\subsubsection{Juntas no software ADAMS}

As juntas no software ADAMS são vínculos de movimentos que atuam em determinadas coordenadas generalizadas. Matematicamente, tal vínculo toma forma na expressão:

$$
\text { (3.14) } \Phi(q)=0
$$

Tome-se como exemplo uma junta de revolução agindo entre dois corpos resulta em cinco vínculos como os da equação (3.14) permitindo assim apenas um grau de liberdade entre os dois corpos vinculados pela junta.

Tomando-se a derivada temporal da equação (3.14) resultam as equações de velocidades cinemáticas dos vínculos:

$$
\text { (3.15) } \quad \Phi_{q} \dot{q}=0
$$

Derivando novamente a equação (3.15) são obtidas as equações de acelerações cinemáticas de vínculo: 


$$
\Phi_{q} \ddot{q}=-\left(\Phi_{q} \dot{q}\right)_{q} \equiv \tau
$$

As equações (3.14),(3.15),(3.16) garantem que a evolução do sistema faça sentido, ou seja, uma vez que o modelo é construído, suas partes movam-se de tal forma que os vínculos impostos pelas juntas são satisfeitos a todo instante.

\subsubsection{Movimentos no software ADAMS}

No software ADAMS os movimentos indicam que uma coordenada generalizada do sistema ou uma expressão dependente de coordenadas generalizadas explicitamente depende do tempo. Assim, os movimentos podem ser descritos como segue:

$$
\text { (3.17) } \Phi(q, t)=0
$$

De forma análoga a feita para se definir as velocidade e acelerações cinemáticas de vínculo, pode ser encontrada as seguintes equações:

$$
\Phi_{q}(q, t) \dot{q}=-\Phi_{t}(q, t)
$$

$$
\Phi_{q}(q, t) \ddot{q}=-\left(\Phi_{q} \dot{q}\right)_{q} \dot{q}-2 \Phi_{q t} \dot{q}-\Phi_{t t}(q, t)
$$

As equações (3.18) e (3.19) são obtidas derivando-se respectivamente uma e duas vezes a equação (3.17).

Assim, para um conjunto de coordenadas generalizadas serem consistentes, devem satisfazer as posições, velocidades e acelerações cinemáticas impostas pelas condições de movimento, da mesma forma que para os vínculos de junta.

\subsubsection{Análise de Condição Inicial}

No software ADAMS a análise de condições iniciais está relacionada com a determinação de uma configuração consistente do sistema multicorpos modelado no instante inicial t0, o início da simulação. Durante a análise de condições iniciais, o sistema deve ser montado de forma consistente.Para tal, o conjunto de coordenadas generalizadas deve satisfazer as equações de vínculos:

$$
\Phi\left(q, t_{0}\right)=0
$$


A mesma premissa vale para as velocidades generalizadas, que devem ser consistentes para satisfazer as equações de vínculos de velocidades:

$$
\Phi_{q}\left(q, t_{0}\right) \dot{q}=-\Phi_{t}\left(q, t_{0}\right)
$$

Normalmente uma solução que satisfaz as equações de vínculos de posição nãolineares é encontrada com poucas iterações, e a aproximação falha apenas caso a linearização do sistema represente muito mal o sistema não-linear. Porém mesmo que o sistema lide com grandes não-linearidades, a definição de um conjunto de coordenadas iniciais suficientemente próximas da solução já garantem a convergência do problema inicial.

Raciocínio idêntico vale para a análise de velocidade inicial, com a vantagem que as equações de vínculo já se encontram na forma linear, e assim basta uma iteração para encontrar a solução inicial.

Para o problema da análise de condições iniciais de aceleração e forças uma solução linear do sistema modelado pelas equações de movimento e equações das acelerações cinemáticas de vínculo devido à ausência de forças de atrito.

$$
\left[\begin{array}{cc}
M & \Phi_{q}\left(q^{0}\right) \\
\Phi\left(q^{0}\right) & 0
\end{array}\right]\left[\begin{array}{l}
\ddot{q} \\
\lambda
\end{array}\right]=\left[\begin{array}{c}
F \\
-\Phi_{q} \ddot{q}
\end{array}\right]=\left[\begin{array}{c}
F \\
\tau
\end{array}\right]
$$

O sistema da equação (3.22) é um sistema linear, e como tal o processo iterativo converge tipicamente em uma iteração. O usuário não especifica uma aceleração inicial. Assim as forças de reação e acelerações iniciais são calculadas baseando-se no cálculo da posição inicial, velocidade inicial e forças aplicadas ao sistema no instante inicial.

Além de “q, a solução do sistema também fornece a solução dos multiplicadores de Lagrange. As forças e torques de reação devido às juntas do modelo são calculados pelas equações a seguir:

$$
\begin{aligned}
F^{C} & =-\left(\frac{\partial \dot{\Phi}^{(j)}}{v_{i}}\right) \lambda_{i}^{(j)} \\
T^{C} & =-\left(\frac{\partial \dot{\Phi}^{(j)}}{\omega_{i}}\right) \lambda_{i}^{(j)}
\end{aligned}
$$


O índice C indica que as grandezas são descritas no referencial inercial do sistema, onde $v_{i}$ são as velocidades, $\omega_{i}$ são as velocidades angulares dos corpos e $\Phi^{(j)}$ representa o conjunto de equações introduzidas em decorrência das juntas.

\subsubsection{Análise Cinemática}

Para o cálculo da análise cinemática normalmente é necessário um número de equações de vínculos independentes igual ao número de coordenadas generalizadas no modelo. Para que o sistema realmente altere sua configuração no tempo é necessário que alguns desses vínculos sejam movimentos.

\section{- Análise Cinemática de Posições}

Dada a posição de um sistema no instante de tempo $t$, o problema cinemático é determinar a posição do sistema em um instante $t_{1}>t_{0}$. Devido a natureza não-linear das equações de vínculos, o método iterativo de Newton-Raphson é usado no software ADAMS a fim de calcular a posição $q_{1}$ no instante $t_{1}$. O método usa a expansão de Taylor empregada na linearização das equações de vínculos não-lineares.

$$
\Phi\left(q_{1}, t_{1}\right)=\Phi\left(q_{0}, t_{1}\right)+\Phi_{q}\left(q_{0}, t_{1}\right)\left(q_{1}-q_{0}\right)
$$

A matriz $\Phi\left(q_{0}, t_{1}\right)$ é quadrada desde que o número de vínculos no sistema seja igual ao número de coordenadas generalizadas. Outra propriedade da matriz é ser inversível, já que as equações de vínculos são independentes.

Baseado no integrador explícito uma configuração inicial $q_{1}^{(0)}$ é determinada e o algoritmo iterativo prossegue a cada iteração $j$ encontrando a correção $\Delta^{(j)}$.

$$
\Phi\left(q_{0}, t_{1}\right) \Delta^{(j)}=-\Phi\left(q_{1}^{(j)}, t_{1}\right)
$$

O processo iterativo então só é interrompido quando a correção $\Delta^{(j)}$ e/ou o residual $\Phi\left(q_{1}^{(j)}, t_{1}\right)$ torna-se suficientemente pequeno. 
Assim como na análise de condições iniciais, a análise cinemática pode falhar caso a linearização do sistema não seja boa o suficiente, ou seja, as condições iniciais estejam muito distantes de uma solução consistente.

\section{- Análise Cinemática de Velocidades}

Uma vez que as equações de vínculo de velocidades são lineares, a análise cinemática de velocidades é a continuação da análise de posições. Uma vez que a posição $q_{1}$ esteja disponível após o cálculo cinemático de posições, a matriz $\Phi\left(q_{1}, t_{1}\right)$ é calculada e o sistema linear determinado pela equação (3.18) resolvido.

\section{- Análise Cinemática de Acelerações}

A resolução da análise cinemática de acelerações é direta, no instante $t_{1}$ é encontrada a solução do sistema linear da equação (3.19). Uma vez que $\ddot{q}$ esteja disponível, os multiplicadores de Lagrange associados ao conjunto de vínculos do sistema são computados como a solução do sistema linear a seguir:

$$
\Phi_{q}^{T} \lambda=F-M \ddot{q}
$$

Esta equação é idêntica a primeira coluna do sistema linear da equação (3.22) e de fato representa precisamente as equações de movimento.

\subsubsection{Análise Dinâmica}

Para a análise dinâmica, algumas definições extras devem ser feitas em adição às notações definidas anteriormente, de forma a serem usadas na formulação das equações de movimento dos corpos rígidos.

$M$ - matriz de massas generalizadas do sistema multicorpos.

$\bar{J}$ - matriz de inércias generalizadas expressas no referencial principal local do corpo.

$K$ - energia cinemática total do corpo, definida por:

$$
K=\frac{1}{2} u^{T} M \cdot u+\frac{1}{2} \bar{\omega}^{T} \bar{J} \bar{\omega}
$$


$(q, \dot{q}, t)[f \bar{n}]^{T} \in R^{6}-$ Vetor de forças aplicadas.

$Q(q, \dot{q}, t) \in R^{6}$ - Força generalizada atuando no corpo rígido. Usualmente encontrada pela equação:

$$
Q=\left[\begin{array}{l}
\left(\prod^{P}\right)^{T} f \\
\left(\prod^{R}\right)^{T} \bar{n}
\end{array}\right]
$$

Com $v^{P}$ sendo definido como a velocidade do ponto de aplicação da força externa $\mathrm{P}$, as projeções são definidas pelos seguintes operadores:

$$
\begin{aligned}
& \text { (3.30) } \prod^{P}=\frac{\partial v^{P}}{\partial u} \\
& \text { (3.31) } \prod^{R}=\frac{\partial \bar{\omega}}{\partial \zeta}
\end{aligned}
$$

- Formulação das equações de movimento no software ADAMS

O software ADAMS utiliza a formulação de Lagrange para basear seus cálculos dinâmicos. Considerando a escolha de coordenadas generalizadas e as definições de $q$ apresentadas na equação (3.3) a formulação de Lagrange pode ser reescrita para um corpo rígido como:

$$
\frac{d}{d t}\left[\begin{array}{l}
\left(\frac{\partial K}{\partial u}\right)^{T} \\
\left(\frac{\partial K}{\partial \zeta}\right)^{T}
\end{array}\right]-\left[\begin{array}{l}
\left(\frac{\partial K}{\partial p}\right)^{T} \\
\left(\frac{\partial K}{\partial \varepsilon}\right)^{T}
\end{array}\right]+\left[\begin{array}{l}
\Phi_{p}^{T} \cdot \lambda \\
\Phi_{\varepsilon}^{T} \cdot \lambda
\end{array}\right]=\left[\begin{array}{l}
\left(\prod^{P}\right)^{T} f \\
\left(\prod^{R}\right)^{T} \bar{n}
\end{array}\right]
$$

As equações de movimento são obtidas agrupando-se as equações de movimento definidas para cada corpo.

Analisando as partes da equação (3.32)

$$
\frac{d}{d t}\left(\frac{\partial K}{u}\right)^{T}=M . \ddot{u}
$$




$$
\left(\frac{\partial K}{p}\right)^{T}=0
$$

E definindo a quantidade de movimento angular como

$$
T=\frac{\partial K}{\partial \zeta}=B^{T} \bar{J} B \zeta
$$

A equação (3.32) pode ser reformulada pelas equações (3.36) e (3.37).

$$
\begin{gathered}
M . \ddot{u}+\Phi_{p}^{T} \cdot \lambda=\left(\prod^{P}\right)^{T} f \\
T-\frac{\partial K}{\partial \varepsilon}+\Phi_{\varepsilon}^{T} \cdot \lambda=\left(\prod^{R}\right)^{T} \bar{n}
\end{gathered}
$$

As equações diferenciais de primeira ordem (3.36) e (3.37) são chamadas de equações diferenciais cinemáticas, uma vez que determinam como as forças externas influenciam na quantidade de movimento translacional e angular no tempo.

A combinação das equações cinemáticas e diferenciais cinemáticas gera um conjunto de equações que contém a informação necessária para a solução numérica da análise dinâmica do sistema mecânico. Essas equações são descritas de (3.38) a (3.42).

$$
M . \ddot{u}+\Phi_{p}^{T} \cdot \lambda-\left(\prod^{P}\right)^{T} f=0
$$

$$
T-B^{T} \bar{J} B \zeta=0
$$

(3.40) $\quad T-\frac{\partial K}{\partial \varepsilon}+\Phi_{\varepsilon}^{T} \cdot \lambda-\left(\prod^{R}\right)^{T} \bar{n}=0$

$$
\text { (3.41) } \quad \dot{p}-u=0
$$

$$
\text { (3.42) } \dot{\varepsilon}-\zeta=0
$$




\section{- Solução numérica para a análise dinâmica}

As equações (3.38) a (3.42) indicam a ocorrência de relevantes alterações no domínio do tempo. Além disso, a solução do sistema também deve satisfazer as equações de vínculo cinemático, equações (3.17) a (3.19). Em decorrência desses fatos a análise dinâmica é a de resolução mais difícil. É dado o nome de equações diferenciais algébricas ao conjunto de equações diferenciais e equações de vínculos.

O solver do software ADAMS em Fortran possui dois métodos confiáveis para resolução do sistema. As equações de vínculo cinemático de posição estão associadas às equações diferenciais. Testes periódicos das equações de vínculo de velocidades e acelerações são realizados neste algoritmo, chamado de GSTIFF no software ADAMS.

O segundo método reduz o problema para um problema analítico numericamente mais simples. Neste método as equações de vínculo cinemático das velocidades passam a ser resolvidas juntamente com as equações diferenciais. Este algoritmo é chamado de SI2 e em geral resulta em respostas mais precisas.

O que segue o algoritmo de solução do problema é a integração das equações por meio de uma formulação implícita de integração. Esta fórmula é a simplificação da fórmula de Euler para um passo. A formulação encontra o valor da derivada de uma quantidade $\dot{y}_{1}$ no tempo por:

$$
y_{1}=\frac{1}{h} \dot{y}_{1}-\frac{1}{h} \dot{y}_{0}
$$

Baseando-se na equação(3.43), o problema do valor inicial $\dot{y}=g(t, y), y=\left(t_{0}\right)=y_{0}$, é resolvido encontrando $y\left(t_{1}\right)=y_{1}$ no tempo $t_{1}>t_{0}$ que é a solução da equação (3.44) conhecida como a formulação discreta implícita de Euler.

$$
\frac{1}{h} \dot{y}_{1}-\frac{1}{h} \dot{y}_{0}-g\left(t_{1}, y_{1}\right)=0
$$

Quase sempre a função $g$ é não-linear e precisa de uma solução interativa para a solução do problema. O algoritmo usado pelo software ADAMS é o algoritmo de integração de Newton-Raphson. 
Baseada na formulação discreta implícita de Euler, todas as derivadas no tempo presentes nas equações (3.38) a (3.42) são substituídas e produzem um conjunto de equações algébricas não-lineares. As equações de vínculo cinemático são introduzidas neste sistema pela definição das funções de força $F$ e $T$. As variáveis do sistema não-linear são definidas pelo vetor $y$ na equação (3.45):

$$
\text { (3.45) } \quad y=\left[\begin{array}{l}
u \\
T \\
\zeta \\
P \\
\varepsilon \\
\lambda \\
f \\
\bar{n}
\end{array}\right]
$$

E o sistema não-linear pode ser reescrito como

$$
\text { (3.46) } \quad \Psi(y)=0
$$

O algoritmo de Newton-Raphson então resolve o problema. Portanto a primeira previsão de $y(0)$ da solução é encontrada através de um algoritmo de previsão baseado em um integrador explícito. Uma vez a primeira previsão feita, o algoritmo se torna iterativo dado pelas equações (3.47) e (3.48).

$$
\begin{gathered}
\text { (3.47) } \Psi\left(y_{0}\right) \Delta^{(j)}=-\Psi\left(y^{(j)}\right) \\
\text { (3.48) } \quad y^{(j+1)}=y^{(j)}+\Delta^{(j)}
\end{gathered}
$$

As interações são realizadas até que o resíduo $\Psi\left(y^{(j)}\right)$ e/ou a correção $\Delta^{(j)}$ sejam pequenos.

\subsection{Ride}

O estudo dos fenômenos de ride desenvolveu-se ao longo do século XX através da aplicação da teoria de vibrações no ambiente de funcionamento dos veículos automotores, especialmente a iteração do veículo com o pavimento no qual trafega, e podem-se desenvolver via entendimento do conforto humano quando exposto a tais vibrações. 
Uma vez que os veículos automotores trafegam em uma ampla faixa de velocidades e dada a diversificada natureza das pistas usadas em todo o mundo, os sistemas de suspensão experimentam vibrações em um amplo espectro de frequências. Tais vibrações são então transmitidas aos ocupantes e percebidas pelos sentidos de audição, visão e tato.

$\mathrm{O}$ estudo do ride concentra-se nos fenômenos que estão contidos em uma faixa de frequência que vai de $1 \mathrm{~Hz}$ até aproximadamente $100 \mathrm{~Hz}$. Dessa forma, é comum dentro da indústria automotiva a divisão dos fenômenos de ride em termos de frequência de excitação, e a teoria de ride é então subdividida em ride primário (de $1 \mathrm{~Hz}$ a $7 \mathrm{~Hz}$ ) e ride secundário (de $7 \mathrm{~Hz}$ a $100 \mathrm{~Hz})$.

Porém nessa faixa de freqüência o veículo está exposto a excitações de diversas fontes, tais como vibrações do conjunto motor e transmissão (relacionadas ao funcionamento do sistema), excitação de modos de vibrar da carroceria e movimentação de amplitude variada da suspensão do veículo.

O estudo de ride e da dinâmica vertical do veículo concentra-se na transmissão das vibrações entre o pavimento e o sistema de suspensão, até seus pontos de fixação ao chassi ou carroceria do veículo. A partir daí até os elementos de interface entre o veículo e o condutor e passageiro, tais como assentos, direção e pedais, traduzindo-se assim com a percepção ao ride do veículo Gillespie, (1992).

A principal fonte de excitação abordada neste trabalho é o perfil, ou rugosidade, de pista e suas frequências de acordo com cada fenômeno de ride. Porém, de acordo com o fluxograma apresentado na Figura 6, outras fontes de excitação também geram vibrações ligadas a percepção de ride pelos ocupantes do veículo. Tais fontes são tratadas como reações ao movimento de carroceria (movimentação do conjunto powertrain sobre seus coxins) ou inerentes ao procedimento de simulação proposto (vibrações do conjunto pneu e roda). 


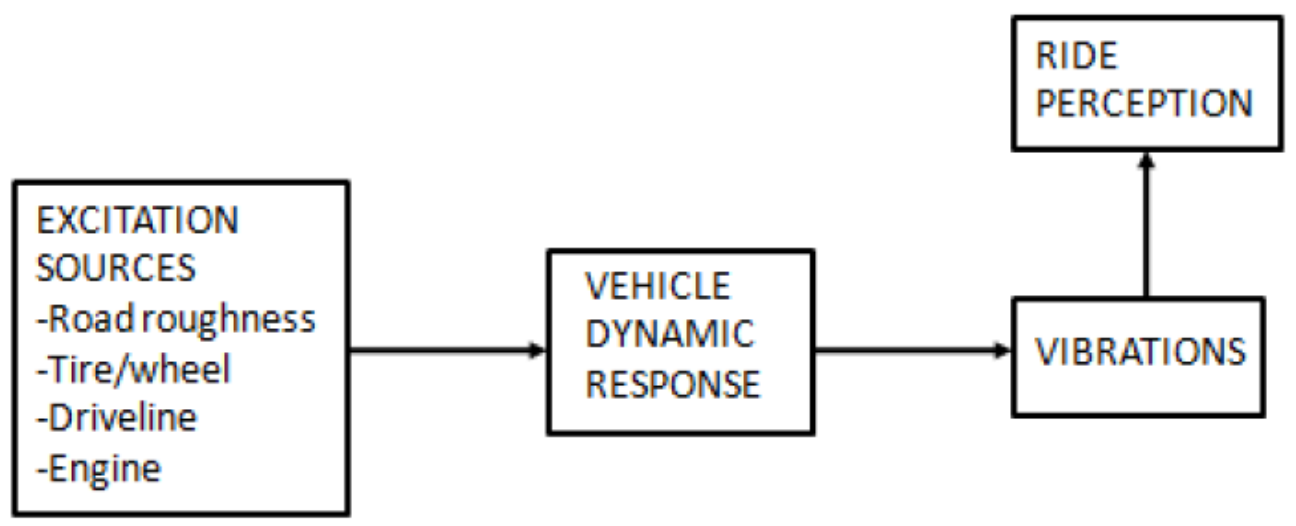

Figura 6 - O sistema dinâmico de Ride - Gillespie, (1992)

\subsubsection{Rugosidade do pavimento}

A definição de rugosidade ou perfil de pista engloba desde potholes resultantes de falhas localizadas no pavimento até as variações aleatórias na superfície das pistas, que refletem as limitações práticas de precisão com a qual as pistas podem ser construídas e mantidas. Faz parte ainda dessa definição obstáculos controlados tais como lombadas e emendas de pista como em pontes e viadutos. Assim a rugosidade pode ser descrita pelo perfil de elevação ao longo do qual o veículo trafega.

Em geral tais perfis podem ser descritos como a elevação vertical ao longo do eixo longitudinal da pista ou através de suas propriedades estatísticas representadas, por exemplo, pela função Power Spectral Density (PSD).

Em função de tais características, perfis de pista específicos são desenvolvidos para teste e otimização de componentes e atributos na indústria automotiva. A performance e durabilidade de componentes de suspensão são alguns dos fatores mais críticos para o projeto de veículos e para o controle da resposta dinâmica do veículo trafegando sobre um pavimento.

Muitas das superfícies de maior representatividade para fenômenos de ride são reproduzidas fielmente em pistas especiais de teste, que podem assim fornecer dados objetivos em veículos instrumentados ou em modelos computacionais trafegando por perfis idênticos aos observados nas pistas. Assim torna-se possível desenvolver sistemas de suspensão que apresentam o comportamento desejado em tais obstáculos. 
As pistas tipicamente usadas durante o desenvolvimento de ride de um veículo podem ser classificadas de forma simplificada em dois tipos de eventos:

- Eventos discretos.

- Eventos aleatórios.

\section{- Eventos discretos}

São consideradas pistas de eventos discretos aquelas que apresentam perfil de elevação bem definido, com a finalidade de excitar fenômenos de ride de frequência específica, de forma a possibilitar a avaliação de movimentos isolados de carroceria ou a performance de componentes específicos de suspensão.

Outra característica importante das pistas consideradas como eventos discretos é a grande repetibilidade de resultados que é possível atingir com um veículo. Uma vez que o obstáculo é bem caracterizado, também é possível avaliar com maior rigor a influência de outros fatores tais como velocidade e atitude da suspensão.

Um importante exemplo de evento discreto são as lombadas. Em pistas reais, tais obstáculos têm como função reduzir a velocidade do tráfego, com o intuito de aumentar a segurança da via. Tipicamente esses obstáculos têm perfil com entrada suave a elevação bastante significativa quando comparada ao seu comprimento.

A característica de entrada suave permite o trabalho da suspensão predominantemente na direção vertical, evitando assim grandes impactos longitudinais, o que permite o estudo de diversas características de ride tais como bounce (deslocamento vertical) e proporcionalidade de bounce entre o eixo dianteiro e traseiro e amortecimento dos eixos dianteiro e traseiro em baixas frequências. A Figura 7 mostra um perfil de lombada e o resultante deslocamento vertical de roda observado. 


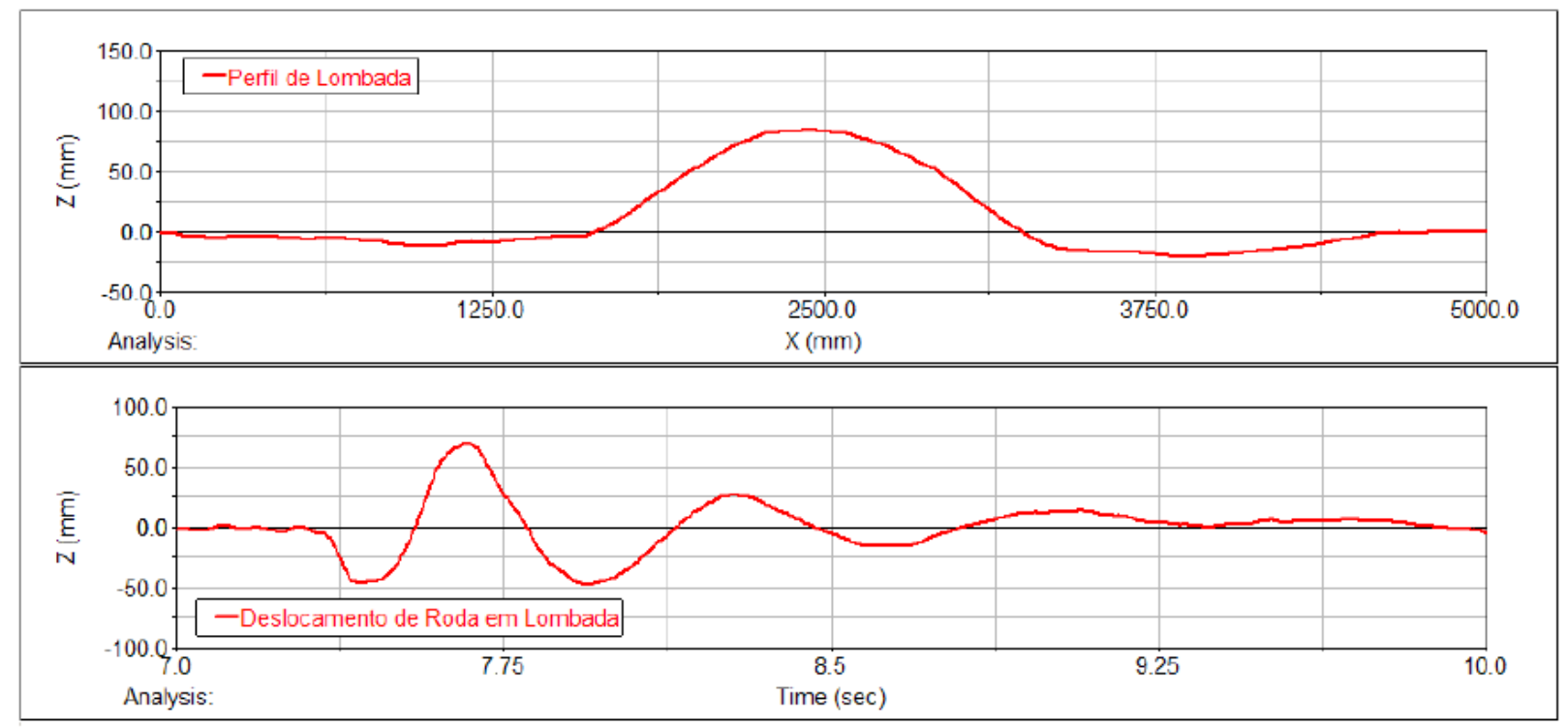

Figura 7 - Perfil de lombada e deslocamento vertical de roda em lombada

Uma limitação destas pistas é o espectro de frequências de excitação em geral limitado, sendo necessário assim desenvolver outros perfis de pista para capturar fenômenos de ride presentes nas vias de tráfego externas aos campos de provas.

\section{- Eventos aleatórios}

As chamadas pistas com entrada aleatória têm como característica principal um espectro de frequências de excitação significativas maior, sendo assim importantes para a avaliação de fenômenos como harshness e powertrain shake, que se apresentam em faixas de frequência mais largas.

Tais pistas também são utilizadas como eventos de rotas de durabilidade, pois dependendo da elevação média da pista, carregamentos de diversas magnitudes tornam-se presentes nos componentes de suspensão e carroceria do veículo avaliado.

Talvez a superfície mais característica dessa classe de eventos aleatórios seja a chama Belgian Blocks ou Belgian Pavé. Esta pista típica de algumas regiões da Bélgica, França, Holanda e Alemanha na verdade foi produto da manutenção deficiente (ou até mesmo negligenciada) de estradas construídas usando blocos de pedra como pavimento durante a segunda guerra mundial. 
Automóveis vendidos no mercado europeu durante o período imediatamente pósguerra apresentavam rápida deterioração de componentes como amortecedores e buchas de suspensão e falhas estruturais de diversas formas.

Com isso este tipo de estrada passou a fazer parte do conjunto de pistas avaliadas por toda a indústria automotiva, com reconstruções em diversos campos de provas ao redor do mundo. Um exemplo típico é a pista denominada Belgian Pavé no campo de provas de MIRA (British Motor Industry Research Association). Esta pista foi construída usando blocos de pedra aleatórios com comprimento entre 0.15 e $0.23 \mathrm{~m}$, variação de altura do perfil vertical de $\pm 0.025 \mathrm{~m}$ e um padrão de repetição entre 4.5 e $6 \mathrm{~m}$. A Figura 8 mostra a elevação vertical de uma pista do tipo Belgian Pavé e o espectro de frequências excitado pela mesma.

Além da superfície chamada de belgian blocks, outro pavimento de interesse para o ride secundário é denominado de emendas irregulares. Tal pavimento é caracterizado por diversos obstáculos de altura variável (em geral com elevação vertical entre $5 \mathrm{~mm}$ e $10 \mathrm{~mm}$ e com diferentes ângulos de inclinação em relação a direção principal da pista.

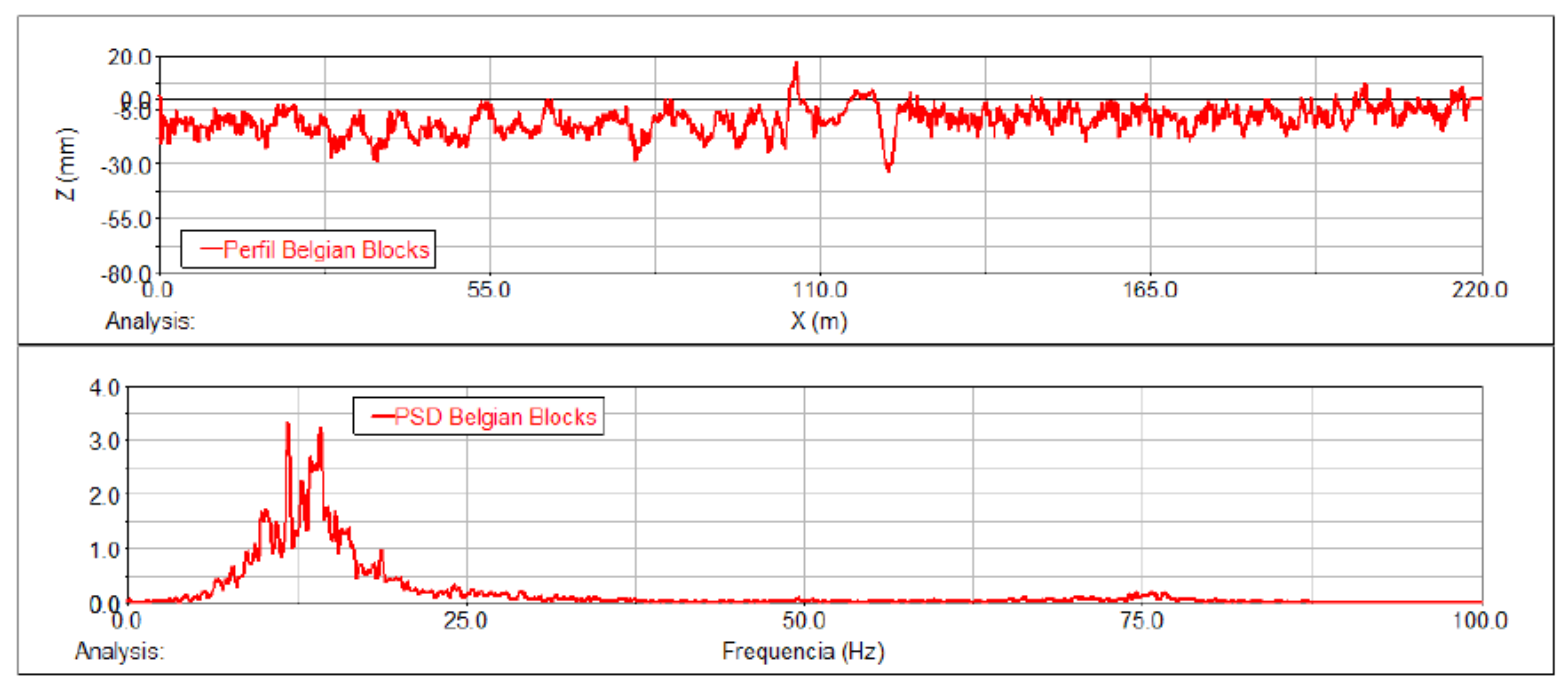

Figura 8 - Elevação vertical e PSD de pista do tipo Belgian Pavè

Estes obstáculos são bastante comuns em estradas brasileiras, reflexo das técnicas de construção de pavimento e de manutenção das estradas, que devido às grandes cargas de caminhões e incidência de chuvas apresentam buracos ao longo da via que são então cobertos com asfalto e pedras sem manter o mesmo nível de elevação da pista principal. 
Estes eventos apresentam em geral uma significativa parcela de excitação longitudinal, e com espectro de frequência de excitação bastante variado, devido a grande variedade de emendas produzidas no processo de recuperação das vias.

Uma vez caracterizados os tipos de eventos mais representativos para o estudo do ride em toda sua faixa de frequência, é possível descrever os diversos fenômenos e como estes são percebidos e avaliados pelo corpo humano.

\subsubsection{Ride Primário}

$\mathrm{O}$ espectro de frequências do ride primário (de $1 \mathrm{~Hz}$ a $7 \mathrm{~Hz}$ ) compreende diversos fenômenos, e caracteriza-se por maiores amplitudes de movimento de carroceria e grande influência de componentes tais como molas, amortecedores e barras estabilizadoras.

De modo a caracterizar os principais fenômenos e seus parâmetros de influência, os tópicos subsequentes desta seção apresentam as características dos fenômenos de ride primário.

Os tópicos a seguir apresentam definições e discussões acerca de alguns dos principais fenômenos do ride primário.

\section{- Movimentação vertical (bounce)}

Ao longo do século XX a teoria de ride foi amplamente discutida na indústria automotiva, e o principal foco desde o princípio foi o de controle dos movimentos de carroceria em grandes amplitudes e baixa frequência de excitação vertical.

O fenômeno de bounce caracteriza-se pela movimentação vertical da carroceria do veículo em resposta as mudanças de elevação da pista em que trafega. Tal movimentação se dá em baixas frequências, nas faixas de frequência dos modos de vibrar de suspensão.

Em geral carros de passeio possuem frequências de ride na ordem de $1.2 \mathrm{~Hz}$ a $1.6 \mathrm{~Hz}$ para o eixo dianteiro e traseiro. Os principais parâmetros que influenciam o fenômeno de bounce são as constantes elásticas de mola e as acurvas de amortecedor escolhidas para um dado veículo.

De forma simplificada, modelos de 1 grau de liberdade como o apresentado anteriormente, podem ser usados para estimativas iniciais de amplitude de movimentação 
vertical em um sistema de suspensão conhecido. Da mesma forma o amortecimento desta suspensão pode ser avaliado em termos do decaimento da movimentação de roda após um dado obstáculo, seja ele de grande ou pequena amplitude.

\section{- Balanço de Deslocamento}

Além de caracterizar o fenômeno de bounce, eventos de baixa frequência também são importantes para a definição e otimização do balanço de movimentação e amortecimento entre as suspensões dianteira e traseira. Este balanço tem papel importante, pois ajuda a definir o comportamento de pitch do veículo.

Um bom exemplo é um veículo que tenha este balanço dividido igualmente entre a suspensão dianteira e traseira. Caso esta movimentação ocorra fora de fase, induzirá ao veículo um pronunciado comportamento de pitch, localizado entre os eixos do veículo, em geral próximo aos assentos dianteiros. Assim não é incomum encontrar veículos de passeio atualmente com maior movimentação em um dos eixos.

\section{- Headtoss}

Ao longo das últimas décadas houve uma tendência de aumento na rigidez lateral dos sistemas de suspensão, em geral através do uso de barras estabilizadoras. O motivo desse aumento é a busca por parte dos fabricantes de veículos com características de dinâmica lateral cada vez mais refinada. Dentro dessa busca, o nível de rolagem do veículo é fator de grande importância, pois afeta diretamente a estabilidade e segurança dos automóveis.

Porém o acréscimo de rigidez de rolagem dos sistemas de suspensão traz também um efeito colateral, que é o aparecimento de acelerações laterais e movimentações percebidas em geral na cabeça dos ocupantes em eventos de baixa amplitude e deslocamento fora de fase entre os lados direito e esquerdo do veículo (fenômeno conhecido como headtoss). Este fenômeno normalmente é subdividido em duas categorias: de baixa frequência e grande amplitude e de grande frequência e baixa amplitude.

O compromisso entre baixos níveis de gradiente de rolagem e a minimização do headtoss é de grande importância na definição do acerto de suspensão em um veículo moderno. 
Para tal é necessário em geral balancear as curvas de extensão e compressão dos amortecedores (para baixas frequências) e otimizar os valores de rigidez das buchas de barra estabilizadora e braços de controle do sistema (para altas frequências).

\subsubsection{Ride Secundário}

Os fenômenos de ride secundário ocorrem em uma faixa de frequências acima da faixa do ride primário, entre $8 \mathrm{~Hz}$ e $100 \mathrm{~Hz}$. Estes fenômenos são caracterizados principalmente por vibrações causadas pela rugosidade do pavimento e por diferentes perturbações em pistas de pavimentos bons ou mesmo severas.

Tais fenômenos são percebidos pelo motorista ou passageiros do veículo através dos diferentes pontos de interface entre o ocupante e o veículo, tais como bancos, volante de direção e assoalho. A resposta do corpo humano aos níveis de vibração do ride secundário se dá de formas diferentes para cada fenômeno e é avaliado subjetivamente pelos ocupantes, o que dá margem a diferentes interpretações do fenômeno.

Ao contrário do ride primário, no ride secundário as amplitudes de movimento são menores (e de frequências maiores), e assim a maior influência se dá nos elementos elásticos dos sistemas de suspensão como buchas de braço de controle, top mount dos amortecedores e nos coxins do sistema powertrain. Além disso, e em especial para o fenômeno de harshness, a rigidez e resposta em frequência da carroceria do veículo são também importantes na definição do comportamento do veículo.

A faixa de baixa frequência $(7 \mathrm{~Hz}$ a $12 \mathrm{~Hz})$ caracteriza-se por maiores amplitudes de movimento, enquanto na faixa de alta frequência (de $12 \mathrm{~Hz}$ a $25 \mathrm{~Hz}$ ) os níveis de aceleração são maiores. A definição das curvas de rigidez dos coxins tem grande influência na interação das duas faixas de frequência.

Assim o desenvolvimento dos coxins passa pelo compromisso entre deslocamento do sistema (permitido por componentes com baixa rigidez) e níveis de aceleração em frequências mais altas (em componentes com grande rigidez). Em geral o shake de baixa frequência tem grande interação com outros fenômenos como impactos (na forma de decaimento das vibrações excitadas por um impacto singular).

\section{- Harshness}


A partir de $25 \mathrm{~Hz}$ e até aproximadamente $100 \mathrm{~Hz}$, o nível de vibrações do veículo a partir da interação pneu-pavimento passa a ser de amplitude muito baixa, e inclui modos de vibrar da carroceria do veículo. Tal fenômeno é chamado de aspereza (ou harshness) e é percebido pelos ocupantes nas regiões de interface entre os mesmos e o veículo. As principais regiões são então: o volante de direção, assoalho e bancos.

Os principais elementos de suspensão que tem a função de filtrar tais vibrações são os pneus e as buchas de suspensão. Nesta faixa de frequência as buchas trabalham em torno do seu ponto de equilíbrio, dentro da região de rigidez linear do componente.

Dessa forma a definição das características do material elástico e da dureza usada no componente (bucha) é fundamental na otimização do comportamento do veículo quanto a aspereza.

\subsection{Diretrizes para um Planejamento de Experimentos}

Nos processos de fabricação das indústrias existem vários fatores e níveis de regulagens que influenciam as características de qualidade dos produtos, e um problema comum encontrado pelas empresas ao realizar experimentos é a necessidade de estudar simultaneamente o efeito desses fatores com diferentes níveis de regulagens.

Neste caso, observa-se que o número de testes requeridos para a experimentação tende a crescer à medida que a quantidade de fatores aumenta. Isso torna os experimentos inviáveis nas empresas, uma vez que os custos e o tempo de execução se tornam elevados.

Experimentos industriais são realizados pelas empresas, principalmente, para se resolver os problemas críticos do produto ou processos de fabricação. Com esses testes procura-se reduzir o número de produtos com defeitos fabricados e responder a uma série de questões relacionadas aos níveis e parâmetros que influenciam o desempenho do produto final.

Coleman \& Montgomery, (1993) sugerem que a solução dos problemas pode ser alcançada com mais facilidade quando os experimentos são planejados e as respostas analisadas com métodos ou técnicas estatísticas. 
Nesse sentido, Barker, (1985) ressalta que ao realizar as atividades dos experimentos de forma planejada, as informações obtidas dos produtos tornam-se mais confiáveis e, com isso ações de melhoria mais eficientes podem ser tomadas.

\subsubsection{Conceitos gerais de experimentação}

Alguns conceitos e termos fundamentais para a aplicação das técnicas de planejamento e análise de experimentos industriais são apresentados por Werkema \& Aguiar, (1996), Montgomery, (1991). Tais conceitos estão descritos a seguir.

Variáveis de resposta: são as variáveis dependentes que sofrem algum efeito nos testes, quando estímulos são introduzidos propositalmente nos fatores que regulam ou ajustam os processos de fabricação. Nos experimentos, podem existir uma ou mais variáveis de resposta (y) que são importantes de se avaliar.

Fatores de Controle: estes são os fatores alterados deliberadamente no experimento. O objetivo principal de introduzir estímulos, os fatores de controle, é avaliar o efeito produzido nas variáveis de resposta e, com isso poder determinar os principais fatores do processo.

Fatores de Ruído: são os fatores, conhecidos ou não, que influenciam nas variáveis de resposta do experimento. Cuidados especiais devem ser tomados na hora de realizar os testes com esses fatores, pois, é importante evitar que os efeitos produzidos pelos fatores de controle, fiquem misturados ou mascarados com os efeitos provocados pelos fatores de ruído.

Níveis dos fatores: são as condições de operação dos fatores de controle investigados nos experimentos. Os níveis são identificados por nível baixo (-1) e nível alto (+1).

Tratamentos: é a combinação dos níveis de fatores de controle, isto significa que cada uma das corridas do experimento representará um tratamento.

Efeito principal: é a diferença média observada na reposta quando se muda o nível do fator de controle investigado.

Efeito de interação: é a metade da diferença entre os efeitos principais de um fator nos níveis de outro fator.

Matriz de experimentos: é o plano formal construído para conduzir os experimentos. Nesta matriz são incluídos os fatores de controle, os níveis e tratamentos do experimento. 
Aleatorização: é o processo de definir a ordem dos tratamentos da matriz experimental, através de sorteios ou por limitações específicas dos testes. Esse conceito também se refere ao processo de alocação do material e equipamento às diferentes condições de experimentação.

Repetição: é o processo de repetir cada uma das combinações (linhas) da matriz experimental sob as mesmas condições de experimentação. Segundo Montgomery, (1991), este conceito permite encontrar uma estimativa do erro experimental, que é utilizado para determinar se as diferenças observadas entre os dados são estatisticamente significativas.

Blocos: é a técnica utilizada para controlar e avaliar a variabilidade produzida pelos fatores perturbadores (controláveis ou não-controláveis) dos experimentos. Com esta técnica procurase criar um experimento (grupo ou unidades experimentais balanceadas) mais homogêneo e aumentar a precisão das respostas que são analisadas.

\subsubsection{Processo para conduzir os experimentos}

Antes de iniciar qualquer experimentação, é importante estabelecer o planejamento dos testes. Werkema \& Aguiar, (1996), Coleman \& Montgomery, (1993) ressaltam a importância do domínio do problema e recomendam que durante os experimentos, o processo seja cuidadosamente monitorado, para garantir que tudo seja realizado de acordo com o planejado.

Um plano estratégico de coordenação das atividades do planejamento experimental é proposto por vários autores como Werkema \& Aguiar, (1996), Coleman \& Montgomery, (1993), Antony, et al. (1998). Dentro desse plano existem algumas atividades padrões como:

1. Definição dos objetivos do experimento: nesta fase inicial é importante definir os problemas dos produtos e processos de fabricação, os objetivos do experimento e principalmente, selecionar uma equipe que seja responsável por todas as atividades do processo experimental. Ao realizar o brainstorming, todas as idéias ou informações coletadas devem ser criticamente examinadas pela equipe responsável.

Segundo Antony, et al. (1998), é natural que as pessoas descrevam vários problemas nos produtos ou processos de fabricação e, neste caso, outras ferramentas como os gráficos de Pareto e o diagrama de Causa e Efeito podem ser utilizadas para se identificar os principais problemas. 
2. Parâmetros do experimento: esta fase envolve a coleta de informações técnicas do produto ou processo de fabricação, na qual, as pessoas devem listar todos os fatores de controle, fatores de ruído, os níveis de ajustagem e as variáveis de resposta. Nessa fase, segundo Montgomery, (1991), as informações técnicas podem resultar de uma combinação entre o conhecimento prático (experiência) e a compreensão teórica do objeto de estudo.

3. Seleção dos fatores de controle e das variáveis de resposta: nesta fase a equipe deve selecionar os fatores de controle (variáveis independentes), as faixas de variação dos níveis de ajustagem desses fatores e as respostas do experimento (variáveis dependentes), assim como, definir o método de medição dos fatores de controle e a escala numérica que será utilizada para se avaliar as respostas do experimento definidas nas fases anteriores.

Coleman \& Montgomery, (1993) sugerem que nesta fase os parâmetros do processo sejam classificados por categorias (grau de influência na resposta, capacidade de se controlar ou capacidade de se medir), apresentadas na Figura 9. Esse esquema pode ajudar a selecionar e a priorizar os fatores críticos que afetam as respostas do experimento.

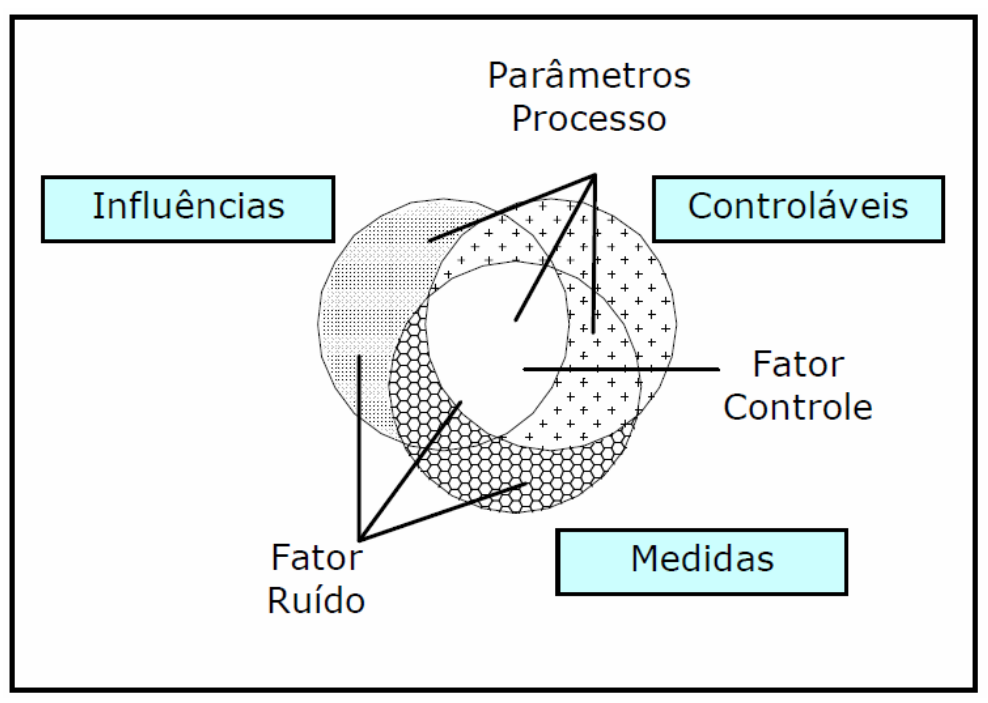

Figura 9 - Diferentes categorias dos fatores - Coleman and Montgomery,(1993)

4. Seleção da matriz experimental: segundo Montgomery, (1991), se as três etapas anteriores foram seguidas corretamente, esta quarta etapa será relativamente simples de realizar. Ao selecionar ou construir a matriz experimental, devem ser considerados o número de fatores de controle, o número de níveis e os fatores não controláveis do processo. Ainda, nesta fase são definidas as seqüências das corridas (aleatoriamente), o número de replicas, as restrições dos experimentos e as possíveis interações que possam vir a ocorrer entre os fatores 
que estão sendo avaliados. Algumas das técnicas de planejamento de experimentos que podem ser utilizadas nesta fase são descritas nas próximas seções.

5. Realização do experimento: nesta etapa é importante que o processo seja acompanhado pela equipe ou por um responsável, para assegurar-se que todos os procedimentos sejam executados conforme o plano. Qualquer mudança no momento em que os experimentos são realizados deve ser registrada, relatórios devem ser apresentados no final da experimentação, visto que, essas informações podem enriquecer os resultados obtidos pela análise de dados e verificar se os experimentos foram corretamente executados pelo responsável.

6. Análise de dados: nesta etapa podem ser utilizados softwares estatísticos (MINITAB, EXCEL, STATISTICA), que ajudam a usar as técnicas de planejamento e análise de experimentos.

Os conceitos estatísticos são aplicados nos resultados de um experimento, para descrever o comportamento das variáveis de controle, a relação entre elas e para estimar os efeitos produzidos nas respostas observadas.

7. Interpretação dos resultados: ao finalizar a etapa anterior, as pessoas responsáveis pelo plano de atividades, devem extrair as conclusões práticas dos resultados e recomendar as ações de melhorias contínua do processo de fabricação. Uma prática comum nesta fase é descrever os resultados através de gráficos, especialmente quando são apresentados às pessoas externas ao projeto.

Elaboração de relatórios: Werkema \& Aguiar, (1996) ressaltam que o trabalho realizado deve ser descrito, identificando-se as limitações práticas e teóricas encontradas, as recomendações para futuros experimentos e as conclusões obtidas. Esta etapa é importante porque demonstra que o estudo desenvolvido é um processo contínuo de aprendizado.

\subsubsection{Técnicas de planejamento e análise de experimentos}

Os experimentos industriais devem ser planejados em uma matriz experimental. A construção dessa matriz corresponde a etapa número quatro do roteiro para conduzir os ensaios, apresentado anteriormente.

O objetivo dessa atividade é garantir que as informações obtidas sejam confiáveis e que os recursos disponíveis para experimentação sejam bem utilizados. Nesta fase do projeto 
experimental diversas técnicas de planejamento e análise de experimentos podem ser utilizadas, conforme será descrito a seguir.

\section{- Planejamento fatorial}

Ao planejar os experimentos industriais com a técnica fatorial, considera-se que todos os tratamentos da matriz experimental são realizados pela equipe responsável por esta atividade. Segundo Button, (2001), o planejamento fatorial é indicado para a fase inicial do procedimento experimental quando há necessidade de se definir os fatores mais importantes e estudar os efeitos sobre a variável resposta escolhida. Ainda, "é um modelo de efeitos fixos, isto é, a análise dos efeitos provocados pelos fatores não pode ser transferida para outros níveis que não os analisados no planejamento".

Para ilustrar o procedimento dessa técnica considere-se um experimento com dois fatores (A e B), cada um desses parâmetros serão testados com $a$ níveis para o fator A e $b$ níveis para o fator $\mathrm{B}$.

Assim, nesse experimento existem $a b$ combinações de teste. A matriz de planejamento para o experimento fatorial de dois fatores de controle, nos níveis a e b, é representada pelo Tabela 1. Essa organização também representa o caso geral do experimento fatorial de dois fatores, para uma reposta $\left(y_{i j k}\right)$ observada quando o fator A está no i-ésimo nível $(i=1,2$, $\ldots, \mathrm{a})$

Tabela 1 - Experimento fatorial de dois fatores

\begin{tabular}{|c|c|c|c|c|c|}
\hline & & \multicolumn{4}{|c|}{ Fator B } \\
\hline & Níveis & 1 & 2 & $\ldots$ & $\mathrm{b}$ \\
\hline \multirow{4}{*}{ Fator A } & 1 & $\mathrm{y}_{111}, \mathrm{y}_{112}, \ldots, \mathrm{y}_{11 \mathrm{n}}$ & $\mathrm{y}_{121}, \mathrm{y}_{122}, \ldots, \mathrm{y}_{12 \mathrm{n}}$ & $\ldots$ & $\mathrm{y}_{1 b 1}, \mathrm{y}_{1 b 2}, \ldots, \mathrm{y}_{1 b n}$ \\
\hline & 2 & $\mathrm{Y}_{211}, \mathrm{y}_{212}, \ldots, \mathrm{y}_{21 \mathrm{n}}$ & $\mathrm{Y}_{221}, \mathrm{y}_{222}, \ldots, \mathrm{y}_{22 \mathrm{n}}$ & $\cdots$ & $\begin{array}{c}\mathrm{Y}_{2 \mathrm{~b} 1}, \mathrm{y}_{2 \mathrm{~b} 2} \\
\ldots, \mathrm{y}_{2 \mathrm{bn}}\end{array}$ \\
\hline & $\cdot$ & $\cdot$ & $\cdot$ & . & . \\
\hline & a & $\mathrm{Y}_{\mathrm{a} 11}, \mathrm{y}_{\mathrm{a} 12}, \ldots, \mathrm{y}_{\mathrm{a} 1 \mathrm{n}}$ & $\mathrm{Y}_{\mathrm{a} 21}, \mathrm{y}_{\mathrm{a} 22}, \ldots, \mathrm{y}_{\mathrm{a} 2 \mathrm{n}}$ & $\ldots$ & $\mathrm{Y}_{\mathrm{ab} 1}, \mathrm{y}_{\mathrm{ab} 2}, \ldots, \mathrm{y}_{\mathrm{abn}}$ \\
\hline
\end{tabular}


Com o experimento organizado dessa forma é possível verificar se:

- a reposta é alterada significativamente quando muda o nível do fator A;

- a resposta é alterada significativamente quando muda o nível do fator B;

- a interação dos fatores (coluna x linha) altera significativamente a resposta.

Os autores também definem que o modelo estatístico do planejamento fatorial é dado pela equação (3.49)

$$
y_{i j k}=\mu+\tau_{i}+\beta_{i}+(\tau \beta)_{i j}+\varepsilon_{i j k}
$$

sendo que,

$\mu$ é a média dos resultados

$i$ é o efeito principal do fator A,

$\beta_{i}$ é o efeito principal do fator $\mathrm{B}$,

$(\tau \beta)_{i j}$ é o efeito da interação dos fatores A e B;

$\varepsilon_{i j k}$ é o erro experimental

No planejamento de experimentos fatoriais é comum encontrar experimentos planejados com as técnicas fatoriais com dois, três ou mais níveis.

\section{Planejamento fatorial $2^{K}$}

Um experimento fatorial com $\mathrm{k}$ fatores, cada um deles com dois (2) níveis, é denominado de experimento fatorial $2^{K}$. O processo experimental dessa técnica consiste em realizar testes com cada uma das combinações da matriz experimental, para em seguida, determinar e interpretar os efeitos principais e de interação dos fatores investigados e assim, poder identificar as melhores condições experimentais do produto ou processo de fabricação.

Para ilustrar o procedimento dessa técnica considere-se um experimento com três fatores (x1, x2 e x3), cada um desses parâmetros foi testado com dois níveis $(-1,+1)$. Esse 
exemplo é apresentado por vários autores que estudam as técnicas de planejamento e análise de experimentos.

Assim, a matriz de planejamento para o experimento fatorial $2^{3}$ é representada pela Tabela 2. A respostas de cada ensaio ou tratamento é descrita pela coluna $y_{i}$. É importante ressaltar que a ordem de realização do teste é definida aleatoriamente.

$\mathrm{Na}$ matriz de planejamento as colunas representam o conjunto de fatores investigados $(\mathrm{x} 1, \mathrm{x} 2, \mathrm{x} 3, \mathrm{x} 4 \ldots, \mathrm{xk})$, e as linhas representam os diferentes níveis ou as combinações dos fatores (níveis codificados -1 (mínimo) e +1 (máximo)). 
Tabela 2 - Matriz de experimento do planejamento fatorial $2^{3}$

\begin{tabular}{|c|c|c|c|c|c|}
\hline \multirow{2}{*}{ N Teste } & \multicolumn{3}{|c|}{ Fatores de controle } & \multirow{2}{*}{ Ordem do teste } & \multirow{2}{*}{$\operatorname{Resposta}\left(y_{i}\right)$} \\
\hline & $\mathbf{X}_{1}$ & $\mathbf{X}_{2}$ & $\mathbf{X}_{3}$ & & \\
\hline 1 & -1 & -1 & -1 & 6 & $\mathbf{Y}_{1}$ \\
\hline 2 & +1 & -1 & -1 & 8 & $\mathbf{Y}_{2}$ \\
\hline 3 & -1 & +1 & -1 & 1 & $\mathbf{Y}_{3}$ \\
\hline 4 & +1 & +1 & -1 & 2 & $\mathbf{Y}_{4}$ \\
\hline 5 & -1 & -1 & +1 & 5 & $\mathbf{Y}_{5}$ \\
\hline 6 & +1 & -1 & +1 & 3 & $\mathbf{Y}_{6}$ \\
\hline 7 & -1 & +1 & +1 & 4 & $\mathbf{Y}_{7}$ \\
\hline 8 & +1 & +1 & +1 & 7 & $\mathbf{Y}_{8}$ \\
\hline
\end{tabular}

1. Para $x 1$, a coluna será definida pela combinação dos níveis $-1,+1,-1,+1,-1,+1,-1,+1$, ou seja, o sinal dessa coluna alterna em grupos de $2^{0}=1$.

2. Para $\mathrm{x} 2$, a coluna será definida pela combinação dos níveis $-1,-1,+1,+1,-1,-1,+1,+1, \ldots$, ou seja, o sinal dessa coluna alterna em grupos de $2^{1}=2$.

3. Para x3, a coluna será definida pela combinação dos níveis $-1,-1,-1,-1,+1,+1,+1,+1, \ldots$, ou seja, o sinal dessa coluna alterna em grupos de $2^{2}=4$.

4. Para $x 4$, o sinal alterna em grupos de oito $\left(2^{3}=8\right)$.

5. O procedimento será igual para $\mathrm{x} 5, \mathrm{x} 6, \ldots, \mathrm{xk}$. Para xk, o sinal alterna em grupos de $2^{k-1}$, ou seja, $2^{k-1}$ vezes $(-1)$, seguido de $2^{k-1}$ vezes $(+1)$.

O modelo estatístico do experimento fatorial $2^{3}$ é dado por:

$$
y_{i j k}=\mu+\tau_{i}+\beta_{i}+\gamma_{k}+\left(\tau \beta_{i j}\right)+\left(\tau \gamma_{i k}\right)+\left(\beta \gamma_{j k}\right)+\left(\tau \beta \gamma_{i j k}\right)+\varepsilon_{i j k}
$$


sendo que,

$\mu$ é a média dos resultados

i é o efeito principal do fator $\mathrm{x} 1$,

$\beta_{i}$ é o efeito principal do fator $\mathrm{x} 2$,

$k$ é o efeito principal do $\mathrm{x} 3$,

$\beta_{i j}$ é o efeito de interação entre os fatores x1 e x2,

( ik) é o efeito de interação entre os fatores x1 e x3,

( jk) é o efeito de interação entre os fatores x2 e x3,

( ijk) é o efeito de interação dos fatores x1, x2 e x3,

ijk é o erro experimental

A seguir é apresentado o método generalizado que pode ser utilizado para estimar os efeitos principais e de interação dos fatores. Esse método descrito em Montgomery, (1991) é também conhecido como método de sinais.

Os efeitos principais correspondem à mudança da resposta média quando o nível de um fator é alterado de (-1) para (+1), mantendo os outros fatores constantes. O procedimento consiste em multiplicar os resultados da coluna $y_{i}$ pelos valores 1 associados a coluna $x_{i}$ da matriz experimental correspondente ao efeito principal que se deseja estimar. Em seguida, os valores obtidos devem ser somados e divididos pela metade do número de ensaios realizados. Como mostra a equação (3.51).

$$
E_{i}=\sum y_{i} * x_{i} /\left(\frac{N}{2}\right)
$$

Sendo que $E_{i}$ será o efeito estimado, $\mathrm{N}$ é o número total de observações, $\sum y_{i} * x_{i}$ é a soma dos resultados $\left(y_{i}\right)$ do experimento multiplicados pela coluna $x_{i}$. 
Para determinar o efeito de interação, primeiramente devem ser construídas as colunas das interações da matriz de planejamento. Essas colunas são formadas por meio da multiplicação das colunas dos efeitos principais. Por exemplo, para estimar o efeito de interação $E_{12}$, serão multiplicadas as colunas dos fatores $x_{1}$ e $x_{2}$. Em seguida, os valores \pm 1 associados à coluna $x_{1} x_{2}$ da matriz experimental são utilizados para estimar o efeito de interação, conforme descrito anteriormente.

Para representar e interpretar graficamente os efeitos principais e de interação é necessário definir duas propriedades, conforme segue Devor et al., (1992).

- o sinal $( \pm$ ) indica a direção do efeito, isto é, se a resposta aumenta ou decresce com a variação do nível de $(-1)$ para $( \pm 1)$;

- a magnitude indica a intensidade do efeito.

A forma gráfica do efeito principal $\left(E_{i}\right)$ é representado pela Figura 10. Esse gráfico linear ilustra a variação média das respostas em função da mudança no nível $(-1,+1)$ de um fator $\left(x_{i}\right)$, mantendo os outros fatores constantes.

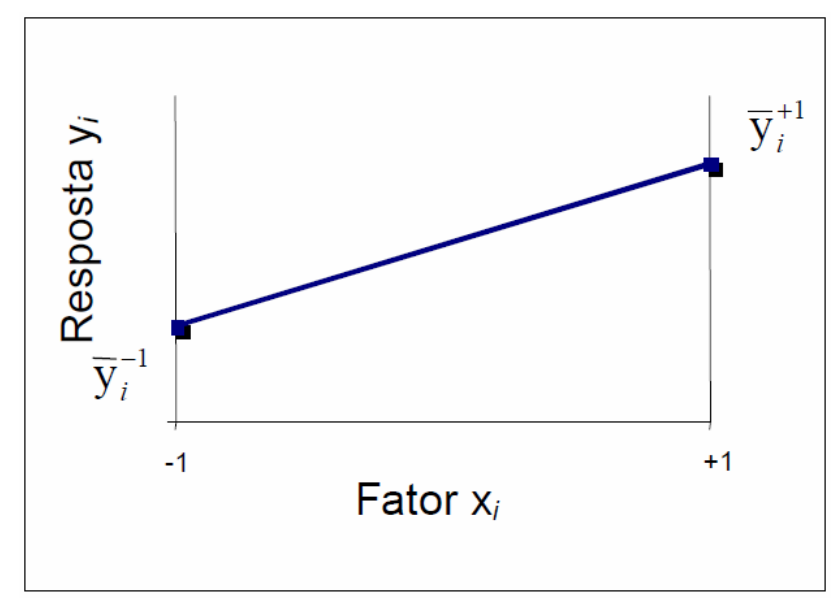

Figura 10 - Gráfico de efeitos principais, planejamento fatorial $2^{k}$

Os gráficos dos efeitos de interação descrevem a variação média de um fator em função dos níveis de outros fatores. Por exemplo, a Figura 11(a) ilustra que o efeito provocado pela mudança de nível do fator $x_{1}$ na resposta depende do nível do fator $x_{2}$, portanto, existe interação entre os fatores $x_{1}$ e $x_{2}$. A Figura 11 (b) demonstra que o efeito 
provocado pela mudança do nível do fator $x_{1}$ na resposta é independente do nível do fator $x_{2}$, portanto não existe interação entre esses fatores.

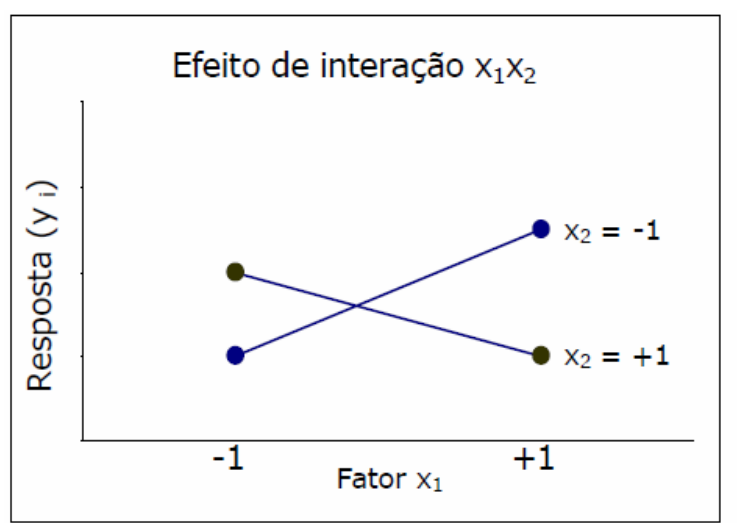

(a)

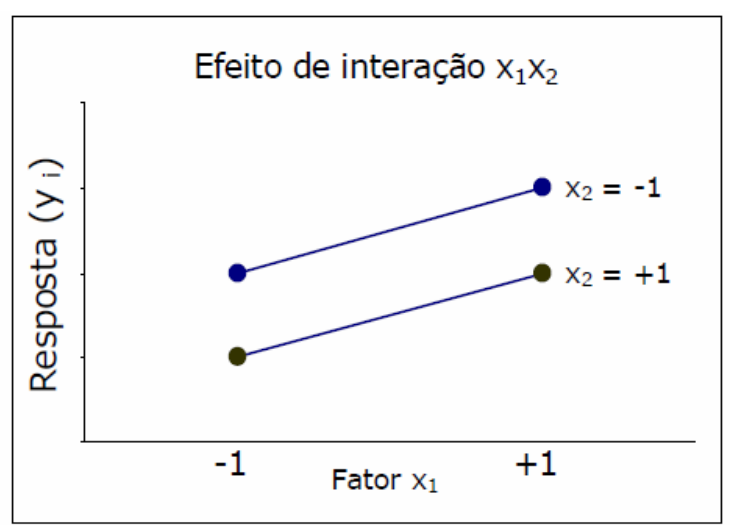

(b)

Figura 11 - Gráficos de efeitos de iteração

As principais vantagens da técnica fatorial $2^{k}$ é que através da análise dos experimentos pode-se indicar as principais tendências e determinar uma direção promissora para as experimentações subseqüentes Montgomery, (1991). Ainda, os autores ressaltam que com esse tipo de experimento também é possível quantificar o erro experimental.

As limitações atribuídas à técnica de fatorial $2^{k}$ são apresentadas a seguir:

- com esse tipo de técnica de planejamento de experimento não é possível obter informações dos fatores em níveis intermediários;

- não é suficiente avaliar os efeitos significativos apenas sob o ponto de vista estatístico, mas torna-se necessário avaliá-los também em termos práticos para as empresas;

- torna-se inviável utilizar a técnica nas empresas quando existe um número grande de fatores; ao utilizar essa técnica existe o risco de construir e planejar experimentos super dimensionados, uma vez que, são considerados vários fatores para realizar os testes.

\section{Planejamento fatorial fracionado $2^{k-p}$}

Ao realizar experimentos industriais, é comum verificar a necessidade de estudar o efeito de um ou mais fatores de controle ao mesmo tempo. A aplicação das técnicas de 
planejamentos de experimentos fatoriais fracionados $2^{k-p}$, mostra-se como uma das soluções para esse tipo de problema.

Montgomery, (1991) ressalta que, com essas técnicas, é possível analisar os efeitos sobre uma resposta de interesse, de $\mathrm{k}$ fatores com dois níveis cada um, em $2^{k-p}$ combinações de testes. Realizando-se apenas uma parte (metade do experimento quando p é igual a um, ou um quarto do experimento quando p é igual a dois), do experimento sem comprometer significativamente a precisão das conclusões decorrentes da análise de resultados. Simultaneamente, os custos e o tempo de duração dos ensaios são significativamente reduzidos.

Quando são utilizadas as técnicas de experimentos fatoriais $2^{k-p}$, a equipe responsável assume que os efeitos de interação de ordem superior são desprezíveis. Montgomery, (1991) ressalta três idéias importantes que justificam a utilização das técnicas de experimentos fatoriais fracionados.

A primeira delas é a dispersão dos efeitos. Isto é, quando existem vários fatores de controle, torna-se provável que o processo seja influenciado apenas por alguns efeitos principais e de interação de ordem inferior.

A segunda característica é denominada de propriedade de projeção. Neste caso, os experimentos fatoriais fracionados podem ser planejados em matrizes maiores, que podem ser construídas a partir de um subconjunto de fatores significativos. A terceira característica desse tipo de técnica é a experimentação seqüencial. Ocorre quando é possível combinar as corridas de dois ou mais experimentos fatoriais fracionados.

Considere-se um estudo com três fatores de controle (1, 2, e 3), com dois níveis cada um. A equipe responsável por conduzir o experimento determinou que é inviável economicamente realizar as oito combinações $\left(2^{3}=8\right)$ da matriz. Porém, é possível realizar um experimento com quatro (metade) observações $\left(2^{3} / 2=2^{3-1}=4\right)$. Esse exemplo é apresentado por Montgomery, (1991) e Devor et al. (1992).

Na Tabela 3, aparecem todas as combinações possíveis do experimento fatorial completo $2^{3}$. As colunas 12, 13, 23 e 123 foram estimadas pela multiplicação das colunas que contem os fatores 1, 2 e 3 . Por conveniência as combinações (linhas da matriz) foram separadas pelos sinais de positivo e negativo da coluna de interação de maior ordem, ou seja, 
pela interação 123. Essa coluna da matriz é denominada de relação definidora do experimento. Nesse tipo de experimento a equipe responsável pode optar pela execução das combinações referentes à parte positiva (teste número 1, 2, 3 e 4), o que é mais usual, ou executar a outra parte (corridas 5, 6, 7 e 8). No primeiro caso a combinação dos ensaios é representada por $I=123$. Se for selecionada a parte negativa, deve-se lembrar que a relação definidora do experimento será $\mathrm{I}=-123$.

Tabela 3 - Experimento fatorial $2^{3}$ Devor et al. (1992)

\begin{tabular}{|c|c|c|c|c|c|c|c|c|c|}
\hline \multirow{2}{*}{$\begin{array}{c}\text { Combinações } \\
\text { tratamento }\end{array}$} & \multicolumn{8}{|c|}{ Efeito Fatorial } & \multirow{2}{*}{$y_{i}$} \\
\hline & I & 1 & 2 & 3 & 12 & 13 & 23 & 123 & \\
\hline 1 & +1 & +1 & -1 & -1 & -1 & -1 & +1 & +1 & $\mathrm{Y}_{1}$ \\
\hline 2 & +1 & -1 & +1 & -1 & -1 & +1 & -1 & +1 & $\mathrm{Y}_{2}$ \\
\hline 3 & +1 & -1 & -1 & +1 & +1 & -1 & -1 & +1 & $\mathrm{Y}_{3}$ \\
\hline 4 & +1 & +1 & +1 & +1 & +1 & -1 & +1 & +1 & $\mathrm{Y}_{4}$ \\
\hline 5 & +1 & +1 & +1 & -1 & +1 & -1 & -1 & -1 & $\mathrm{Y}_{5}$ \\
\hline 6 & +1 & +1 & -1 & +1 & -1 & -1 & +1 & -1 & $\mathrm{Y}_{6}$ \\
\hline 7 & +1 & -1 & +1 & +1 & -1 & -1 & +1 & -1 & $\mathrm{Y}_{7}$ \\
\hline 8 & +1 & -1 & -1 & -1 & +1 & -1 & -1 & -1 & $\mathrm{Y}_{8}$ \\
\hline
\end{tabular}

A seguir, com objetivo de ilustrar o processo de planejamento experimental com a técnica fatorial fracionado será utilizada a parte positiva do experimento, apresentado na Tabela 3. Nessa matriz são identificadas as seguintes combinações lineares para estimar os efeitos principais dos fatores 1,2 e 3 , conforme segue.

$l 1=1 / 2(+1-2-3+4)$

$l 2=1 / 2(-1+2-3+4)$

$13=1 / 2(-1-2+3+4)$

e para os efeitos de interação 12, 13 e 23 se obtém: 
$112=1 / 2(-1-2+3+4)$

$113=1 / 2(-1+2-3+4)$

$123=1 / 2(+1-2-3+4)$

Percebe-se que algumas combinações lineares são iguais $(l 1=l 23, l 2=l 13$ e $l 3=$ l12). Quando isso ocorre torna-se impossível identificar claramente quais são os efeitos principais de cada fator porque estão misturados com os efeitos produzidos pela combinação de dois fatores. Nesse caso, Montgomery, (1991) e Devor et.al., (1992) afirmam que na realidade está sendo determinado o efeito das combinações de $1+23,2+13$ e $3+12$, e está propriedade é conhecida como efeito de "confundimento".

A estrutura de confundimento de um efeito principal ou de interação em um experimento pode se determinar por meio da multiplicação do efeito com a relação definidora. Por exemplo, a estrutura de confundimento do efeito principal pode ser obtida conforme segue:

Para o efeito principal 1;

(1) $I=(1) 123=23$

O mesmo procedimento é utilizado para estimar $2=13$ e $3=12$. Nota-se que não existe confundimento entre os efeitos principais, porém essas informações estão confundidas com os efeitos das interações entre dois fatores.

Sendo assim, um aspecto importante que deve ser considerado nos experimentos fatoriais fracionados é a resolução que está sendo utilizada. Segundo Montgomery, (1991), a resolução de um planejamento fatorial fracionado está relacionada ao padrão de confundimento entre os efeitos dos fatores.

O autor recomenda que nos experimentos deve-se utilizar a maior resolução possível, porque com isso é possível desprezar os efeitos de interação de mais alta ordem. A seguir são apresentadas as definições de resolução III, IV e V, que são consideras como as mais importantes e utilizadas ao se construir os experimentos industriais.

- Resolução III - isto significa que ao menos alguns efeitos principais são confundidos com efeitos de interação de dois fatores; 
- Resolução IV - se um planejamento é de resolução IV isto significa que ao menos alguns efeitos principais serão confundidos com efeitos de interação de três fatores, e ao menos alguns efeitos de interação de dois fatores são confundidos com outros efeitos de interação de dois fatores;

- Resolução V - se um planejamento é de Resolução V, ao menos alguns dos efeitos principais são confundidos com efeitos de interação de quatro fatores, e os efeitos de interação de dois fatores são confundidos com os efeitos de interação de três fatores.

Em alguns casos dependendo do número de fatores que são investigados, uma fração menor de combinações é necessária para realizar os experimentos fatoriais. Por exemplo a equipe pode apenas realizar um quarto (1/4) do experimento fatorial completo. Este tipo de experimento é conhecido como experimento fatorial fracionado $2^{k-2}$.

O experimento pode ser construído inicialmente com as combinações de tratamento ou colunas da matriz de um planejamento fatorial com k-2 fatores. Em seguida, são adicionadas duas colunas com as interações, escolhidas apropriadamente pela equipe responsável por conduzir os experimentos, que incluem os primeiros k-2 fatores. Uma característica importante desse experimento é a necessidade de determinar duas colunas geradoras para construir a matriz.

Conforme o número de fatores outras frações podem ser utilizadas. Na literatura que estuda as técnicas de planejamento e análise de experimentos industriais estão disponíveis o número de combinações e as estruturas de confundimento para esse tipo de experimento Montgomery, (1991). Ainda, softwares estatísticos (MINITAB, STATISTICA) podem ser usados para construir esse tipo de matriz.

Ao mesmo tempo, ressalta-se que a análise estatística e descritiva (gráficos lineares e de probabilidade normal) dos efeitos principais e de interação dos fatores segue os mesmos princípios apresentados anteriormente para um experimento fatorial $2^{k}$. 


\section{Desenvolvimento do modelo}

Neste capítulo será apresentado o modelo utilizado nas análises, bem como suas principais características. O modelo foi desenvolvido baseado em um protótipo real e sua validação se dará através de dados experimentais. Entradas de pista medidas serão utilizadas na fase de validação como será descrito nas próximas secções.

\subsection{Descrição geral do modelo}

O modelo virtual baseado no protótipo de um veículo comercial atrelado a um semireboque carregado, foi criado em ambiente multicorpos através do software ADAMS View.

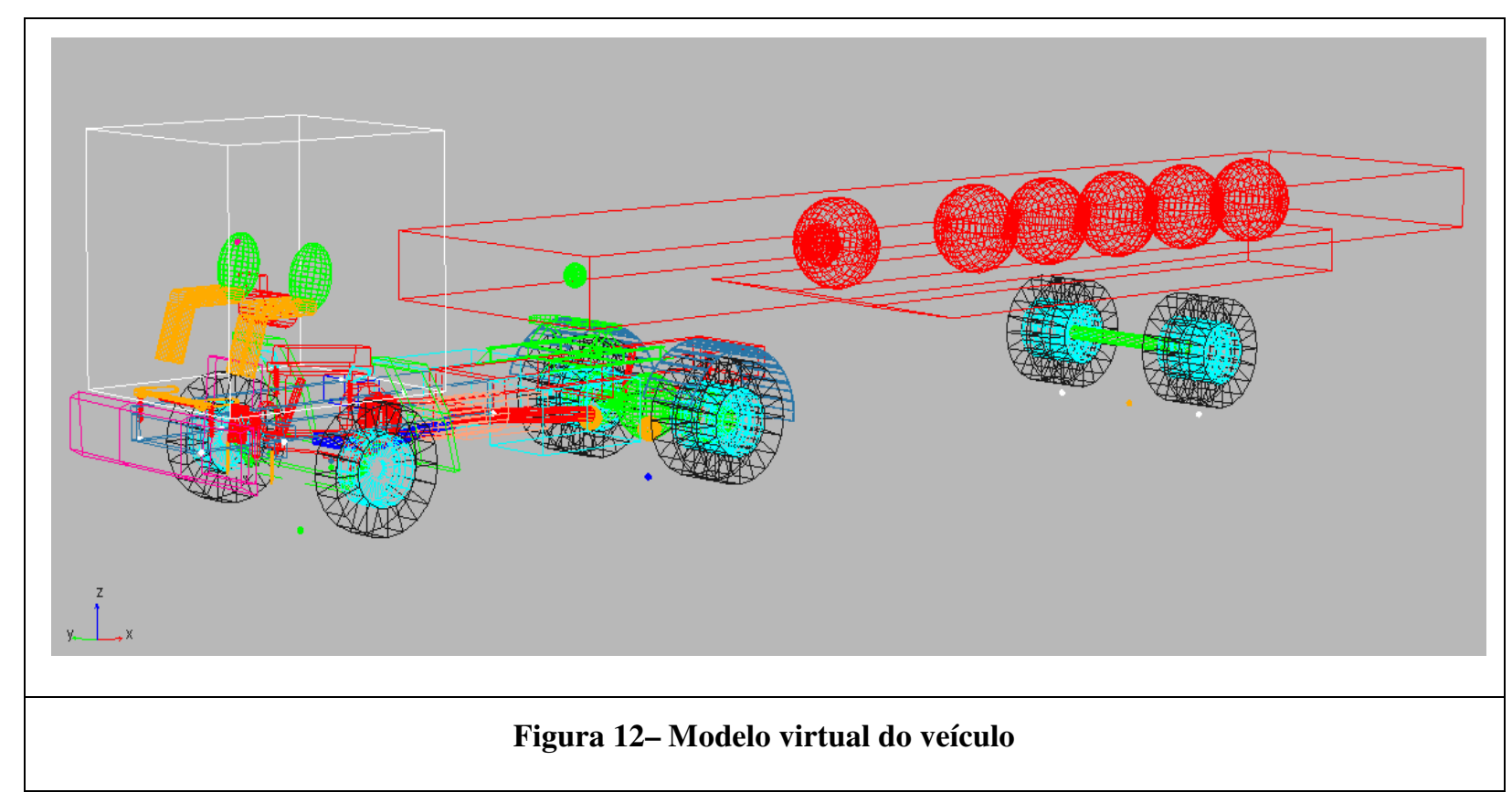

O veículo foi modelado com um chassi rígido levando em consideração os primeiros modos de vibrar de torção e flexão. A suspensão de cabine possui quatro amortecedores e molas posicionadas sob suportes e braços de movimentação. Suspensão primária com feixes de mola simplificados e amortecedores. Foram modelados coxins de motor e pneus simplificados através de elementos de mola. Como mostra a Figura 12 foi modelada também a quinta roda com o semi-reboque carregado e atrelado.

O veículo foi totalmente construído utilizando pesos e momentos de inércia das peças reais, como eixos, conjunto roda-pneu, cabine, barra estabilizadora. As principais características estão descritas na Tabela 4. 
Tabela 4 - Características gerais do modelo

\begin{tabular}{|c|c|c|}
\hline Parâmetro do veículo & Valor & Unidade \\
\hline Peso Eixo Dianteiro & 300 & $\mathrm{Kg}$ \\
\hline Peso Eixo Traseiro & 679 & $\mathrm{Kg}$ \\
\hline Peso Cabine & 807 & $\mathrm{Kg}$ \\
\hline Peso Motor e Transmissão & 980 & $\mathrm{Kg}$ \\
\hline Peso do Conjunto Semi-Reboque Carregado & 21260 & $\mathrm{Kg}$ \\
\hline Entre Eixos & 3750 & $\mathrm{~mm}$ \\
\hline Bitola & 2080 & $\mathrm{~mm}$ \\
\hline
\end{tabular}

\subsection{Subsistemas do modelo}

O veículo foi subdivido em subsistemas que serão apresentados separadamente no decorrer dessa secção. Visto que o principal objetivo do modelo seria avaliar o conforto do protótipo, apenas as partes que seriam relevantes para tal análise foram consideradas.

Dessa maneira seguem os itens a serem apresentados:

- Suspensão primária (dianteira e traseira);

- Suspensão de cabine;

- Chassis;

- Motor e transmissão;

- Semi Reboque.

\subsubsection{Suspensão primária dianteira e traseira}

A suspensão primária dianteira foi modelada utilizando elementos de viga para o eixo, o qual teve sua geometria, momento de inércia, peso, rigidez e pontos geométricos atribuídos através do projeto real do protótipo. Integrando o sistema de suspensão primária estão: rodas, pneus, eixo, amortecedor, feixe de molas e barra anti-rolagem. A rigidez dos pneus foi 
representada por uma bucha modelada através de elementos de mola, e o mesmo aconteceu com o feixe de molas simplificado. Os coeficientes de rigidez e amortecimento do sistema serão utilizados na fase de tuning, por isso foram parametrizados (representados por variáveis).

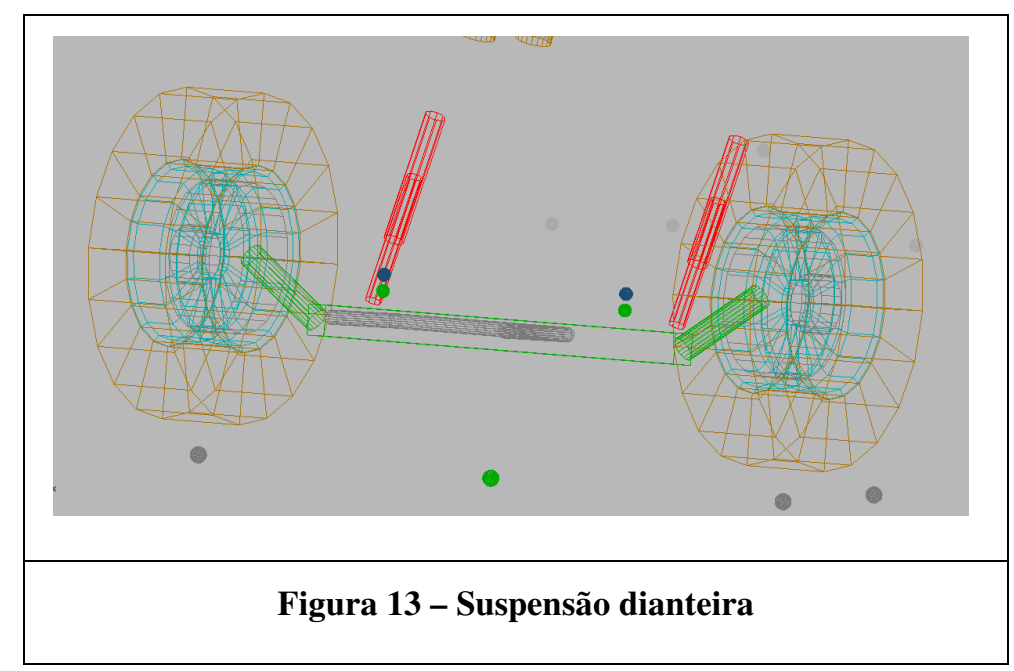

Suspensão traseira foi composta por pneus, eixo considerando o peso do diferencial, feixes simplificados e amortecedores.

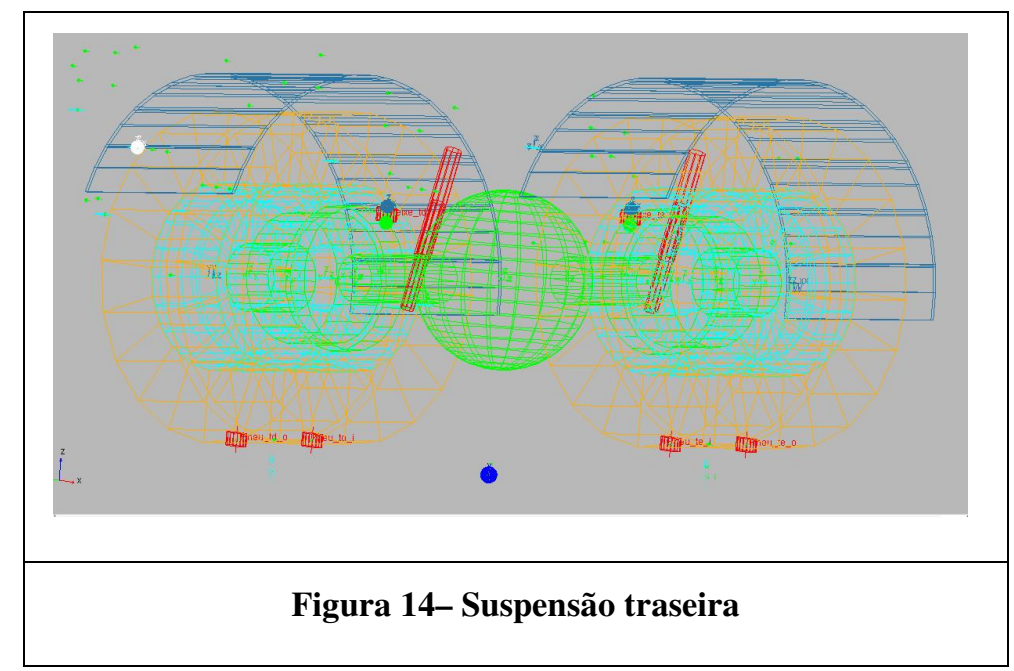

\subsubsection{Suspensão de cabine}

A suspensão da cabine foi modelada utilizando conjuntos mola-amortcedores nos quais para as molas foi utilizada uma variável que representa a rigidez constante $K$, utilizada no processo de tuning. Para o amortecimento do sistema foi utilizada também uma variável 
que representa o coeficiente de amortecimento, neste caso foi considerado o mesmo coeficiente para tração e compressão dos amortecedores.

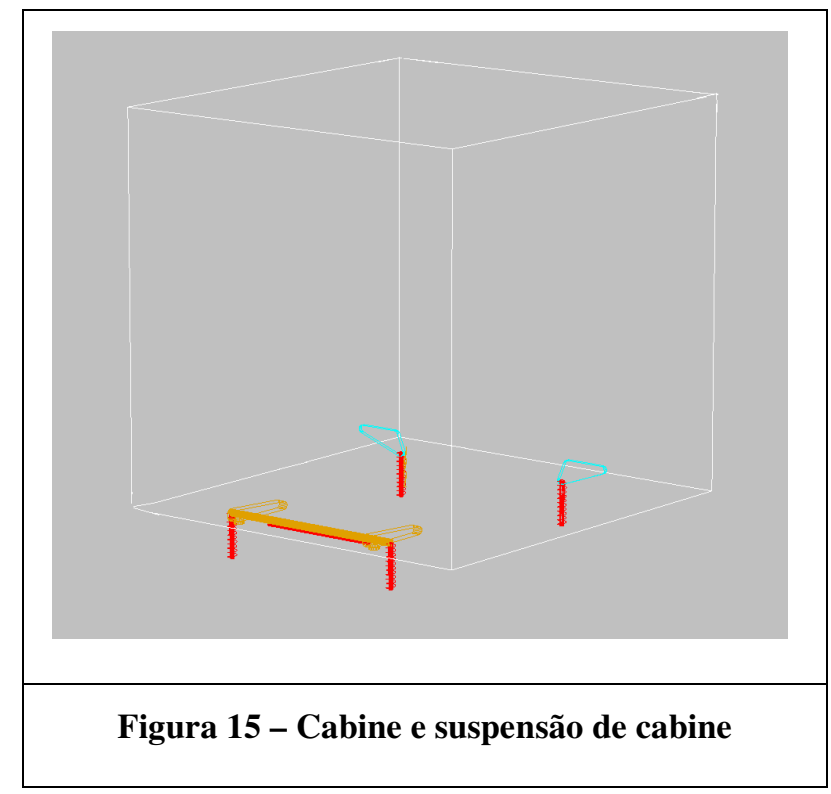

\subsubsection{Chassis}

O chassi do veículo foi modelado através de elementos de viga com massa e momentos de inércia previamente estabelecidos como mostra a Tabela 4. Para representar a rigidez de torção e flexão, a peça foi dividida em duas partes e a ligação entre as elas feita através de junta esférica com rigidez na direção de rotação do eixo longitudinal (X), representando torção e rigidez na direção de rotação do eixo lateral (Y) representando flexão.

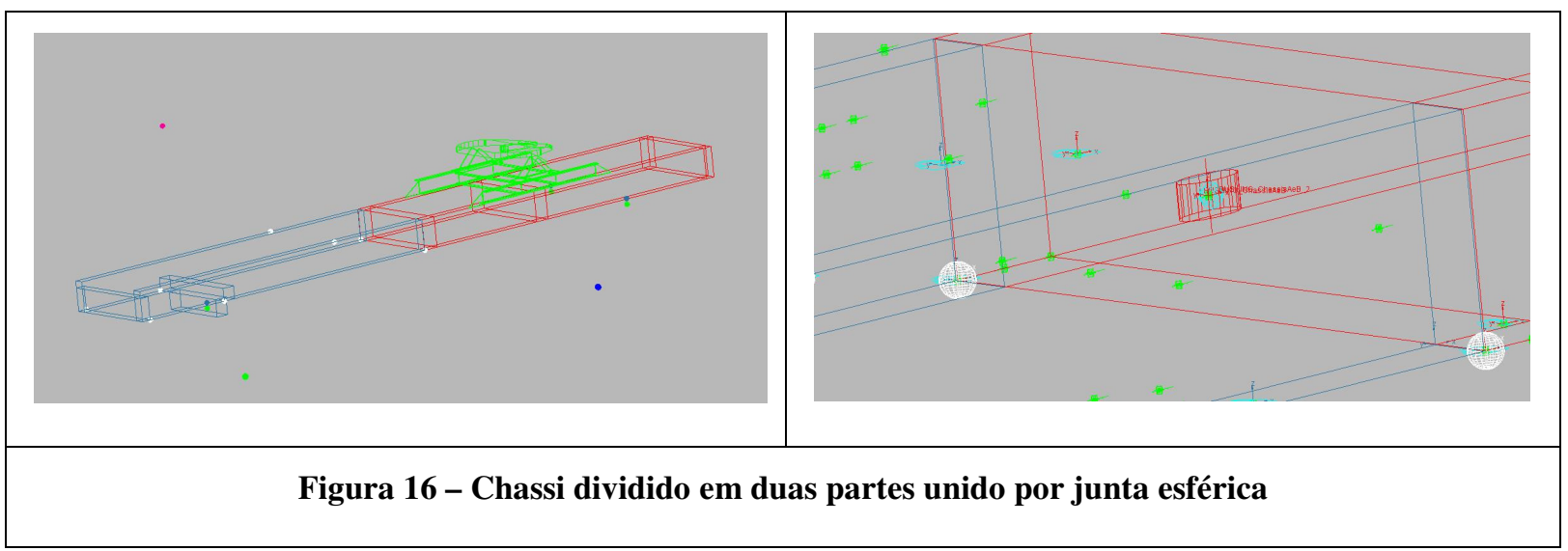

\subsubsection{Motor e transmissão}

Por se tratar de um elemento importante no ride de veículos, tanto comerciais como de passeio, o motor e transmissão devem ser considerados no modelo. Nesse caso foram levados 
em consideração apenas a geometria, peso e elementos de fixação (coxins). As vibrações geradas por esses elementos não foram consideradas.

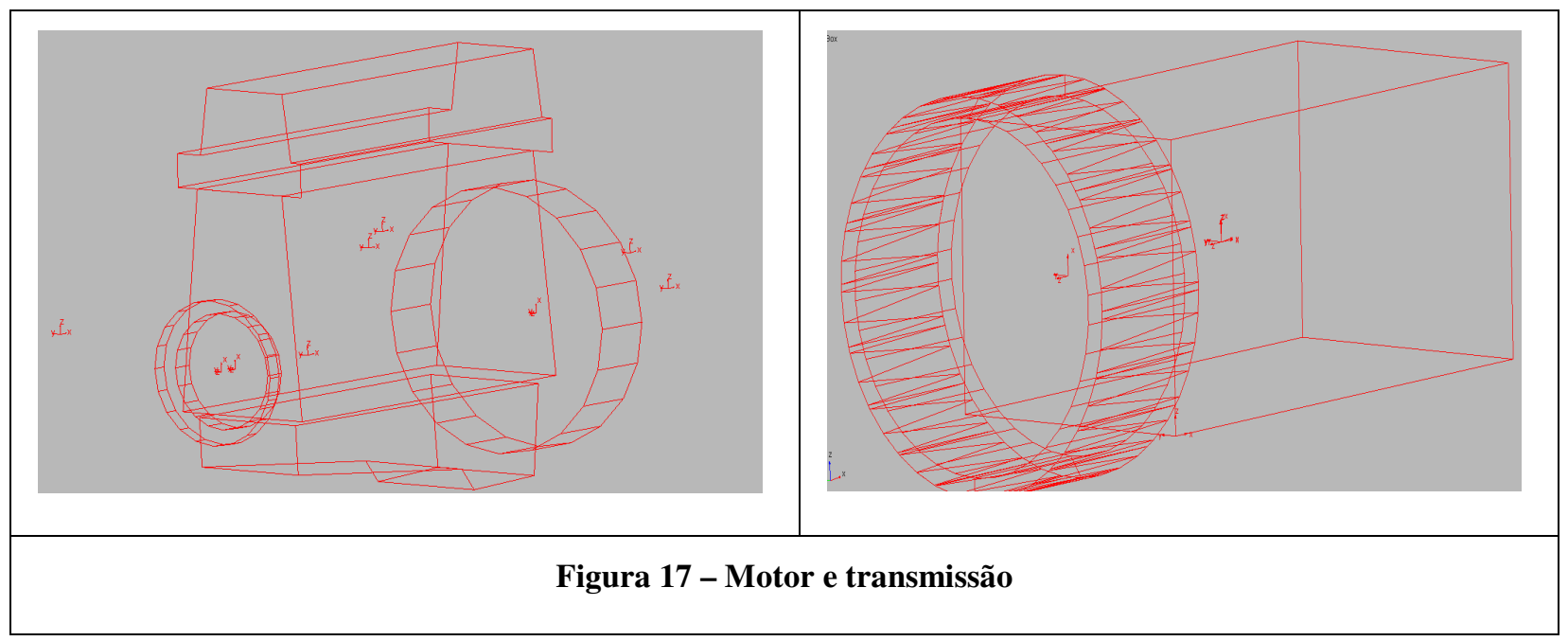

\subsubsection{Semi-Reboque}

Como a condição mais crítica para o conforto de um veículo comercial é quando o mesmo está atrelado a um semi-reboque carregado, o modelo levou em consideração a carga máxima a que o veículo seria capaz de transportar.

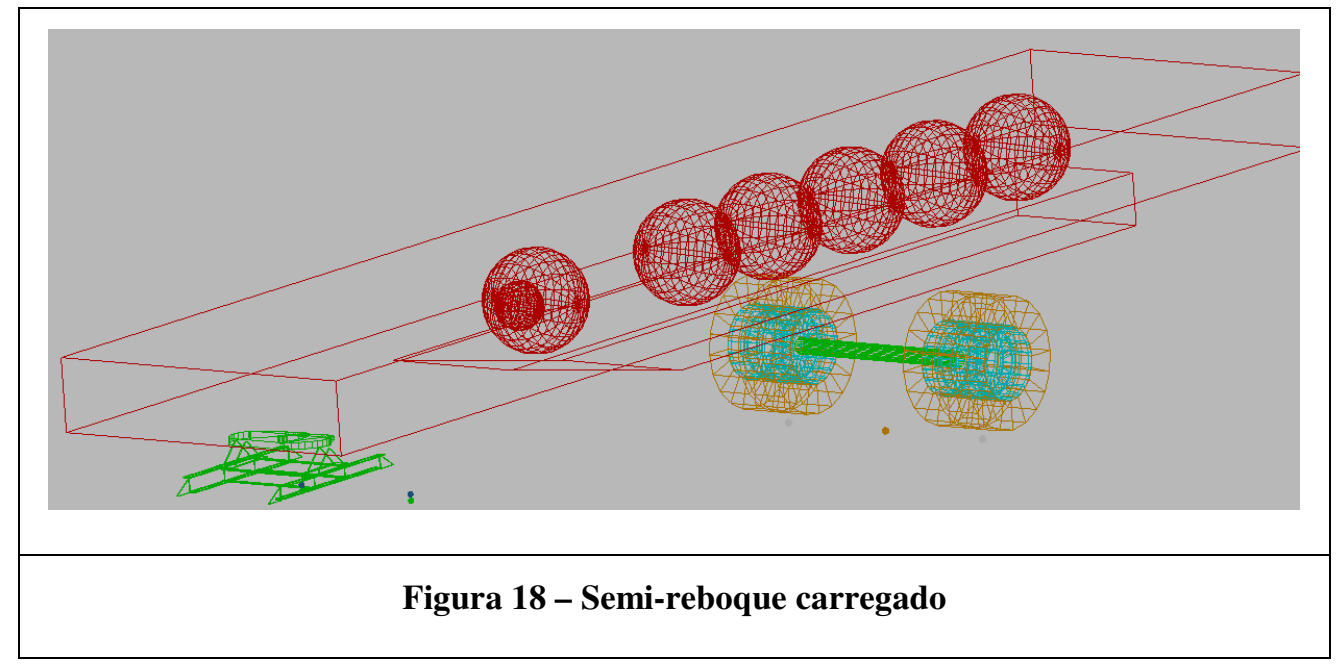

\subsection{Correlação do modelo}

\subsubsection{Instrumentação}

Como o principal foco da metodologia é a análise de conforto, a fase de correlação foi totalmente baseada na aproximação das acelerações e deslocamentos medidos na cabine do 
protótipo com o modelo. Para tanto, acelerômetros foram distribuídos em pontos estratégicos, como pode ser visto nas figuras abaixo.
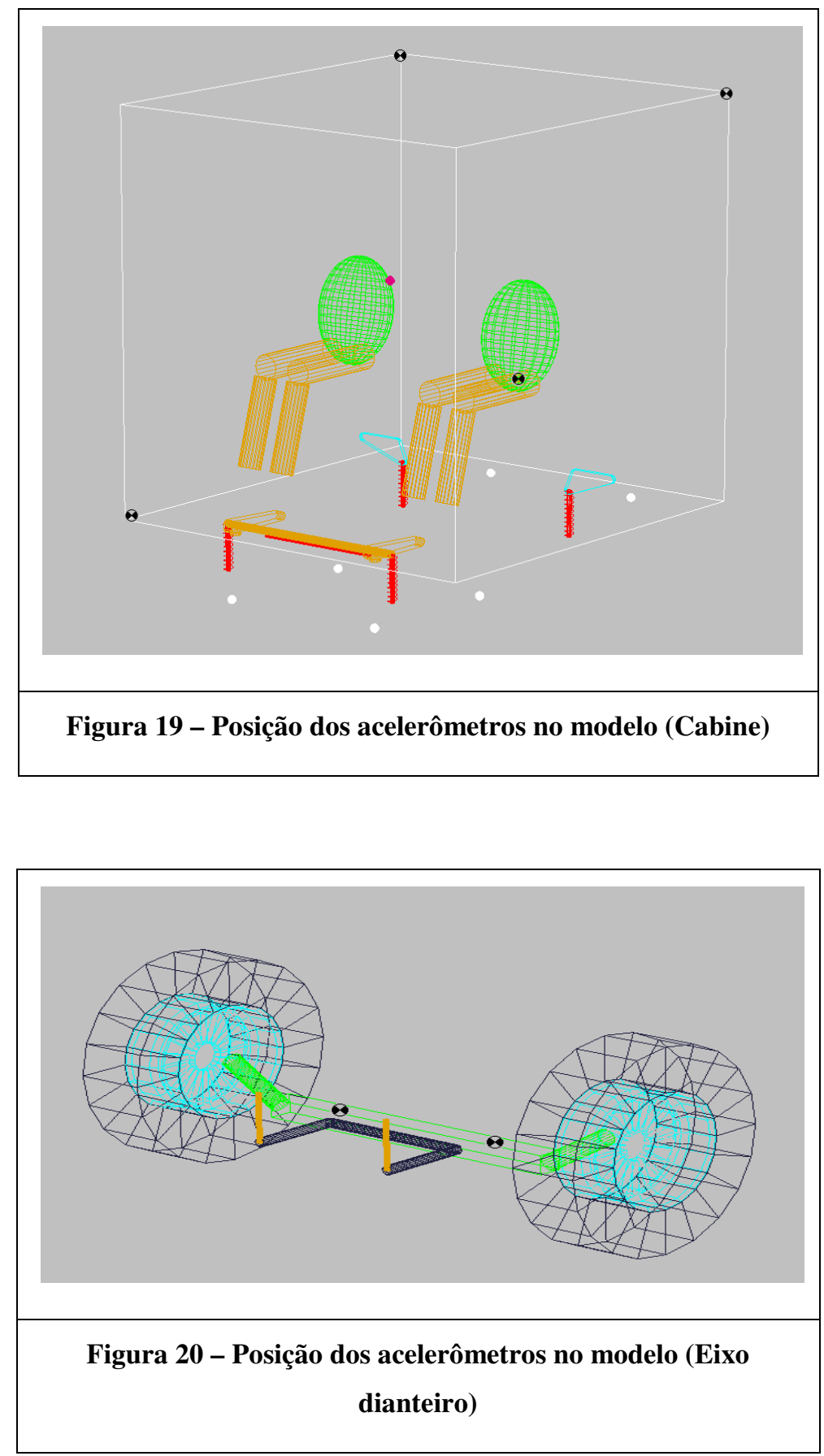

Dois acelerômetros foram posicionados no eixo dianteiro de modo a permitir a comparação dos efeitos da suspensão primária. Com esses sensores foi possível garantir que as excitações de entrada estavam bem aproximadas entre modelo e protótipo. Outros três sensores foram colocados nas extremidades da cabine. 
Tendo em vista o fato de que a assento do veículo é o ponto em que o passageiro ou motorista estará em constante contato, foi dada uma atenção especial para correlação dos sinais de vibração para essa posição.

As figuras abaixo mostram os acelerômetros instalados no protótipo real.

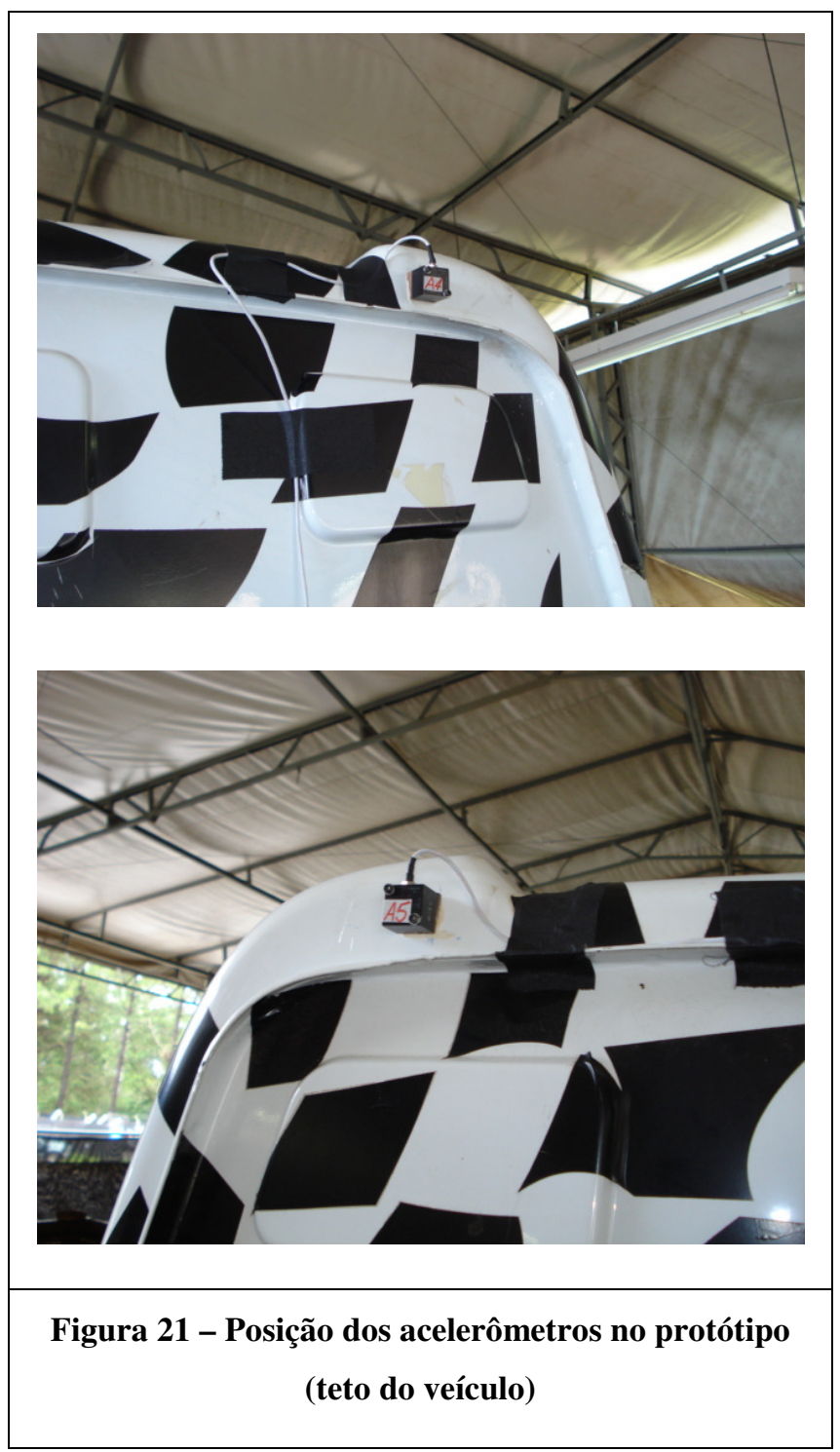



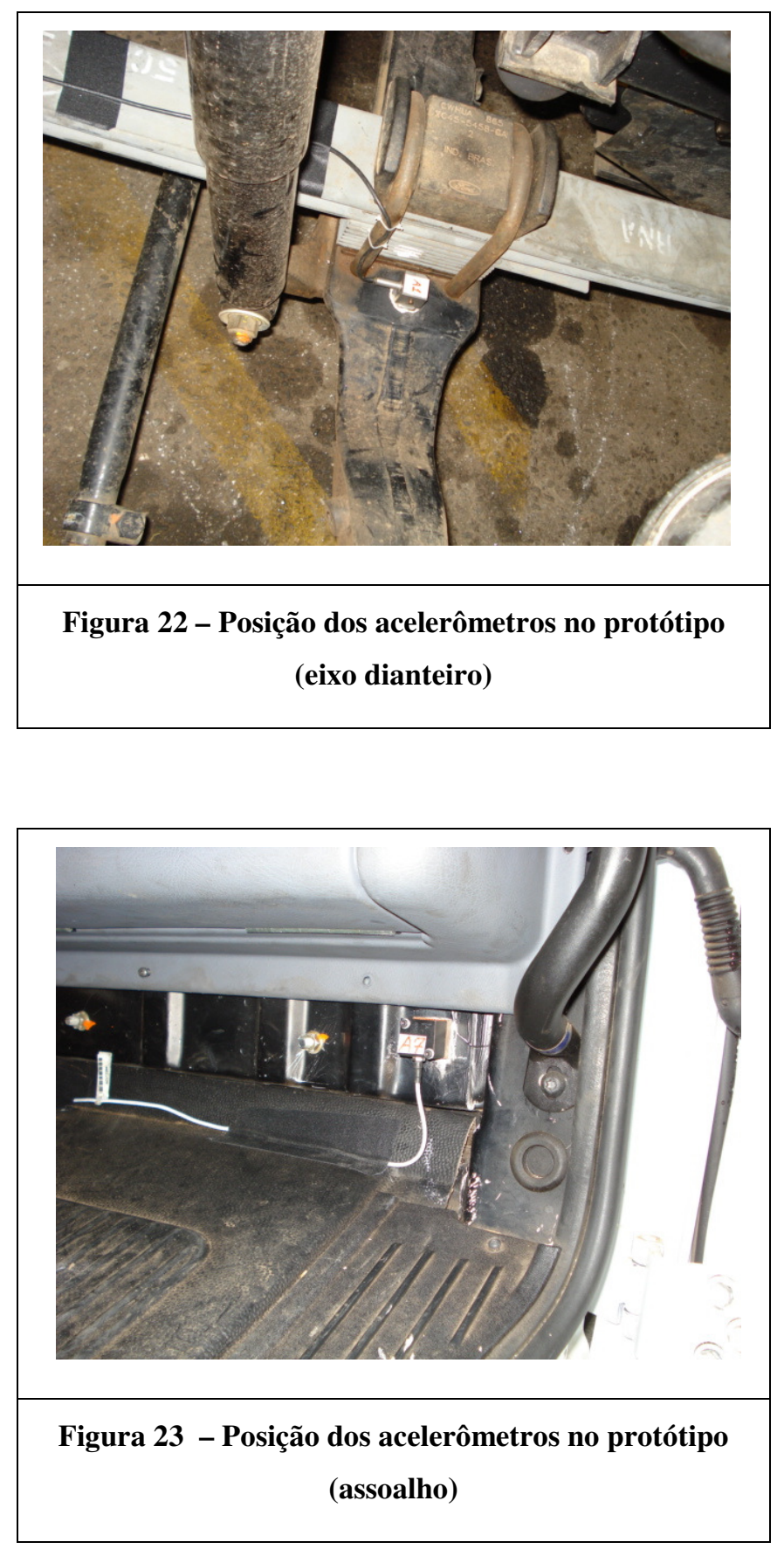

\subsubsection{Entradas do pavimento}

Pistas largamente utilizadas em avaliações subjetivas no campo de provas da Ford foram utilizadas para o desenvolvimento da metodologia, desde a fase de correlação até a fase de confirmação dos resultados. Essas pistas foram medidas e utilizadas também como excitações para o modelo. Existem inúmeras maneiras de medir o perfil de pistas, Fernandes, (2005) propõe um método no qual o objetivo seria desenvolver uma técnica que não demandasse nenhum dispositivo mecânico especial e que não necessitasse de nenhuma 
aproximação para se obter o resultado. A idéia foi um método que poderia ser utilizado em um veículo normal e as medições poderiam ser feitas com velocidades normais, aumentado a eficiência e melhorando o processo em termos de tempo.

Um problema encontrado ao se utilizar um veículo para realizar as medições são os movimentos relativos entre massa suspensa e não suspensa, pois esses movimentos dependem do tipo de suspensão. O sistema de medição deve estar preparado para compensar qualquer movimentação relativa, para tanto, dois sensores ópticos de altura (um em cada lado do veículo) mais dois acelerômetros, na mesma posição dos sensores de altura, foram instalados. A razão para se instalar dois pares de sensores, um em cada lado, é simplesmente para se obter dois perfis de pista ao mesmo tempo.

O sensor de altura mede o deslocamento da massa suspensa em relação ao ground. Os dados do acelerômetro, depois de uma integração dupla, passam a ser o deslocamento total da massa suspensa. A diferença entre esses dois sinais é o perfil da pista.

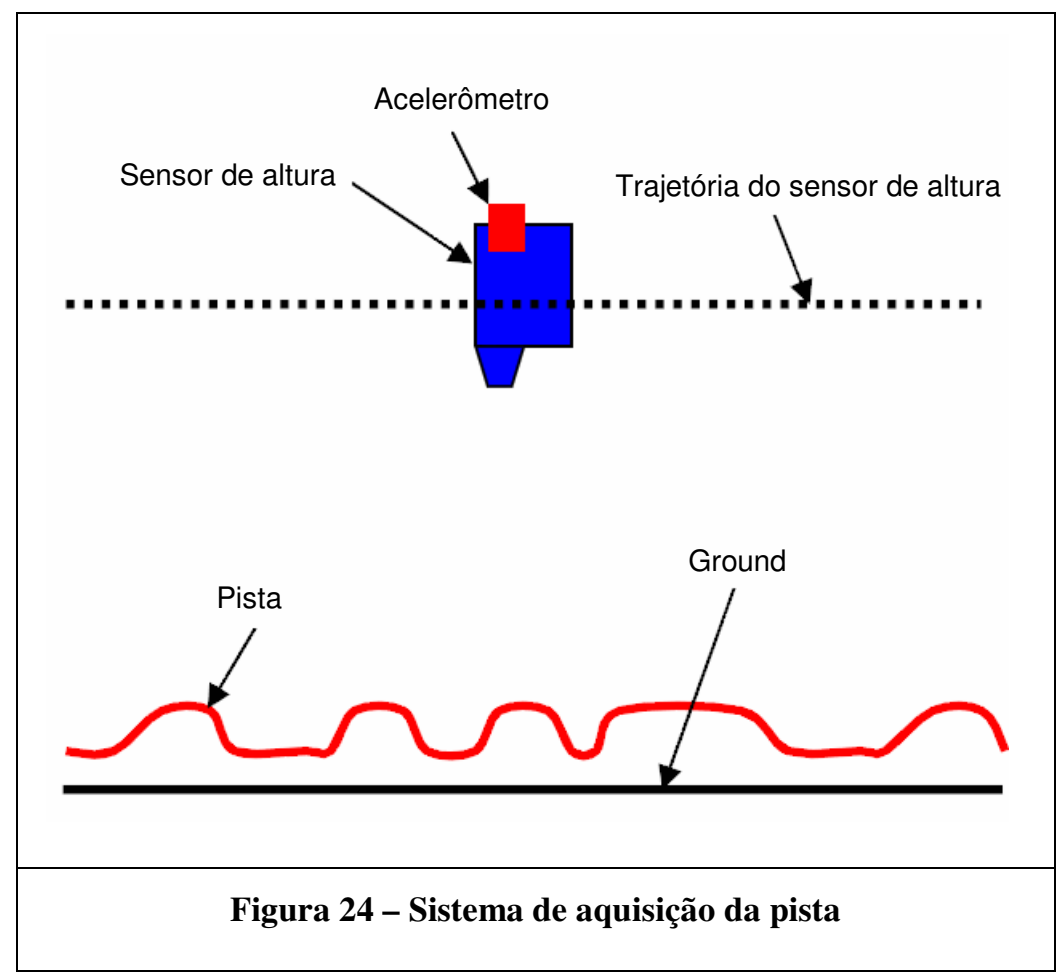


A Figura 24 mostra o esquema para a aquisição do perfil da pista. Uma vantagem desse sistema é compensação das deformações dos pneus, quando a diferença entre os sinais é computada, os erros criados pelas deformações dos pneus são suprimidos do perfil da pista.

Para ter certeza da eficiência do método, lombadas foram medidas geometricamente para ser comparada ao método desenvolvido. A comparação pode ser observada na Figura 25.

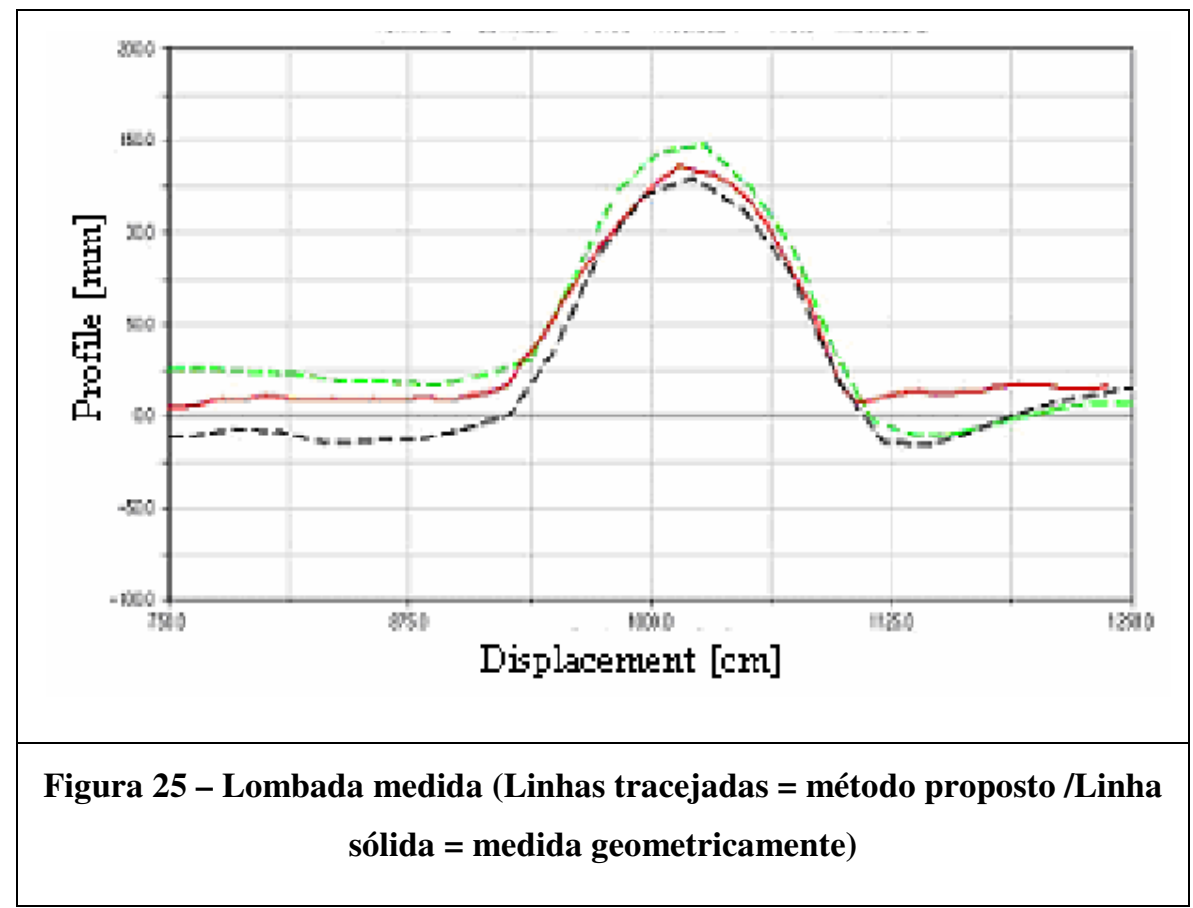

Levando em consideração todas as medições, foi obtida uma precisão de aproximadamente +/- $5 \mathrm{~mm}$, o que foi considerado aceitável para aplicações de análise de conforto.

A Figura 26 mostra a pista de paralelepípedos medida e incluída como excitação no modelo. O método disponibiliza o perfil medido através de dados do deslocamento vertical em função do deslocamento horizontal. Assim é possível excitar o modelo com qualquer velocidade, bastando dividir o eixo de deslocamento horizontal pela velocidade desejada, gerando consequentemente o perfil de deslocamento vertical em função do tempo. 


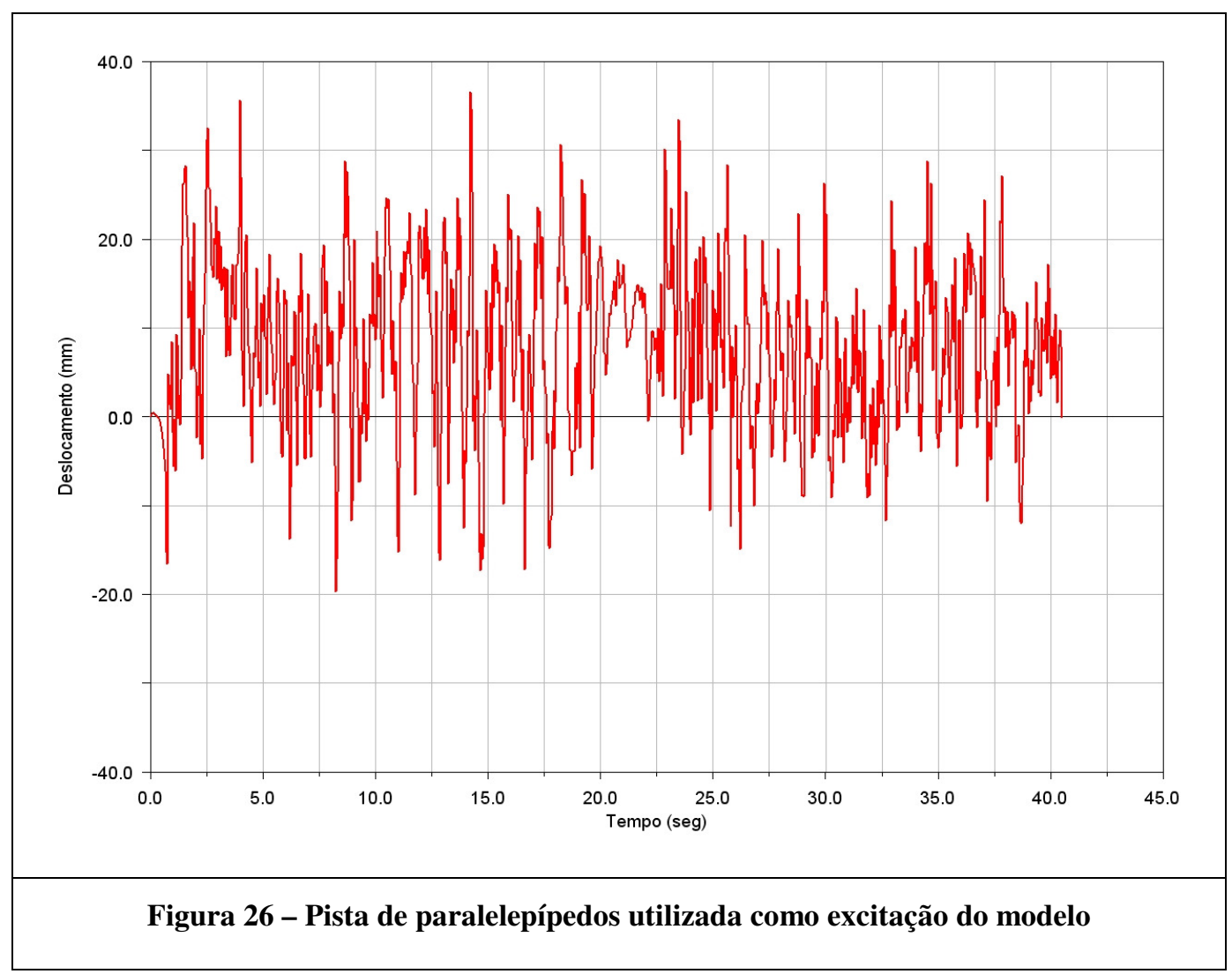

Como se sabe a velocidade é um fator que tem grande influência na dinâmica vertical, uma vez que a aceleração da massa suspensa é diretamente afetada pela velocidade longitudinal do veículo. Por esse motivo para efeitos de correlação e comparação é necessário utilizar a mesma velocidade no modelo e no protótipo medido.

\subsubsection{Validação}

As figuras abaixo, mostram a comparação entre de acelerações verticais, longitudinais e laterais no domínio tempo e da freqüência entre modelo e protótipo real.

As Figura 27e Figura 28 ilustram a passagem do veículo sobre uma lombada. Os picos de acelerações ficaram muito bem representados, e a pequena variação no eixo do tempo se deu pela dificuldade em se manter uma velocidade constante no momento de aquisitar os dados em pista. Condição essa perfeita no modelo. 


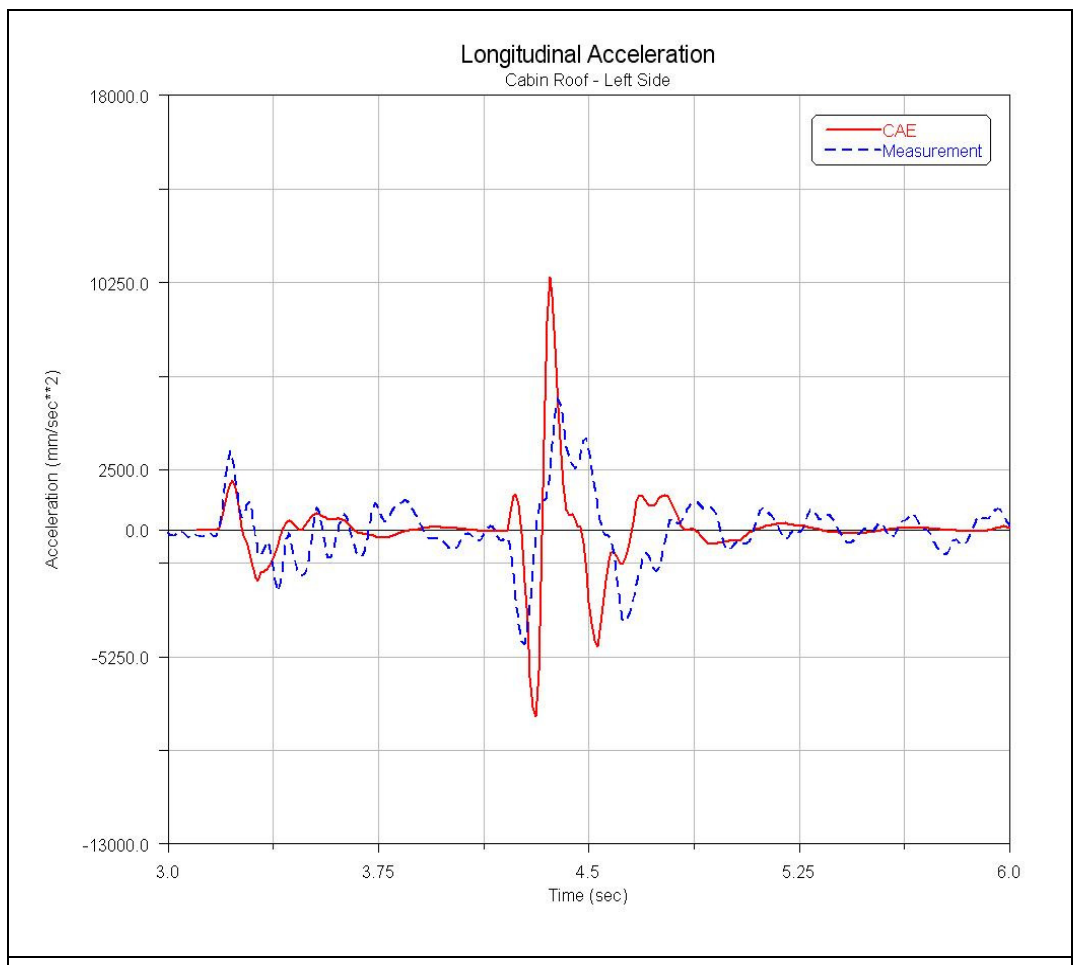

Figura 27 - Aceleração longitudinal no teto do veículo (passando pela lombada)

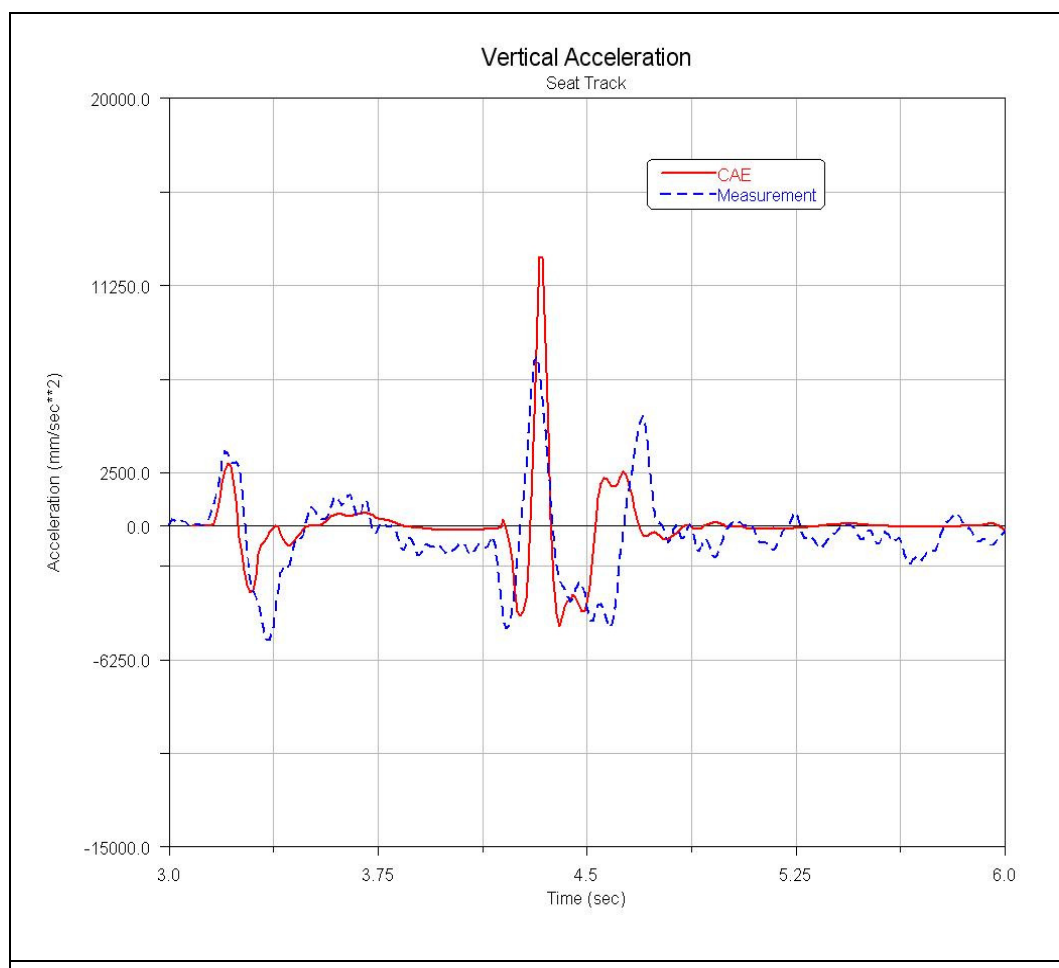

Figura 28 - Aceleração longitudinal no assento do veículo (passando pela lombada) 


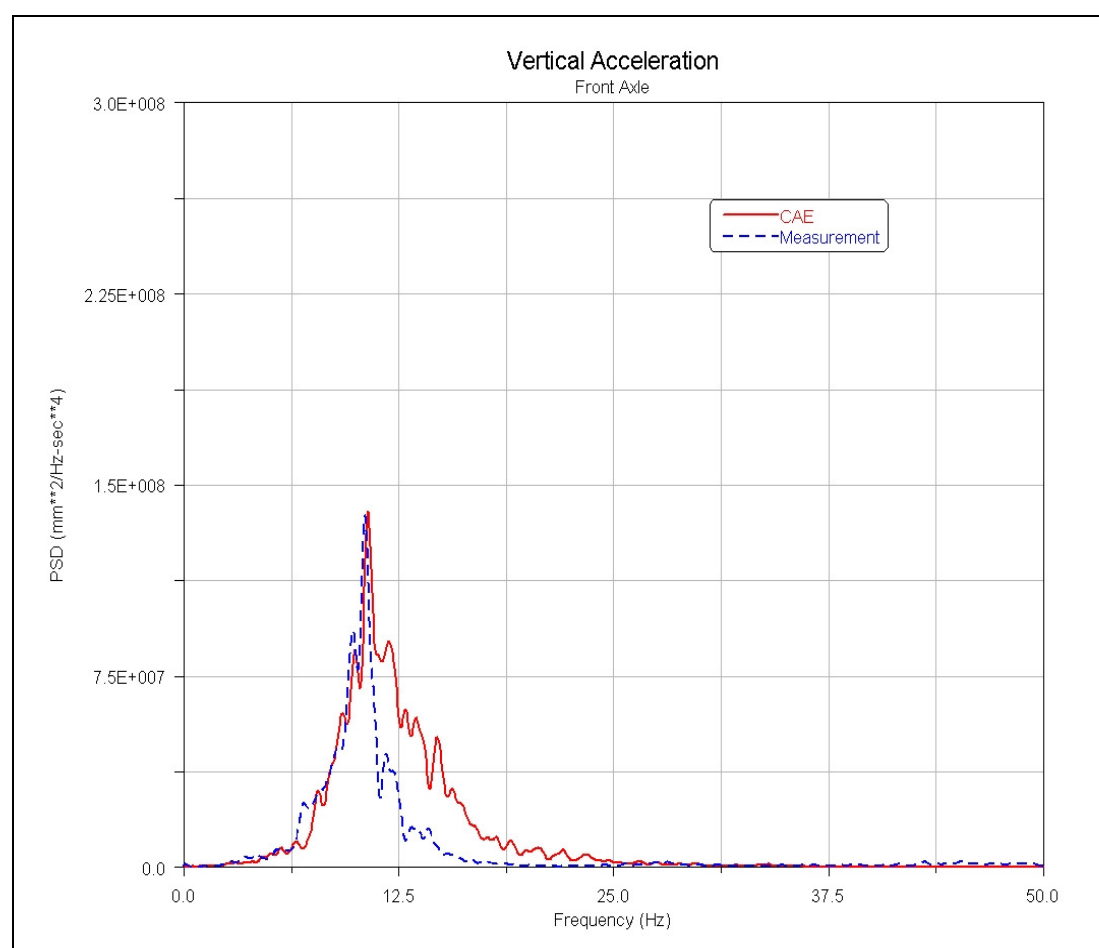

Figura 29 - PSD Aceleração vertical no eixo do veículo (passando por paralelepípedos alinhados)

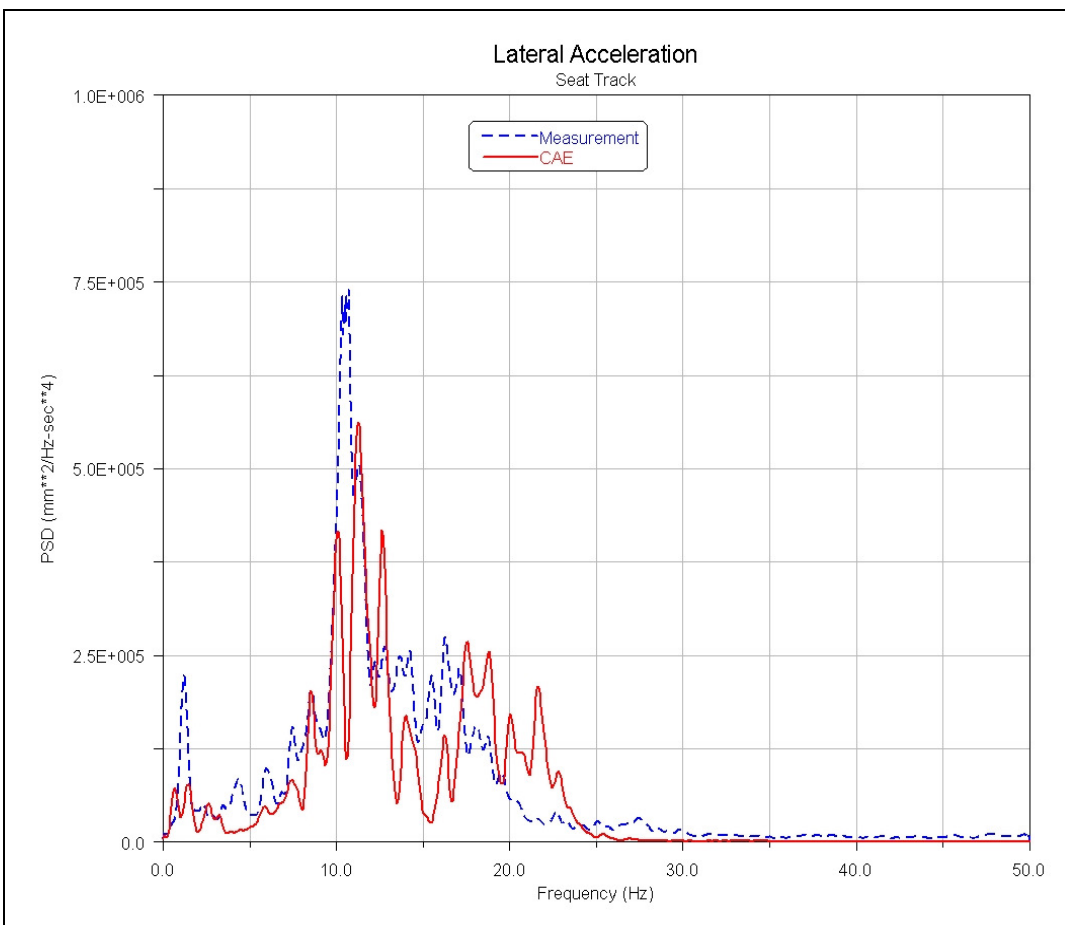

Figura 30 - PSD Aceleração lateral no assento do veículo (passando por paralelepípedos alinhados) 
As Figura 29 e Figura 30 mostram claramente o quanto o modelo aproxima a faixa de shake, uma das mais importantes no conforto. Sendo que no maior pico houve uma variação máxima de apenas $10 \%$.

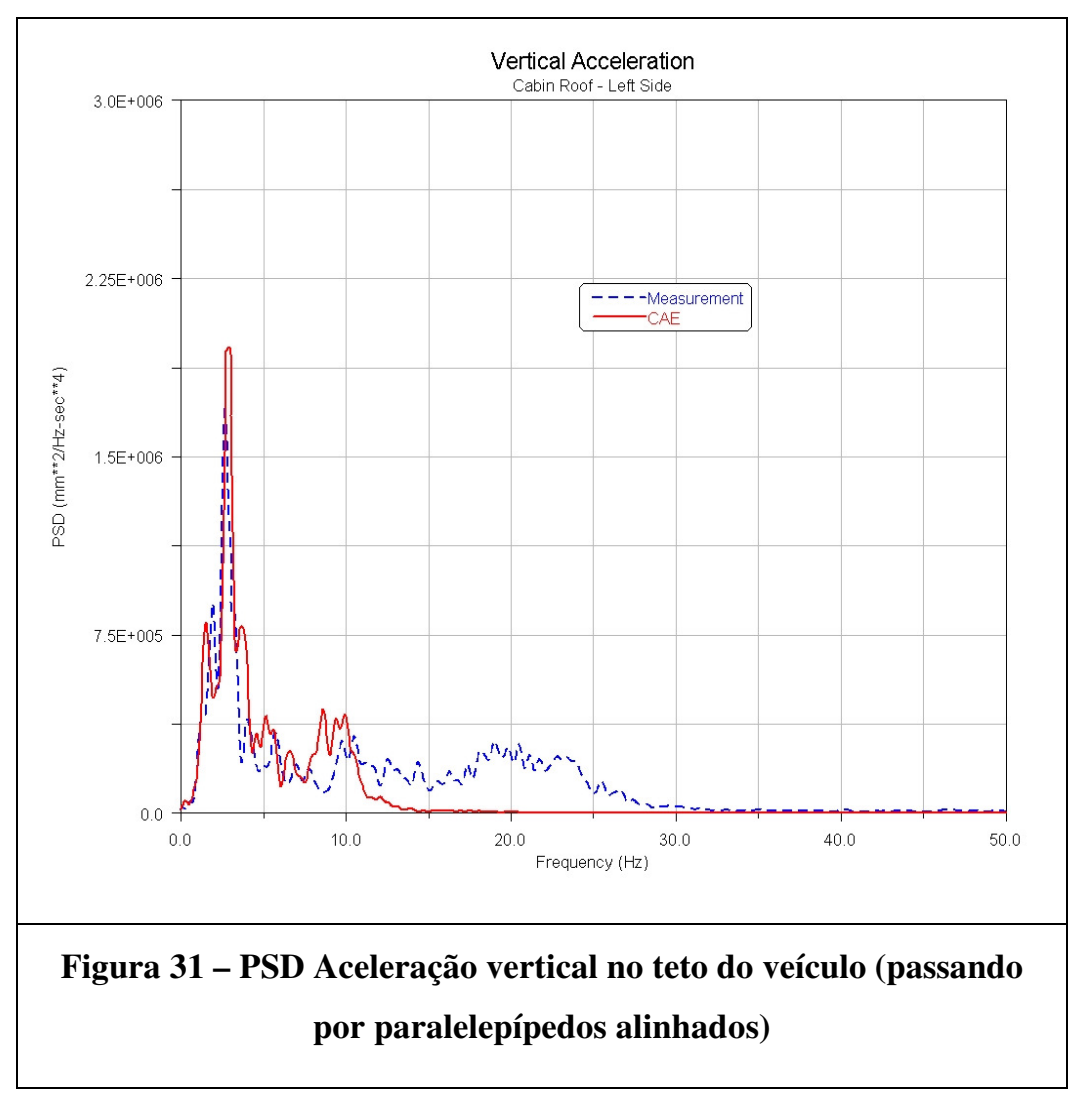

Observando a Figura 31 e Figura 32 é possível concluir que para frequências de bounce, foi obtida uma excelente correlação. Para altas freqüências, a necessidade de um modelo de cabine flexível foi evidenciada, uma vez que o modelo absorveu as vibrações na faixa de harshness. 


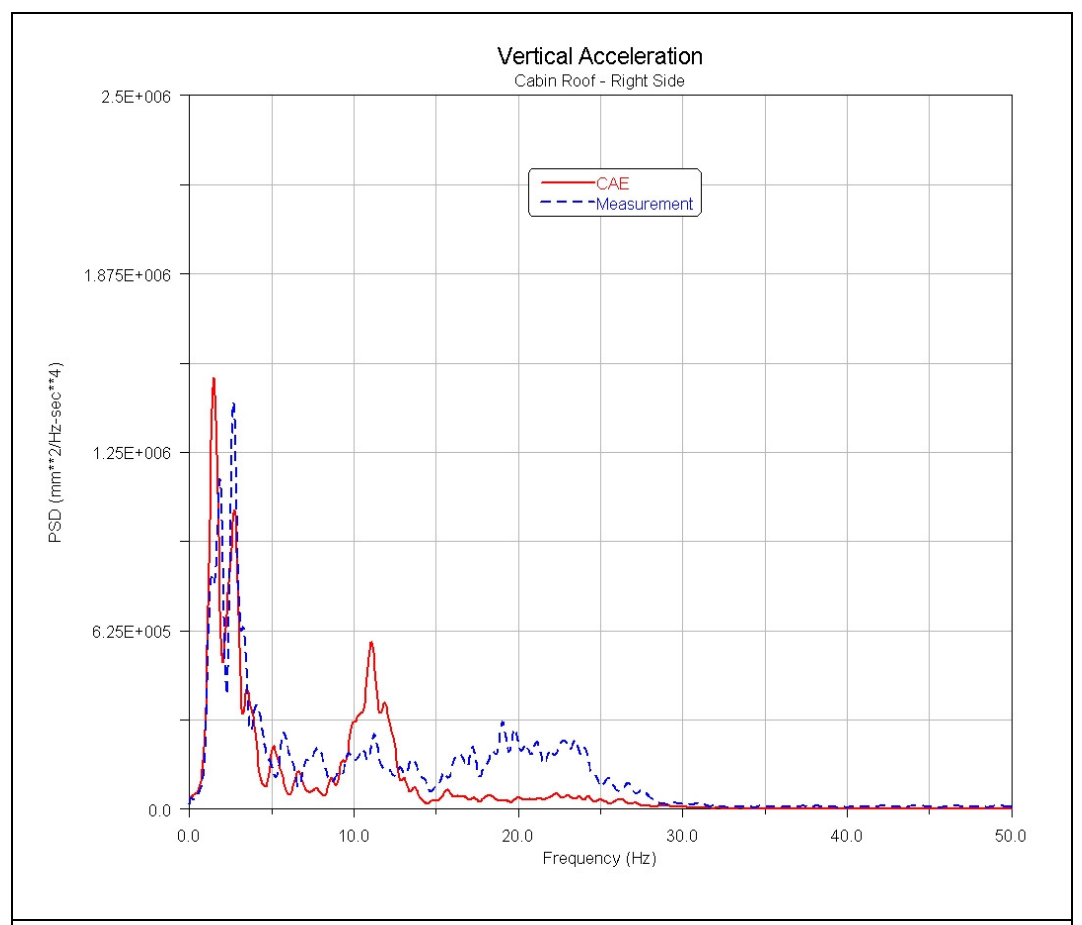

Figura 32 - PSD Aceleração vertical no teto do veículo (passando por paralelepípedos alinhados)

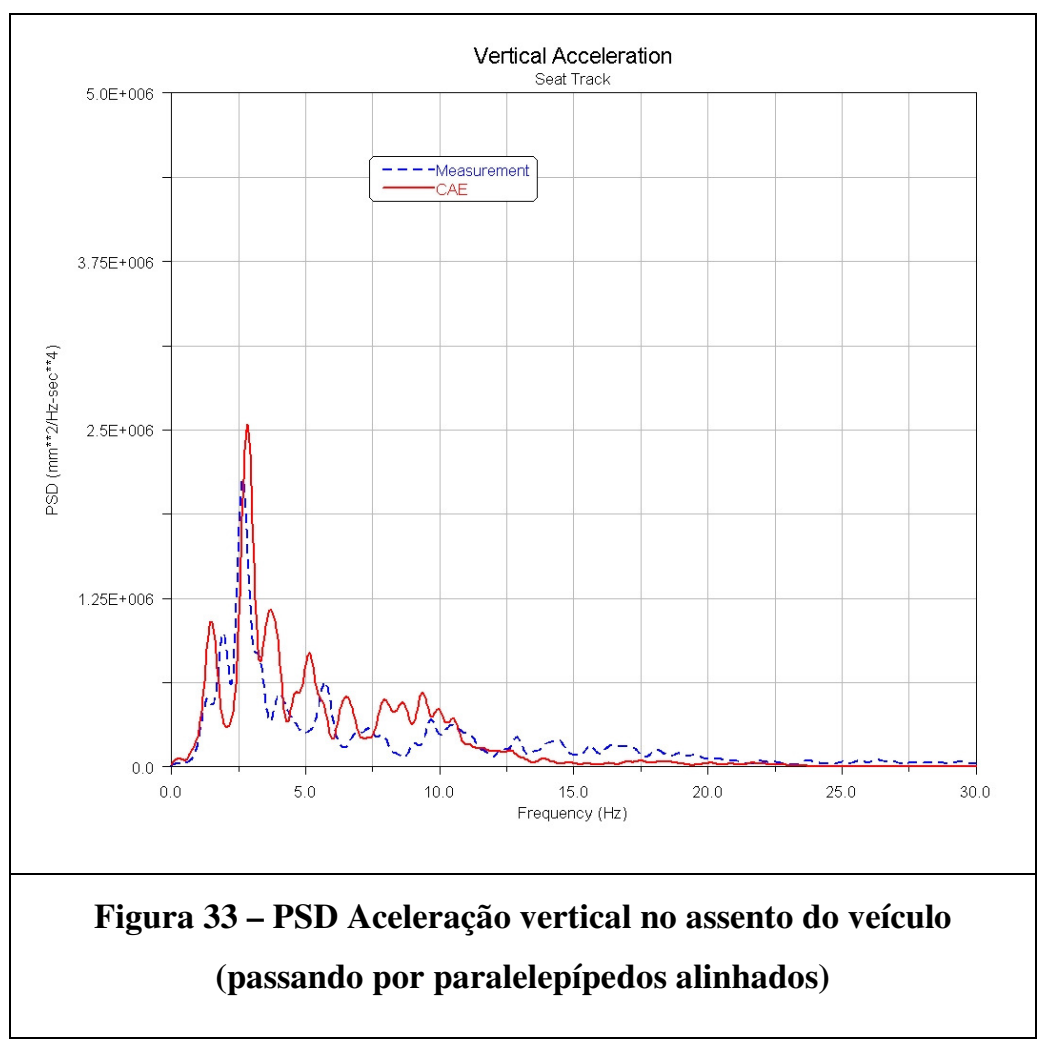




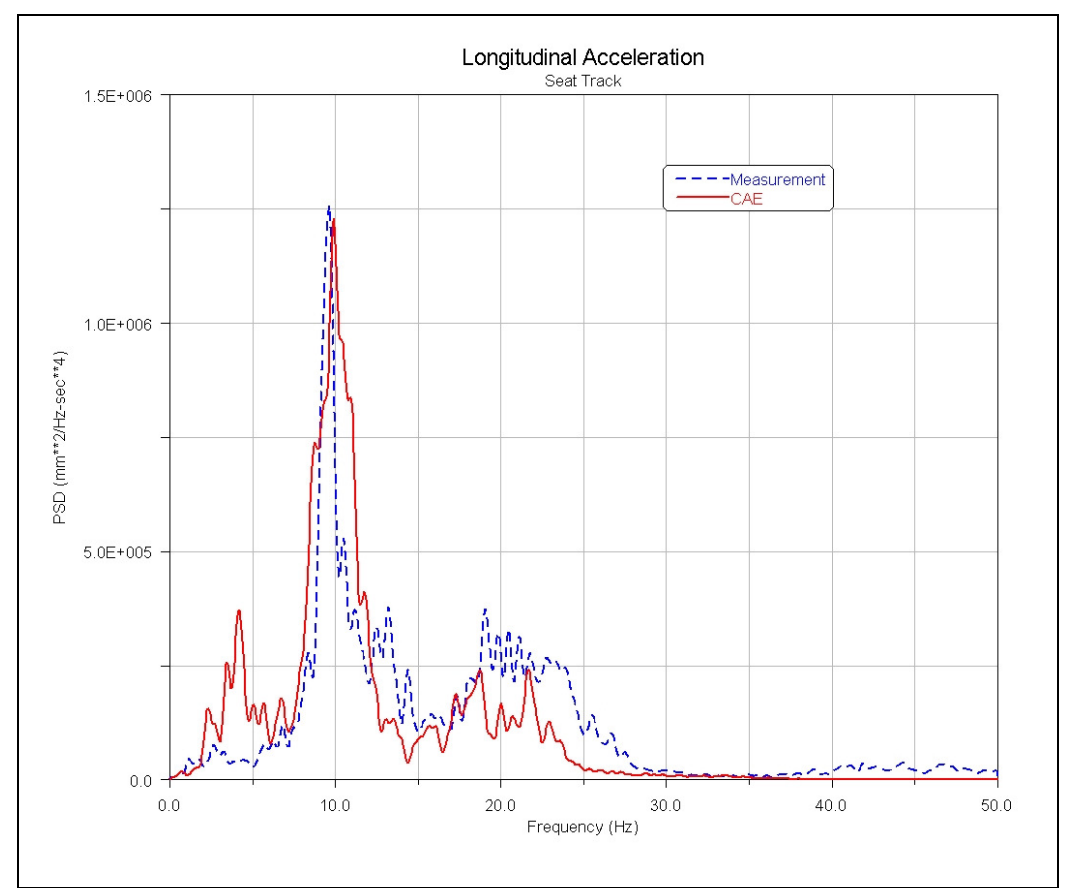

Figura 34 - PSD Aceleração longitudinal no assento do veículo (passando por paralelepípedos alinhados)

Os resultados foram considerados satisfatórios uma vez que as áreas sob as densidades espectrais de potência e os picos das mesmas tiveram uma boa correlação em todas as direções. Manteve a aproximação nas frequências de maior importância e variação máxima de $10 \%$ nos pontos de maior disparidade.

Diante da complexidade do sistema, a média de variação em torno de $5 \%$ entre dados experimentais e numéricos se torna totalmente aceitável dentro da análise necessária na metodologia. 


\section{Desenvolvimento do planejamento de experimentos (DOE)}

\subsection{Descrição geral}

Planejamento de experimentos é uma abordagem sistemática à investigação de um sistema. Uma série de testes estruturados é projetada e as mudanças planejadas são feitas para as variáveis de entrada do sistema. Os efeitos destas alterações em uma saída pré-definida são então avaliados.

A ordem das tarefas para se utilizar essa ferramenta começa com a identificação das variáveis de entrada (fatores) e das respostas a serem medidas. Para cada variável de entrada, níveis são definidos, que representam o intervalo para o qual o efeito dessa variável é desejado ser conhecido. Um plano experimental é produzido, que gera ao pesquisador a matriz de teste mostrando as várias combinações dos parâmetros. A resposta é, então, medida para cada corrida. O método de análise é observar as influências nas respostas (outputs) dos diferentes grupos de mudanças nas entradas. Estas diferenças são então atribuídas às variáveis de entrada isoladamente (chamado de efeito único) ou em combinação com outra variável de entrada (chamada de interação).

\subsection{Definição de entradas e saídas}

Desta forma, o DOE foi desenvolvido a fim de descobrir o parâmetro de suspensões que têm maior influência em cada métrica, tornando o processo de ajuste mais preciso.

As entradas escolhidas no desenvolvimento do planejamento de experimentos foram os itens ajustáveis da suspensão, que são os principais focos da análise.

As respostas foram escolhidas com base na literatura e levando em consideração os principais valores utilizados no cálculo de métricas para avaliação do conforto. Abaixo estão listadas as variáveis de entrada e respostas:

Entradas:

- Rigidez de molas dianteiras e traseiras da suspensão da cabine;

- Curvas dos amortecedores dianteiros e traseiros da (coeficiente de amortecimento); 
- Curva dos amortecedores da suspensão primária (coeficiente de amortecimento).

Respostas:

- RMS das acelerações longitudinal e lateral na cabeça do motorista;

- RMS da aceleração vertical no assento do motorista;

- RMS da velocidade vertical no assento do motorista;

- Desvio padrão do deslocamento lateral e longitudinal na cabeça do motorista;

- Desvio padrão do deslocamento vertical do assento do motorista.

\subsection{Resultados do experimento}

Figura 36 mostra os resultados do planejamento de experimentos proposto. Essa forma de apresentação dos dados é feita através do software ADAMS Insight.

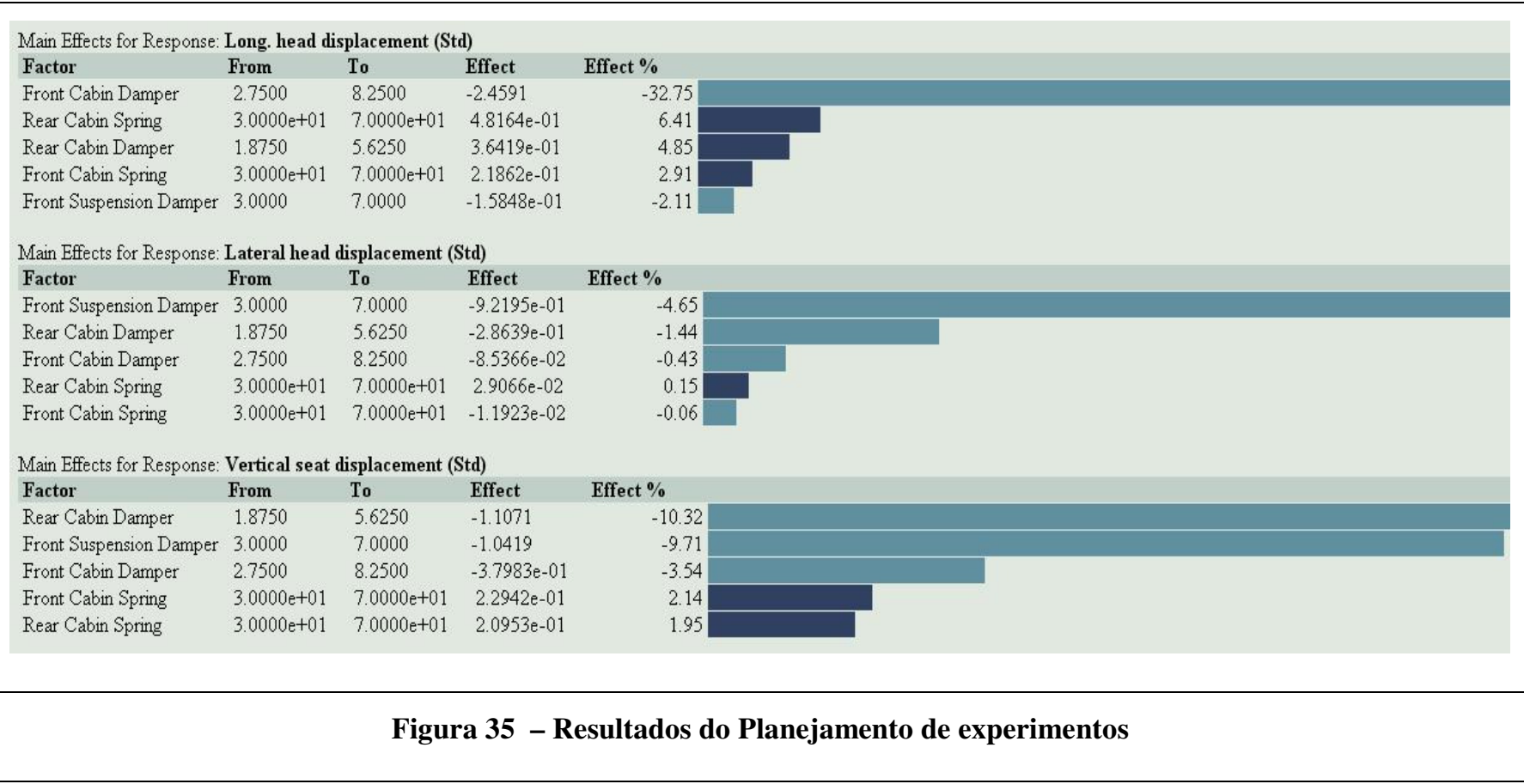




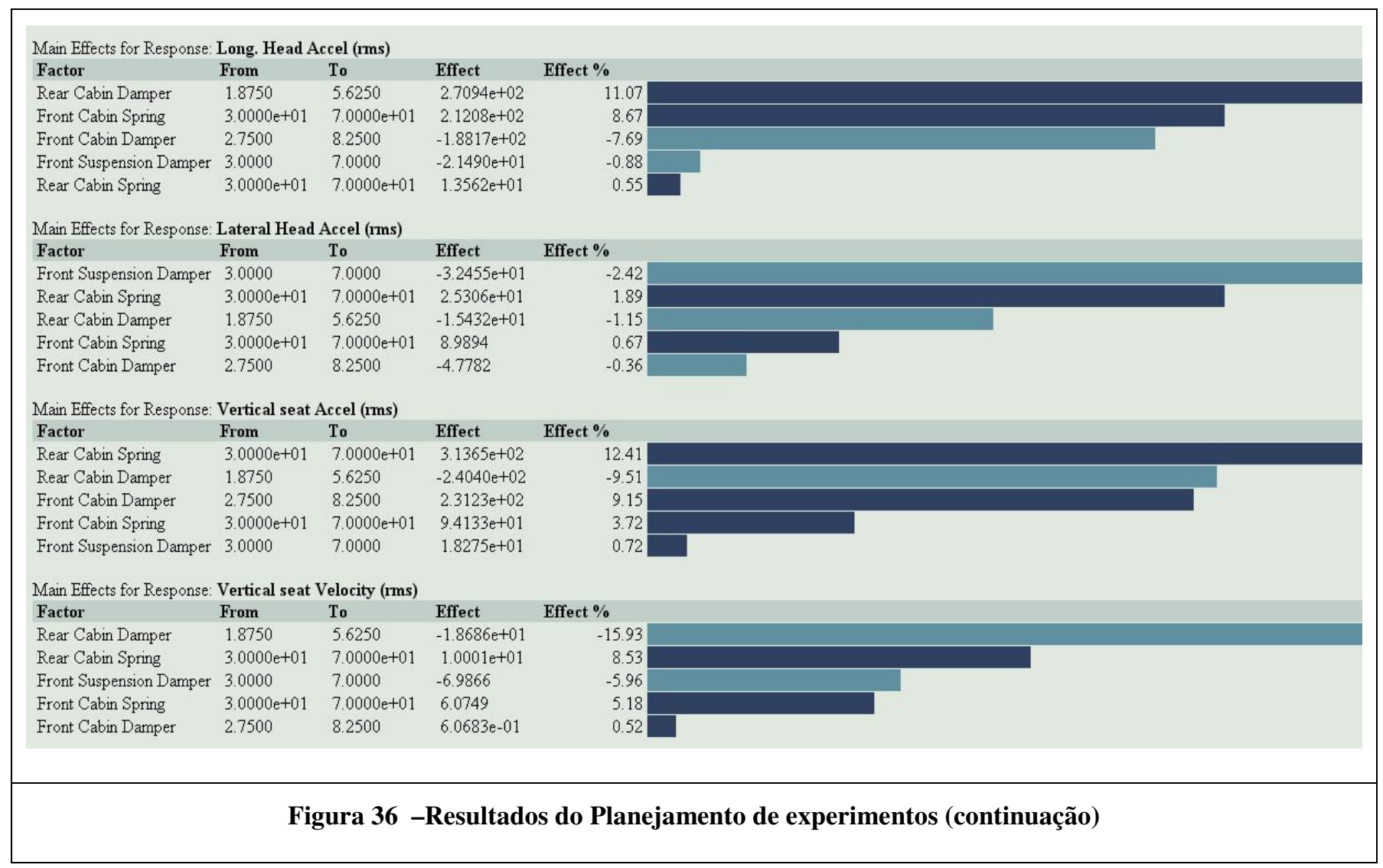

Com o resultado do DOE em mãos, se tornou possível saber qual item da suspensão seria necessário alterar para atenuar os problemas de vibrações e movimentações indesejadas do veículo.

Com o objetivo de melhorar o conforto, foi gerada a estratégia de diminuir as movimentações da cabine (Bounce) e as vibrações em torno da frequência de shake (10 e 25 $\mathrm{Hz}$ ). Para isso foi gerada a seguintes tabelas ordenando as entradas que mais influenciaram nessas métricas:

Tabela 5 - Ordem de influência das entradas no deslocamento vertical

\begin{tabular}{|c|c|}
\hline Entrada & Influência \\
\hline$\uparrow$ Amortecimento traseiro da cabine & $\downarrow 10 \%$ \\
\hline$\uparrow$ Amortecimento dianteiro da primária & $\downarrow 9 \%$ \\
\hline$\uparrow$ Amortecimento dianteiro da cabine & $\downarrow 3 \%$ \\
\hline$\uparrow$ Rigidez da mola dianteira da cabine & $\uparrow 2 \%$ \\
\hline$\uparrow$ Rigidez da mola traseira da cabine & $\uparrow 1 \%$ \\
\hline
\end{tabular}


Tabela 6 - Ordem de influência das entradas na aceleração vertical

\begin{tabular}{|c|c|}
\hline Entrada & Influência \\
\hline$\uparrow$ Rigidez da mola traseira da cabine & $\uparrow 12 \%$ \\
\hline$\uparrow$ Amortecimento traseiro da cabine & $\downarrow 9 \%$ \\
\hline$\uparrow$ Amortecimento dianteiro da primária & $\uparrow 9 \%$ \\
\hline$\uparrow$ Rigidez da mola dianteira da cabine & $\uparrow 3 \%$ \\
\hline$\uparrow$ Amortecimento dianteiro da primária & $\uparrow 1 \%$ \\
\hline
\end{tabular}

As setas indicam que aumentado o valor da entrada a influência no valor final da métrica aumenta ou diminui cada uma em sua proporção. Diante dos dados apresentados nas tabelas acima as seguintes ações foram tomadas:

- Reduzir as rigidezes das molas dianteiras e traseiras da cabine;

- Aumentar as cargas dos amortecedores dianteiros e traseiros da cabine;

- Aumentar a carga nos amortecedores dianteiros da suspensão primária.

As consequências das ações tomadas a partir dos dados obtidos no DOE serão apresentadas na próxima secção.

Como mostrado na secção 3.3.3, uma análise possível de ser feita nesses casos é a influência da combinação de fatores em certa resposta. Como observado na Figura 37, nessa análise em questão, não houve influência da combinação dos fatores nas métricas possibilitando o tuning de cada variável individualmente sem se preocupar com a interação das mesmas. 


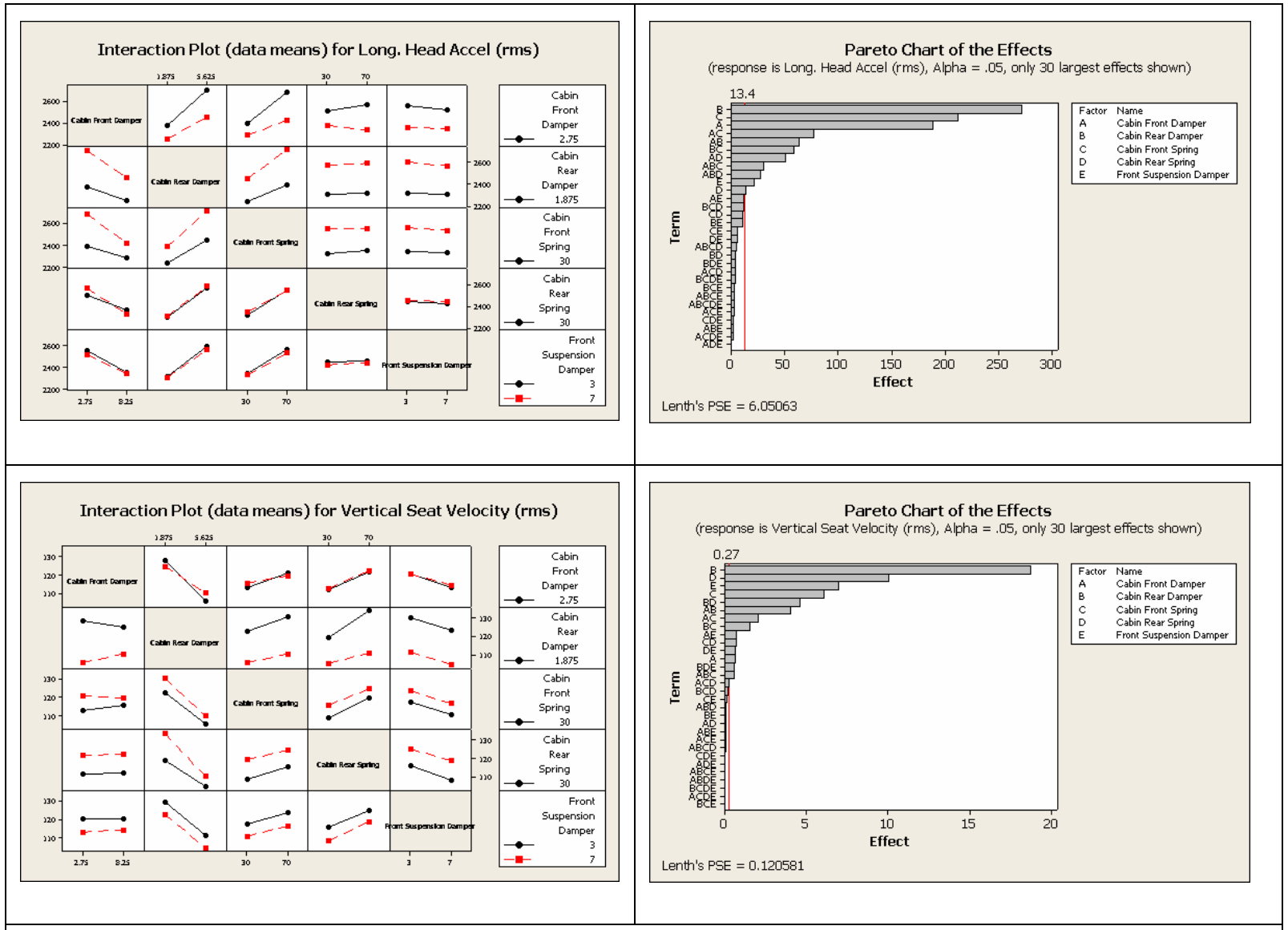

Figura 37 - Influência da combinação de entradas 


\section{Resultados e análises}

Utilizando os resultados obtidos com o planejamento de experimentos, algumas configurações foram testas pelo modelo. Sempre seguindo a estratégia apontada anteriormente, os seguintes valores foram implementados no veículo:

- As rigidezes das molas dianteiras foram reduzidas de $60 \mathrm{~N} / \mathrm{mm}$ para $55 \mathrm{~N} / \mathrm{mm}$;

- As rigidezes das molas traseiras foram reduzidas de $47.5 \mathrm{~N} / \mathrm{mm}$ para $38 \mathrm{~N} / \mathrm{mm}$;

- As cargas dos amortecedores dianteiros da cabine foram aumentadas em 30\% na compressão e $20 \%$ na extensão;

- As cargas dos amortecedores traseiros da cabine foram aumentadas em $30 \%$ na extensão e mantidas na compressão.

A figura seguinte mostra a eficiência da ferramenta e comprova de forma clara que o objetivo inicial da utilização da metodologia foi alcançado. Houve uma redução de aproximadamente $20 \%$ nos movimentos predominantemente verticais (bounce), reduzindo também movimentações laterais e longitudinais.

Segundo a norma ISO 2361-1997, largamente aceita na indústria automobilística, uma das faixas de frequência de vibrações que mais incomoda o ser humano diante de acelerações verticais está entre 4 e $20 \mathrm{~Hz}$ como mostra a Figura 38, faixa essa que sofreu uma significativa melhora após o término do tuning.

Como consequiência das alterações feitas no veículo, houve uma significativa redução nas acelerações e movimentações longitudinais. Justamente na faixa de maior incomodo para acelerações (baixa freqüência) nessa direção como mostra a norma ISO 2361-1997 para direções longitudinais (Figura 39). 


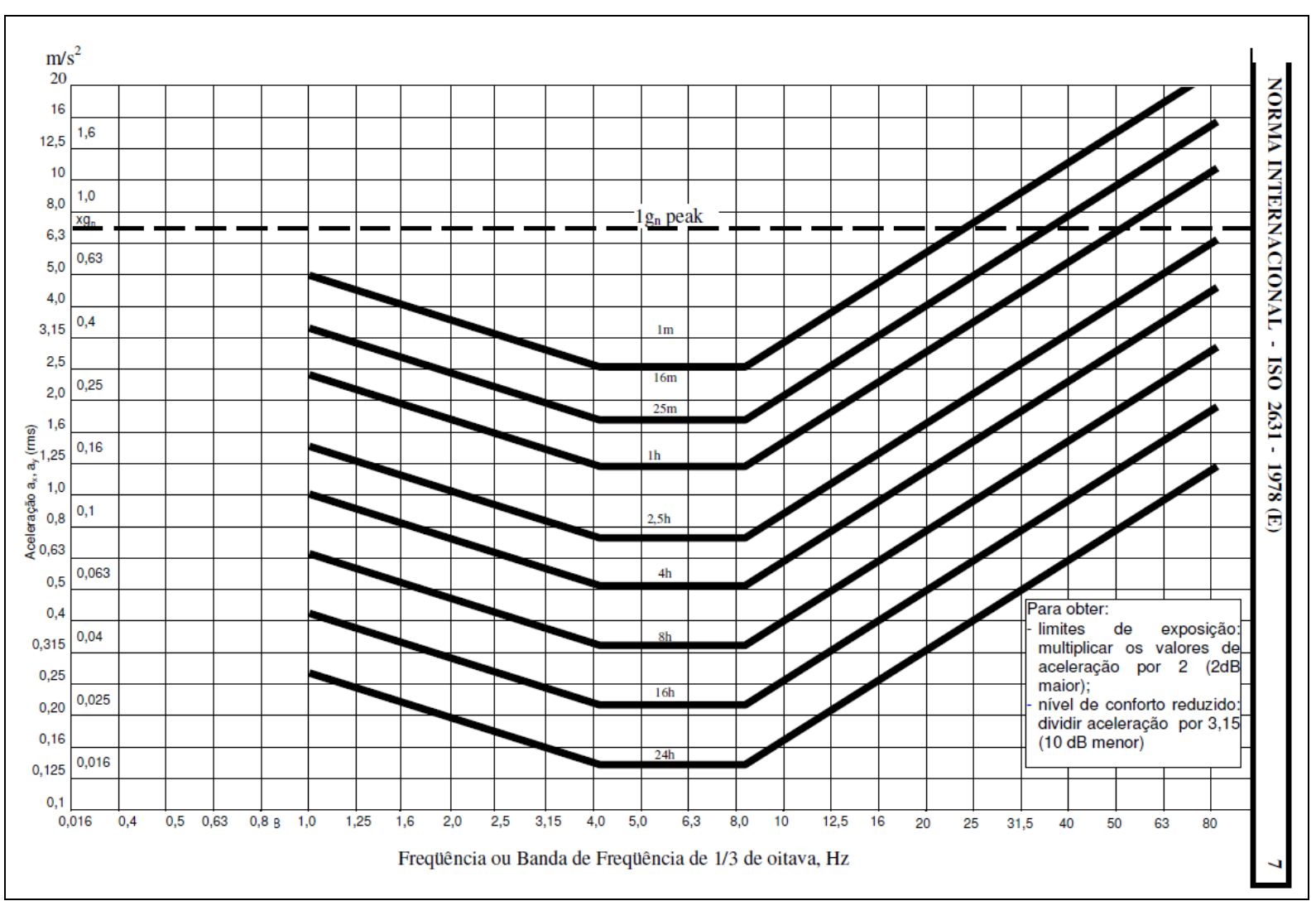

Figura 38 - Curvas de tolerância do corpo humano a acelerações verticais

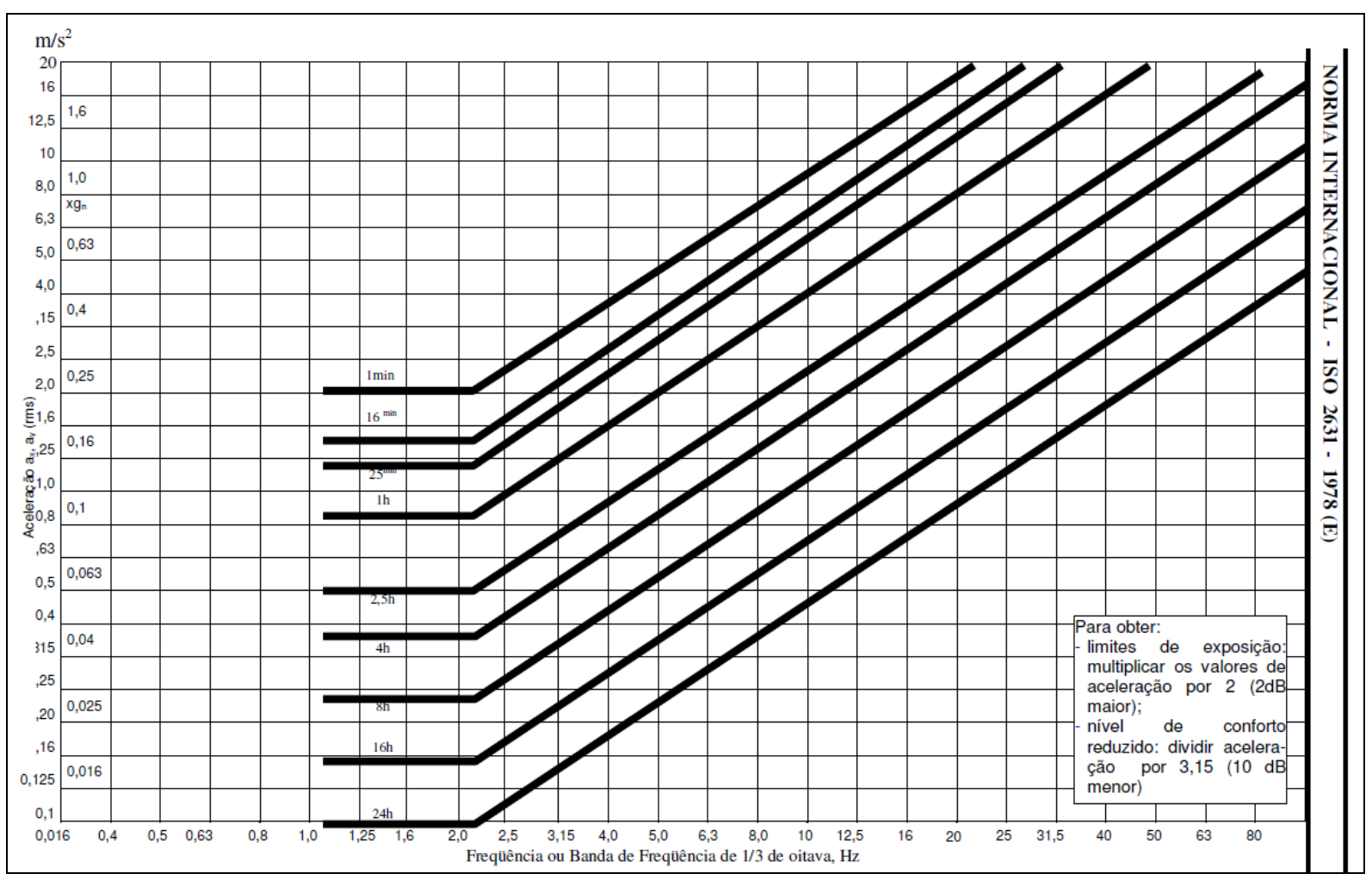

Figura 39 - Curvas de tolerância do corpo humano a acelerações longitudinais 


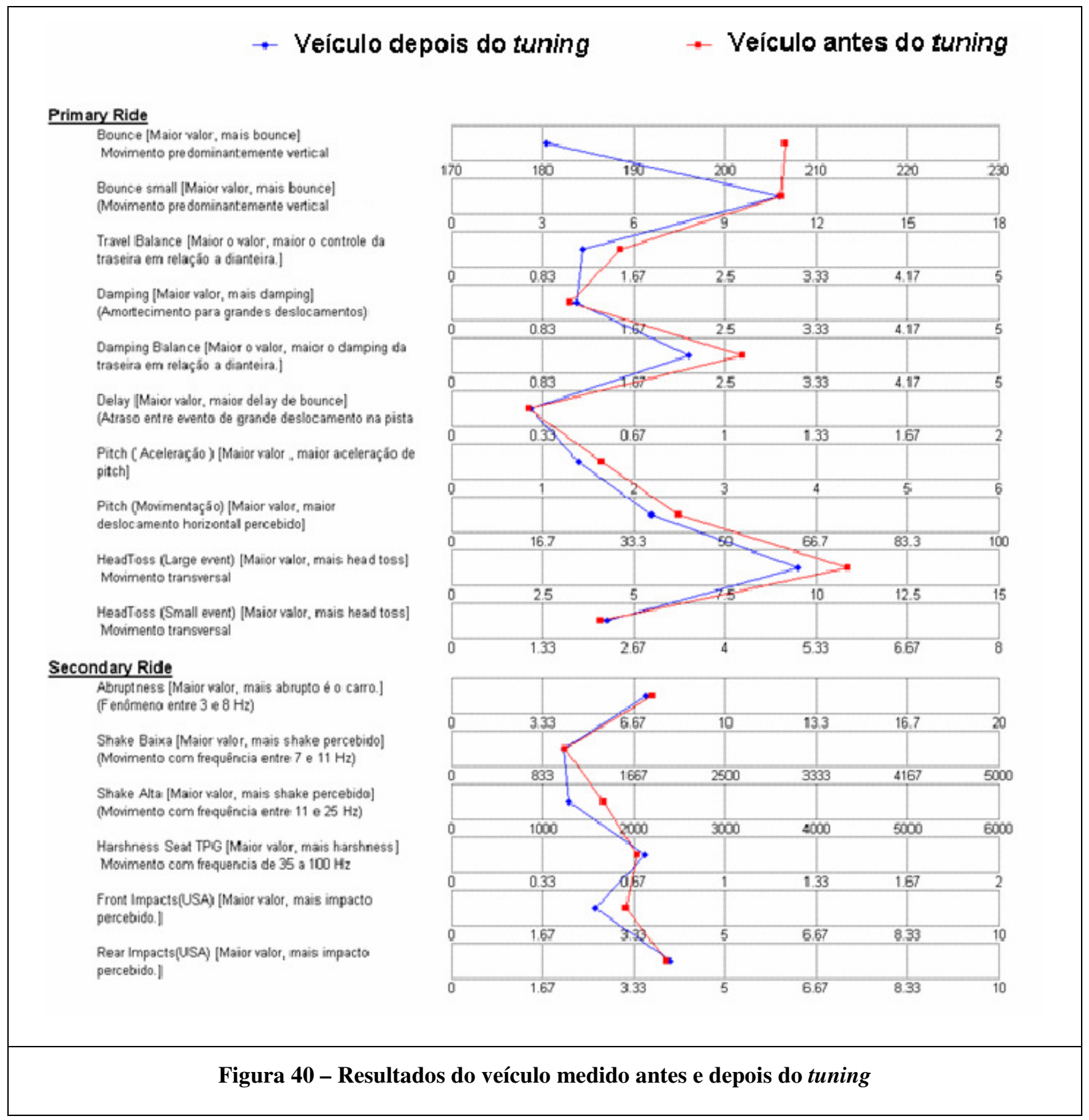

Os valores mostrados na escala da Figura 40 não aparecem com unidades por se tratar de métricas desenvolvidas na Ford Motor Company., que se tratam de informações confidenciais. Mas a critério de comparação é possível utilizar os valores apresentados de forma a comprovar a eficiência do método, uma vez que as métricas foram baseadas em dados experimentais e o objetivo de reduzir deslocamentos e acelerações foi alcançado.

Como descrito na secção 5.3 o objetivo do experimento foi reduzir movimentação vertical (Bounce) e acelerações verticais em torno da frequência de shake. Ao observar a Figura 40, que mostra a comparação de resultados experimentais antes e após o tuning fica 
clara a eficiência da metodologia. Para a métrica Bounce houve uma redução em torno de 20\%. Para as métricas de Ride primário, que são baseadas em movimentações, todas tiveram reduções significativas.

È importante ressaltar que no Ride secundário o resultado foi muito bem aceito visto que mesmo reduzindo as movimentações do veículo em altos níveis, as acelerações na faixa de frequência de abruptness não se alteraram, gerando ainda uma redução de $25 \%$ para o shake.

O único valor que gerou um acréscimo no quadro de métricas, foi a faixa de harshness, que como apresentado pela ISO 2361-1997 não gera tanto desconforto aos ocupantes. Lembrando ainda que seria necessário um modelo mais completo de pneu para estudo e avaliação de vibrações em altas frequências. 


\section{Conclusões}

Levando em consideração que veículos comerciais são sistemas um tanto quanto complexos, uma vez que possuem sistema de suspensão primária e de cabine, o modelo virtual se mostrou uma importante ferramenta de desenvolvimento, pois obteve uma excelente correlação com os dados experimentais e funcionou como base para utilização da ferramenta estatística.

O planejamento de experimentos aumentou a agilidade do modelo evitando horas de simulações desnecessárias, diminuindo assim custo computacional e tempo de desenvolvimento.

O tempo total de tuning foi reduzido significantemente utilizando a metodologia proposta. Foi possível reduzir cerca de $50 \%$ das configurações testadas subjetivamente, significando meses de trabalho.

As avaliações subjetivas comprovaram a eficácia dos resultados obtidos através do planejamento de experimentos sobre a simulação numérica. Com o modelo correlacionado em mãos os engenheiros terão condições de solucionar problemas sem sequer realizar uma avaliação subjetiva.

Novos planejamentos de experimentos poderão ser desenvolvidos, bastando alterar as entradas ou saídas de acordo com as necessidades encontradas no decorrer do desenvolvimento do veículo.

Ficou clara a objetividade do trabalho uma vez que a finalidade principal, redução das movimentações verticais e longitudinais da cabine e os níveis de acelerações em torno da freqüência de shake, foi alcançada.

Para trabalhos futuros é recomendável se utilizar do modelo e aprofundar nas análises dos parâmetros estatísticos. Uma possibilidade concreta seria aproximar as curvas dos amortecedores, tanto da suspensão primária como da cabine, por polinômios de terceiro ou quarto grau, utilizando os coeficientes desses polinômios como entradas do planejamento de experimentos. A idéia dos polinômios possibilitaria uma análise mais aprofundada das curvas dos amortecedores bem como abriria a possibilidade de gerar curvas diferentes para tração e compressão. 
Outro ponto importante a destacar é a possibilidade de gerar modelos mais completos e robustos de pneus, aumentado a correlação do modelo diante a altas frequências, possibilitando a eliminação de vibrações de harshness. 


\section{Referências}

[1] Antony, J.; Kate, M.; Frangou, A. (1998). A strategic methodology to the use of advanced statiscal quality improvement technics. The TQM Magazine, v. 10, n-3.

[2] Avutapalli, B. et al. (2003). Stochastic Analysis of a Body-on-Frame Vehicle to Achieve Reliable and Robust Shake Performance. SAE World Congress (2003).

[3] Barker, T.B. (1985) Quality by experimental design. New York, Marcel Dekker; Milwaukee: ASQC Quality Press. p. 1-20

[4] Box, G.E.P.;Liu, P.Y.T. (1999). Statistics as a catalyst to learning by scientific method part I-an example. Journal of Quality Technology. V.31,n.1. Jan.

[5] Button, S.T. (2001). Metodologia para planejamento experimental e análise de resultado. São Paulo, Universidade Estadual de Campinas. /Apostilal.

[6] Cherian, T. et al. (2007) Combining DFSS and Multi-body Dynamics for Vehicle Ride Tuning. SAE World Congress(2007).

[7] Coleman, D.E; Montgomery,D.C. (1993) A systematic approach to planning for a designed industrial experiment. Technometrics, v.35 Februery.

[8] Costa, A. N., (1992) Application of multibody System (MBS) Techniques to Automotive Vehicle Chassis Simulation for Motion Control Studies, 1992. 337 . Ph.D. Thesis, Eng. Dept., Univ. of Warwick, Coventry, U.K., 1992

[9] da silva, M. M. (2004). Análise de dirigibilidade de um veículo comercial leve em ambiente multicorpos considerando flexibilidade do quadro. Master's thesis, Universidade de São Paulo.

[10] Devor, R.E,; Chang, T.; Sutherland, J.W. (1992). Statistical quality design and control Contemporary concepts and methods. New Jersey, Prentice Hall, Inc.

[11] Dohi, M.; Maruyama, Y. (1990). Ride Comfort Optimization for Commercial Trucks. SAE Trucks and Bus Meeting exposition(1990). 
[12] Duarte, M. D. R. (2010). Simulação de ride primário e secundário através do uso de carregamento de pista. 112 f. Dissertação (Engenharia Mecânica), Universidade de São Paulo.

[13] Fernandes, C.G. et al. (2003). Ride Comfort Measurements. SAE XIV Congresso e Exposição Internacionais da Tecnologia da Mobilidade (2003).

[14] Fernandes, C.G. et al. (2005). Ride Comfort Measurements. SAE XIV Congresso e Exposição Internacionais da Tecnologia da Mobilidade (2005).

[15] Galdámez, E. V. C. (2002). Aplicação das técnicas de planejamento de análise de experimentos na melhoria da qualidade de um processo de fabricação de produtos plásticos. 121f. Dissertação (Engenharia de Produção), Universidade de São Paulo (2002).

[16] Gobbi, M. et al (2006). Multi-objective stochastic optimisation of the suspension system of road vehicles. Journal of Sound and Vibration 298 (2006) 1055-1072

[17] Gillespie, T. D. (1992). Fundamentals of Vehicle Dynamics. SAE Inc. Warrendale.

[18] Hassan, R.; McManus, K. (2001). Heavy Vehicle Ride and Driver Comfort. SAE World Congress(2001).

[19] Kudritzki, D. (2007). Ridemeter - Calculated Ride Comfort. SAE Noise and Vibration Conference and Exhibition(2007).

[20] Lamps, M. F.; Ekert, E. C.(1993). Improving the Suspension Design Process by Integrating Multibody System Analysis and Design of Experiments. SAE International Congress and Exposition (1993).

[21] Montgomery, D. C. (1984). Design and Analysis of Experiments. 2nd Ed., John Wiley and Sons, New York (1984)

[22] Montgomery, D. C. (1991). Diseño y análisis de experimentos. Trad. Por Jaime Delgado Saldivar. Mexico, Iberoamérica. 
[23] Perseguim, O. et al. (2000). Comfort and Vibration Study of a Tractor and Trailer Combination Using Simulation and Experimental Approaches: the Jumping Ride Behavior. SAE Truck and Bus Meeting and Exposition(2000).

[24] Reimpell, J. and Stoll, H. (1996). The Automotive Chassis Engineering Principles. SAE Inc, Warrendale.

[25] Rill, G. (2003) Vehicle Dynamics - Lecture Notes. Fachhochschule Regensburg, University of Applied Sciences.

[26] Schiehlen, W. (1997). Multibody systems dynamics: Roots and perspectives. Multibody System Dynamics, 16.

[27] Soliman, A.M.A. (2008). Improvement of the Truck Ride Comfort Via Cab Suspension. SAE World Congress(2008).

[28] Strandemar, K.; Thorvald, B. (2004). Truck Characterizing Through Ride Diagram. SAE Commercial Vehicle Engineering Congress and Exhibition (2004).

[29] Suh, Y.;Yoon, Y. (2000). Optimization of Front Bump Steer Using Design of Experiments. SAE Automotive Dynamics \& Stability Conference (2000)

[30] Vilela, D.; Gueler, G. F. (2005). Simulation Applied to Ride Comfort Suspension Optimization. SAE XIV Congresso e Exposição Internacionais da Tecnologia da Mobilidade (2005).

[31] Wambold, C.J. (1986). Vehicle Ride Quality - Measurement and Analysis. SAE West Coast International Meeting(1986).

[32] Wang, G. et al.(2004). A Virtual Test Approach for Vehicle Ride Comfort Evaluation. SAE World Congress(2004).

[33] Werkema, M.C.C.; Aguiar, S. (1996). Planejamento e análise de experimentos: como identificar as principais variáveis influentes em um processo. Belo Horizonte, Fundação Christiano Ottoni. V.08) 